\title{
COARSE SCALE SIMULATION OF TIGHT GAS RESERVOIRS
}

\author{
A Dissertation \\ by \\ MOHAMED HAMED EL-AHMADY

\begin{abstract}
Submitted to the Office of Graduate Studies of
Texas A\&M University

in partial fulfillment of the requirements for the degree of

DOCTOR OF PHILOSOPHY
\end{abstract}

December 2003

Major Subject: Petroleum Engineering 


\title{
COARSE SCALE SIMULATION OF TIGHT GAS RESERVOIRS
}

\author{
A Dissertation \\ by \\ MOHAMED HAMED EL-AHMADY \\ Submitted to Texas A\&M University \\ in partial fulfillment of the requirements \\ for the degree of \\ DOCTOR OF PHILOSOPHY
}

Approved as to style and content by:

Robert A. Wattenbarger

(Co-Chair of Committee)

David S. Schechter

(Co-Chair of Committee)

Prabir Daripa

(Member)

J. Bryan Maggard (Member)

Hans Juvkam-Wold

(Head of Department)

December 2003

Major Subject: Petroleum Engineering 


\author{
ABSTRACT \\ Coarse Scale Simulation of Tight Gas Reservoirs. (December 2003) \\ Mohamed Hamed El-Ahmady, B.S., Cairo University; \\ M.S., Texas A\&M University \\ Co-Chairs of Advisory Committee: Dr. Robert A. Wattenbarger \\ Dr. David S. Schechter
}

It is common for field models of tight gas reservoirs to include several wells with hydraulic fractures. These hydraulic fractures can be very long, extending for more than a thousand feet. A hydraulic fracture width is usually no more than about $0.02 \mathrm{ft}$. The combination of the above factors leads to the conclusion that there is a need to model hydraulic fractures in coarse grid blocks for these field models since it may be impractical to simulate these models using fine grids.

In this dissertation, a method was developed to simulate a reservoir model with a single hydraulic fracture that passes through several coarse gridblocks. This method was tested and a numerical error was quantified that occurs at early time due to the use of coarse grid blocks.

In addition, in this work, rules were developed and tested on using uniform fine grids to simulate a reservoir model with a single hydraulic fracture. Results were compared with the results from simulations using non-uniform fine grids. 


\section{ACKNOWLEDGEMENTS}

The author wishes to express his sincere appreciation to Dr. Robert A. Wattenbarger for his valuable guidance as his research adviser and for his assistance throughout the period of his master's and his doctoral studies at Texas A\&M University. Words fail to express how fortunate he feels he was to work under his supervision.

The author wishes also to thank Dr. David Schecter, Dr. Bryan Maggard and Dr. Prabir Daripa for reviewing the manuscript of this dissertation and for suggesting many improvements.

Financial support for this research was provided by El-Paso Production Company.

The author also is grateful to his father, Hamed El-Ahmady, his mother, Nahed El-Meligy, and his wife, Amina Mansour. He has been able to finish his studies and his research only through their understanding and continuous encouragement. 
$\begin{array}{ll}\text { Page } & \end{array}$

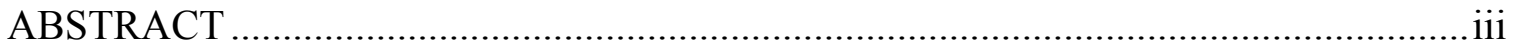

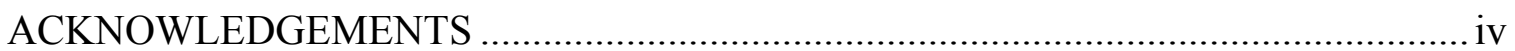

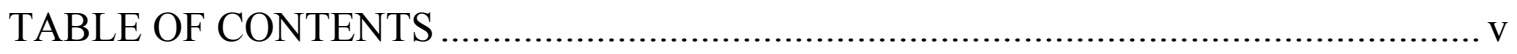

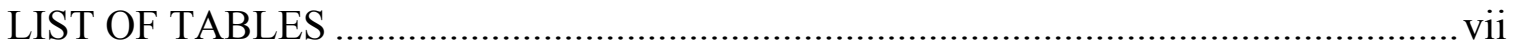

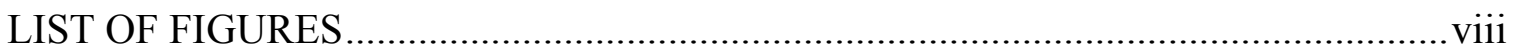

CHAPTER

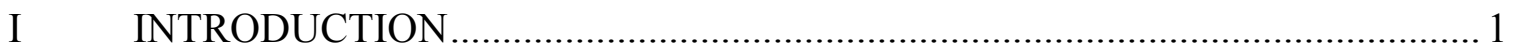

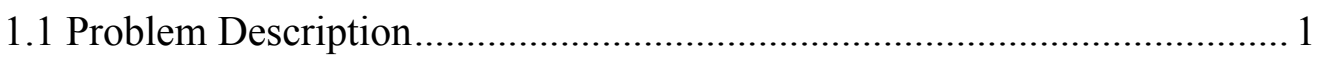

1.2 Literature Review on Well Modeling....................................................... 2

1.3 Literature Review on Vertical Hydraulic Fractures ..................................... 5

1.4 Literature Review on Modeling Fractures in Coarse Blocks ........................

II WELL MODELS AND ARTIFACT WELLBORE STORAGE ………………... 12

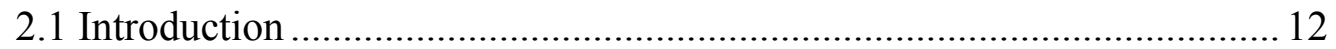

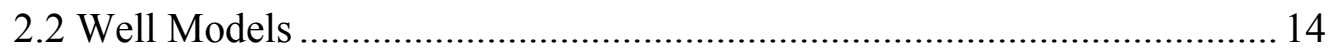

2.3 Artifact Wellbore Storage ...................................................................... 22

III MODELING HYDRAULIC FRACTURES WITH UNIFORM FINE GRIDS ... 27

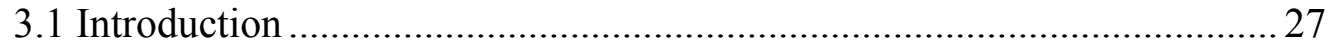

3.2 Simulation of Twenty Cases of Hydraulic Fractures of Different $F_{C D}$ 's

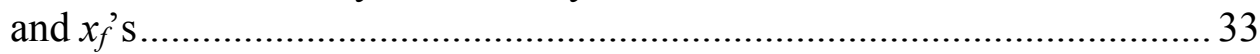

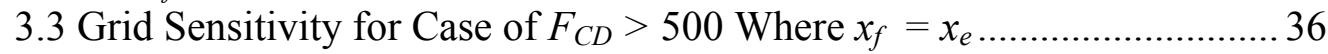

3.4 Grid Sensitivity for Case of $F_{C D}=500$ Where $x_{f}<x_{e} \ldots \ldots \ldots \ldots \ldots \ldots \ldots \ldots \ldots . . . . . . . . . . . .38$

3.5 Grid Sensitivity for Case of Infinite Conductivity Fracture Where $x_{f} / x_{e}$ $=0.2$. 40

3.6 Grid Sensitivity for Case of $F_{C D}=\pi$, Where $x_{f} / x_{e}=0.2 \ldots \ldots \ldots \ldots \ldots \ldots \ldots \ldots . . .44$

3.7 Grid Sensitivity for Cases of $F_{C D}=100 \pi 10 \pi$ and $\pi$ Where $x_{f} / x_{e}=0.1 .45$ 
CHAPTER

Page

IV MODELING HYDRAULIC FRACTURES IN COARSE GRIDBLOCKS 46

4.1 Introduction ............................................................................ 46

4.2 Modeling Hydraulic Fractures in Coarse Blocks Using Pseudo

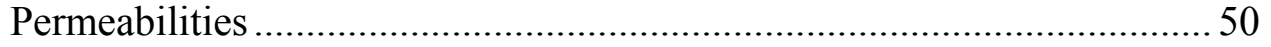

4.3 Modeling Hydraulic Fractures in Coarse Blocks Using

Transmissibilities ................................................................................ 51

4.4 Simulation Results and Matching Analytical Solutions.......................... 53

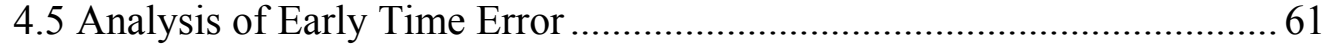

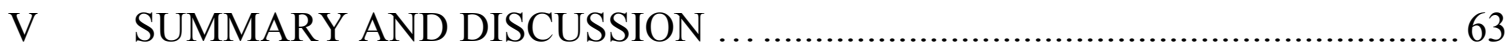

5.1 Summary of Steps to Create a Model of Coarse Scale Simulation ........... 63

5.2 Example Calculation ......................................................................6 64

5.3 Summary of Steps to Interpret Results of Coarse Scale Simulation ......... 65

5.4 Application of the Work in the Dissertation for Gas Reservoirs .............. 65

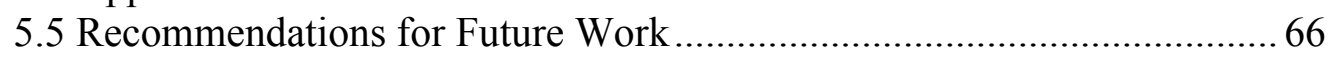

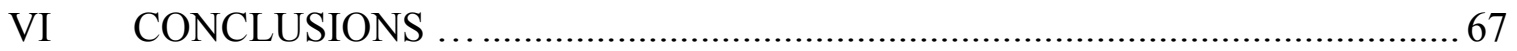

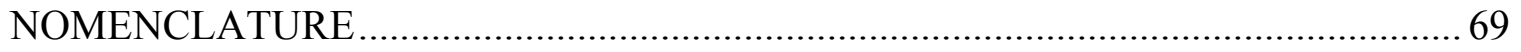

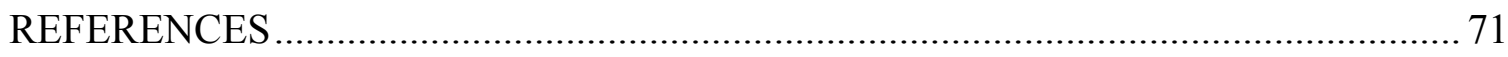

APPENDIX A DERIVATION TO SHOW RELATION BETWEEN $p_{w f}$ and $p_{w b}$ IN

RADIAL FLOW ..................................................................... 75

APPENDIX B DERIVATION TO SHOW THAT $p_{w f}=p_{w b}$ IN LINEAR FLOW ......... 78

APPENDIX C DERIVATION OF PSEUDO VALUES OF $K$ FOR MODELING

COARSE GRIDS ........................................................................ 81

APPENDIX D DERIVATION OF TRANSMISSIBILITY MULTIPLIER FOR MODELING COARSE GRIDS ..................................................... 87

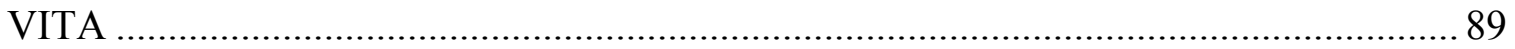




\section{LIST OF TABLES}

TABLE Page

2-1 Reservoir and fluid data for the simulated pressure drawdown test for the radial

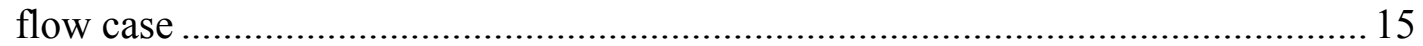

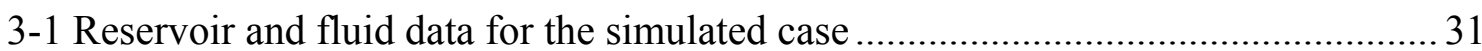

3-2 Summary of 20 case simulated using gridding of 41 x 193 cells .......................... 32

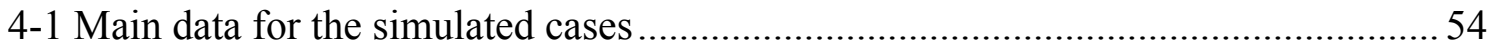

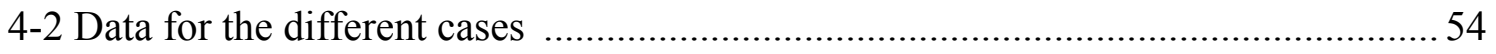

4-3 Data for different grid sets for case \# 1 ........................................................... 54

4-4 Data for different grid sets for case \# 2 .......................................................... 56

4-5 Data for different grid sets for case \# 3 .......................................................... 59

4-6 Percentage of error in dimensionless pressure during transient period ................... 61

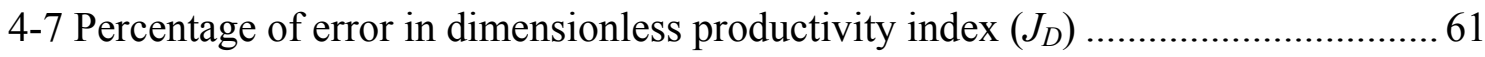




\section{LIST OF FIGURES}

FIGURE

Page

2-1 Schematic of the cross-section of a wellbore gridblock in a reservoir model.........13

2-2 Radial flow in a homogeneous square reservoir modeled by a two-dimensional areal grid system.

2-3 Top view of a model of a square reservoir. This view shows part of the $99 \times 99$ cells gridding.

2-4 Simulation results of $p$ vs. $t$ for well gridblock and five adjacent gridblocks $[i=$ 50 is the well gridblock $i=51$ is adjacent ...etc.] Notice that lines are parallel after $\mathrm{t}=200$ days indicating that we reached steady state

2-5 Simulation results of $p$ vs. $\ln r / \Delta x$ for well gridblock and five adjacent gridblocks appear on the plot. $[i=50$ is the well gridblock $i=51$ is adjacent ...etc. ]. Notice that all results lie on the same straight line except the value of the average pressure of the well gridblock which is equivalent to the analytical solution at $r_{o}=0.21$.

2-6 The plot shows simulation results of $p_{i, j}-p_{w b}$ vs. $\ln r / \Delta x$ for five gridblocks adjacent to well gridblock $[i=50$ is the well gridblock $i=51$ is adjacent ...etc.]. Notice that when $p_{i, j}-p_{w b}=0$ the value of $\ln r / \Delta x=0.21$ and not zero.

2-7 Sketch of a linear reservoir model (linear slab).

2-8 Plot that shows simulation results of $p$ vs. $t$ for well gridblock and five adjacent gridblocks $[i=25$ is the well gridblock $i=26$ is adjacent ...etc. $]$. Notice that lines are parallel after $t=200$ days indicating that we reached steady state.

2-9 Plot that shows simulation results of $p$ vs. $y / \Delta y$ for well gridblock and five adjacent gridblocks. [ $i=26$ is the well gridblock, $i=27$ is adjacent ...etc]. Notice that all results lie on the same straight line including the value for the well gridblock.

2-10 Plot that shows simulation results of $p_{i, j}-p_{w b}$ vs. $y / \Delta y$ for five gridblocks adjacent to well gridblock. [ $\mathrm{i}=26$ is the well gridblock, $\mathrm{i}=27$ is adjacent ...etc. ]. Notice that when $p_{i, j}-p_{w b}=0$ the extrapolated value of $y / \Delta y=0$ 
2-11 Square reservoir of a linear model of grid $1 \times 15$

2-12 Plot that shows simulation results of $\log \Delta p$ vs. $\log t$ for gridding of $1 \times 25,1 \mathrm{x}$ 51 , and $1 \times 193$. Notice that the finer grids match the analytical solution at an earlier time

2-13 Simulation results of $\Delta p$ vs. $t$. This is for the case of $1 \times 25$ grid. The slope is found to be equal to $38.47 \mathrm{psi} / \mathrm{ft}$. This slope agrees with the close value of 39.2 $\mathrm{psi} / \mathrm{ft}$ obtained when applying Eq. 2-9

2-14 Plot that shows simulation results of $p$ vs. $x$ at different times. This is for the case of $1 \times 25$ grid. Notice that $p^{\prime}(x)$ is independent of time for values greater than $t=29$ days which means there is no effect of artifact wellbore storage after this time.

3-1 Schematic of a non-uniform fine grid compared to a uniform fine grid for the case of a quarter model.

3-2 Uniform fine gridding of $9 \times 11$ cells of a hydraulic fracture model.

3-3 Schematic of a typical hydraulic fracture model of a square reservoir $\left(x_{e}=y_{e}\right) \ldots . .30$

3-4 Plot showing a family of constant rate type curves simulated with a set of uniform fine grids in the $\mathrm{x}$ and $\mathrm{y}$ directions of $41 \mathrm{x} 193$ cells. Accuracy is good for the range shown on the plot. All simulated cases had an error at $t_{D}<10^{-3}$. Simulated cases of $F_{C D}<1$ gave a significant error during transient for all ratios of $x_{f} / x_{e}$. Cases of $x_{f} / x_{e}=0.1$ gave a large error during transient for all $F_{C D}$ values.

3-5 A comparison between results of three simulations for the case of $F_{C D}>500$ where $x_{f}=x_{e}$. We notice that finer grids in the direction perpendicular to the fracture result in a match with the analytical solution.

3-6 Three simulations of a uniform fine grid of different $\boldsymbol{x}_{\boldsymbol{f}} / \boldsymbol{x}_{\boldsymbol{e}}$ ratios compared on a $t_{D s f}$ basis showing a match with the analytical solution except for the case of $x_{f} / x_{e}=0.1$

3-7 Three simulations of different ratios of $x_{f} / x_{e}$ compared on a $t$ basis indicating that the error starts at the same time regardless of the $x_{f} / x_{e}$ ratio. 
3-8 Three simulations of $F_{C D}=500$ and $x_{f} / x_{e}=0.2$ compared to the analytical solution showing that the finer grids are important only in the direction perpendicular to the hydraulic fracture for the case simulated.

3-9 $p$ vs. $y$ for the gridblocks of the case of $21 \times 385$ gridding showing that at late time the pressure profiles are parallel indicating that the artifact wellbore storage ended.

3-10 Six simulations for $F_{C D}=100 \pi$ and $x_{f} / x_{e}=0.2$ compared to analytical solution indicating that finer grids in the direction perpendicular to the fracture gives the best match to the analytical solution.

3-11 Grid sensitivity for the case of $F_{C D}=\pi$ where $x_{f} / x_{e}=0.2$ indicating that finer grids are needed in both the direction perpendicular and parallel to the fracture to give the best match to the analytical solution.

3-12 Grid sensitivity for cases of $F_{C D}=100 \pi 10 \pi$ and $\pi$ where $x_{f} / x_{e}=0.1$ using a non-uniform grid of $79 \times 33$ cells

4-1 Quarter model of a single hydraulic fracture using the conventional fine grid.......47

4-2 An example of a field model with several wells with hydraulic fractures .............48

4-3 An example of a hydraulic fracture passing through coarse gridblocks

4-4 An example of a hydraulic fracture not extended till the end of the gridblock.......52

4-5 Top view of a hydraulic fracture not extended till the end of the gridblock ..........52

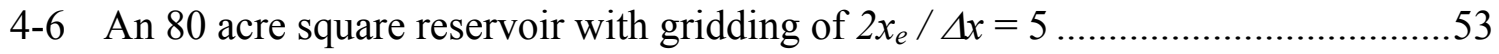

4-7 The log-log p1 ot of $p_{D}$ vs. $t_{D x f}$ for different grid sets of case \# 1 .........................55

4-8 The log-log plot of $p_{D} v s . t_{D x f}$ for different grid sets of case \# 2 ..........................58

4-9 The log-log p1 ot of $p_{D} v s . t_{D x f}$ for comparison of cases \# 1 and \# 2 $\ldots \ldots \ldots \ldots \ldots \ldots . . . . . . . .58$

4-10 The $\log -\log$ plot of $p_{D}$ vs. $t_{D x f}$ for different grid sets of case \# 3 .........................60 


\section{CHAPTER I}

\section{INTRODUCTION}

\subsection{Problem Description}

The modeling of hydraulic fractures in coarse grid field models is a topic that has not been covered in a comprehensive way in the literature. There is definitely a need to document a method to model the behavior of a reservoir with coarse gridblocks that is hydraulically fractured. The simulation of coarse gridblocks may cause to have an early numerical error that is known as artifact wellbore storage. This artifact wellbore storage is important especially in the case of tight gas reservoirs that usually have a long transient period.

It is possible to construct a reservoir model with a grid system that is sufficiently detailed to model near-wellbore behavior. However, gridblocks containing wells are usually too coarse to model near-wellbore behavior directly. Therefore, the calculated pressures in gridblocks containing wells $p_{w b}$ must be corrected to formation face pressure $p_{w f}$. This correction is done using what is known as a well model that is discussed for the case of reservoir models with hydraulic-fractures. The well model is very important in case of coarse gridblocks.

This dissertation follows the style of the SPE Reservoir Evaluation \& Engineering. 
The results from the use of uniform fine grids to simulate a reservoir model with a single hydraulic fracture are compared with the results from simulations using nonuniform fine grids.

This dissertation was confined to the simulation of single-phase oil flow cases that are producing at a constant rate. It was concerned mainly with reservoir models hydraulically fractured of infinite fracture conductivity but case of finite fracture conductivity was also investigated.

\subsection{Literature Review on Well Modeling}

Several studies have been carried out in the area of interpretation of well block pressure in numerical reservoir simulation. In 1978, Peaceman ${ }^{1}$ published his first paper on this subject. Using a repeated five-spot pattern and square grid blocks he showed that for an isotropic square reservoir containing a producer and injector the relation between the well block pressure $p_{w b}$ to the wellbore pressure $p_{w f}$.

In 1983, Peaceman ${ }^{2}$ published a second paper that provided equations for calculating $r_{o}$ values when the well block is a rectangle and/or the formation is an isotropic. He extended the determination of $r_{o}$ to the case of non-square grid blocks with a single isolated well.

In 1987, Peaceman ${ }^{3}$ investigated a number of useful well geometries numerically. He included arbitrary placement of a well within the well block, two or more wells within a single well block, a well exactly on the edge or corner of a grid block, and a well arbitrarily placed within an edge or corner block. In each case, the 
effects of the grid dimensions were investigated and analytical solutions were proposed for the well index.

In 1991, Peaceman ${ }^{4,5}$ determined the analytical solution for the equivalent well block radius for a horizontal well in an anisotropic reservoir with a uniform grid.

Peaceman $^{6}$ also presented a new equation for calculating the equivalent well block radius for all the wells in a reservoir that fully accounts for arbitrary well rates and the interaction between the wells.

Babu and Odeh ${ }^{7}$ presented a relationship between well block and wellbore pressure for use in the numerical simulation of horizontal wells and for arbitrary well locations in cells. In this work, they derived an analytical equation for calculating $r_{o}$ for any well location and for isotropic and anisotropic formations. They presented two methods for calculating the equivalent well block radius. The first one was analytical and the second one was graphical. Both methods start with the general solution relating pressure and flow rate for any well of an arbitrary location in a box-shaped drainage volume. Throughout their work, they neglected the effect of gravity and they manipulated the magnitudes of the aspect ratios of grids and of drainage areas. Mochizuki $^{8}$ extended Peaceman's equation to wells aerially and vertically inclined at arbitrary angles with respect to grid lines in anisotropic reservoirs. Mochizuki's method is based on the transformation of the anisotropic flow equation to an equivalent homogenous equation and then it interpolates the effective well block radius wellbore radius and equivalent well length as a function of the angles. Permeability thickness and well index were expressed as a function of arbitrary angles. 
Mochizuki's proposed method was implemented in a commercial simulator and compared with analytical solutions.

Chen et al. ${ }^{9,10}$ developed a method by which a conventional finite difference simulator can be used together with an analytical model to calculate accurate well pressure and productivity for different types of wells. They introduced a method for accurately calculating the productivity of wells of any deviation $\left(0-90^{\circ}\right)$ for a homogenous reservoir. The analytical solution presented in Chen et al.'s work can handle multiple wells in a parallelepiped-shaped finite-sized uniform permeability reservoir.

Sharpe and Ramesh ${ }^{11}$ modified the Peaceman well model, which restored its validity for non-uniform aerial grids and for problems that model vertical flow process like gas and water coning. They investigated the effect of using the standard Peaceman well model in problems formulated on non-uniform cartesian grids and for problems in which the vertical flow transmissibility is significant compared with the horizontal transmissibility. Sharpe and Ramesh ${ }^{11}$ also demonstrated that the radial well model is not adequate for properly including vertical flow effects.

Ding et al. ${ }^{12}$ demonstrated a new approach based on the finite volume method to compute the wellbore pressure. This work does not involve the equivalent well-block radius concept but requires the pressure distribution in the neighborhood of the well. The analytical solution for pressure near the well was analyzed by modifying the transmissibility between the grid blocks so that fluid flow around a well was described correctly. The proposed method could be applied to non-uniform grids and could be 
evaluated as a generalization of Peaceman's analytical method for equivalent well-block radius.

Wan et al. ${ }^{13}$ compared horizontal well performance simulated by using a uniform coarse grid a uniform fine grid and a non-uniform fine grid using Peaceman's well index model. Wan et al. found that when a coarse grid was used to simulate a partially penetrating horizontal well the flow rate of the well was under-predicted. This is because of the fact that non-uniform grids can introduce large numerical errors into the computation of well block pressure. Wan et al. obtained satisfactory results using nonuniform grids considering uniform local grid refinement in calculations with reasonable computational costs.

\subsection{Literature Review on Vertical Hydraulic Fractures}

Prats et al. ${ }^{14,15}$ studied the effect of vertical fractures on reservoir performance for single phase and two phase flow cases. They studied both the constant rate and constant pressure production. The model included the effect of the boundary. They introduced the concept of using radial flow model with an effective wellbore radius to account for the hydraulic fracture. They found that the effective wellbore radius was equal to one-fourth the total fracture length.

Russell and Truitt ${ }^{16}$ studied the pressure-transient behavior in vertically fractured reservoirs. They presented numerical solutions using conventional finite-difference method for an infinite conductivity fractured well in a square reservoir. They published transient drawdown solutions for vertically fractured liquid wells with constant 
production rate. They developed methods of drawdown and build up testing utilizing these solutions.

Wattenbarger and Ramey ${ }^{17}$ extended Russell and Truitt ${ }^{15}$ solutions to the gas case. They used numerical simulation to study pressure transient testing of fractured gas wells. They showed that the methods developed for testing fractured wells flowing liquid could be extended to gas cases if the real gas pseudo pressure is used if drawdown is small. They also showed that turbulence (non-darcy flow) could be treated as a skin. Rules to identify the end of linear flow and the start of pseudo radial flow were also developed.

Morse and Von Gonten ${ }^{18}$ studied the effect of hydraulic fracturing on well productivity prior to stabilized flow. They used a general numerical simulator to obtain relationship between production rate and time for constant pressure case. Fine grids at the fracture tip and parallel to the fracture were used in the model. They showed that for low permeability reservoirs well productivity varied greatly with time and in the case of well with hydraulic fractures the initial well productivity might be more than ten times the final stabilized productivity depending on the fracture length.

Gringarten et al. ${ }^{19,20}$ developed new analytical solutions for vertical fractures of infinite conductivity and uniform flux in an infinite reservoir and in a square drainage area. The case of horizontally fractured well was also discussed. They considered the case of constant rate production. Applicability of the solutions for analyzing pressuretransient test data was illustrated. 
Cinco-Ley et al..$^{21,22}$ developed analytical solutions for transient behavior of a well with a finite conductivity vertical fracture in an infinite slab reservoir. They consider the case of constant rate production. They developed a set of type curves in terms of dimensionless pressure and time for different values of dimensionless fracture conductivity. For a highly conductive fracture $F_{C D}$ values greater than $100 \pi$ their solutions are in good agreement with those of Gringarten et al. ${ }^{18}$ solutions. The solutions for stabilized flow are in good agreement with those of Prats ${ }^{13}$ steady-state solutions. A type curve matching procedure to analyze early-time pressure-transient data to obtain the formation and fracture characteristics were illustrated. Later they modified their solutions to include the effects of wellbore storage and fracture damage. An infinitesimal skin was considered around the fracture. They found that the well behavior was importantly affected by the fracture damage and important information about the fracture characteristics might be masked when wellbore storage effects were present.

Agarwal et $_{\text {al. }}{ }^{23}$ studied the performance of low-permeability gas wells stimulated by massive hydraulic fracturing (MHF) using a computer program called MHF simulator. The program is a two-dimensional single-phase finite-difference model that simulates real gas flow. They discussed the limitations of the conventional analysis methods for determining fracture length and fracture conductivity in MHF wells. They presented sets of type curves for constant-rate and constant-pressure production cases as alternative solutions for analyzing MHF wells. Wellbore storage effects were not considered. They showed that a curve for $F_{C D}$ values of 500 or greater should represent infinite fracture conductivity (Gringarten et al. ${ }^{19}$ ) approximately. 
Cinco-Ley et al. ${ }^{24}$ discussed thoroughly the limitations and advantages of several methods for analyzing pressure-transient data in fractured wells. Their discussion covered all the flow regimes that might occur in vertically fractured wells. They showed how different methods might be combined to accomplish a more reliable analysis. In addition, a new analytical solution was presented for the analysis of short-time pressuretransient data for wells with a vertical fracture with low or intermediate fracture conductivity.

Narasimhan and Palen ${ }^{25}$ studied the behavior of vertically fractured wells numerically using integral finite-difference method. The elements were accurate near the well and around the fracture tip to efficiently simulate the radial flow. Finite conductivity fracture solutions of Cinco-Ley et $a l^{21,22}$ were used to validate their solutions. New problems such as unequal wing-length, choked fracture, deformable fracture, and effect of fracture storativity were studied.

Bostic $e t a l .{ }^{26}$ presented method to analyze the performance of wells stimulated with massive hydraulic fracturing by combining post fracture performance data with post fracturing buildup data for analysis on the same constant rate type curves. This method is useful when the early-time production data were lost during the cleanup period and significant shut in periods. The combination of buildup and production data is accomplished using superposition principal.

Cinco-Ley and Samaniego ${ }^{27}$ presented the basic pressure behavior differences between a finite conductivity fracture and an infinite conductivity fracture with fracture damage. Two types of fracture damage conditions were studied: damage zone around the 
fracture which is also called fracture-face skin and a damage zone within the fracture in the vicinity of the wellbore which is also called choked fracture. They presented new type curves to analyze early time and long-time pressure data for both choked fracture and fracture face skin cases.

Bennett et al. ${ }^{28}$ studied the influence of the settling of propping agents and the effect of fracture height on the well response in finite-conductivity vertically fractured wells. They used a block-centered finite-difference 3D numerical model to compute the response at the well. They suggested methods to analyze well performance when the fracture-conductivity was a function of fracture height and fracture length. They also presented a systematic procedure to obtain a grid so that accurate results were obtained from a finite-difference model. This procedure can be used for both $2 \mathrm{D}$ and $3 \mathrm{D}$ problems. They suggested to use finer grid near the well and near the fracture tip and to use uniform grid parallel to the fracture.

Ding $^{29}$ studied the simulation of fractured wells with high conductivity and considered the fractures as part of the well. Their method was based on the well model rather than on the gridding technique. This new well model took into account well configurations by using equivalent transmissibility to improve the flow calculation in the well vicinity. To establish a well model it is required to know a steady state or pseudosteady state pressure distribution around the well.

\subsection{Literature Review on Modeling Hydraulic Fractures in Coarse Blocks}

In 1983 , Ngheim $^{30}$ presented a way to model infinite-conductivity fractures in reservoir simulation by the use of source and sink terms. The drawbacks of his work 
were that he used pressure in neighboring cells to compute the production, which is not consistent with standard simulator programming. He also mentioned that hydraulic fractures of finite conductivity fractures such as those that occur in massive hydraulic fracturing cannot be simulated by his method but should rather be simulated by a row of gridblocks with narrow width and high permeability and porosity representative of the fracturing proppant.

In 1985, Schulte ${ }^{31}$ worked on the production behavior of hydraulically fractured wells in which gas or oil in the fracture enters the wellbore over a limited vertical interval smaller than the fracture height such as in the case of deviated or partially penetrated wells. He emphasized importance of fine gridding at tip of fracture and at well.

In 1991, Roberts et al. ${ }^{32}$ studied the effect of fracture and reservoir properties of gas well productivity of multiply fractured horizontal wells in tight gas reservoirs. They reported that numerical problems in the simulation of hydraulic fractures of horizontal wells were solved by increasing the fracture width while decreasing the fracture permeability such that the fracture conductivity was maintained.

In 1993, Lefevre et al. ${ }^{33}$ provided rules of thumb to simulate infinite conductivity fractures in coarse grid models. Their results depend on a very large series of simulations in single-phase steady state conditions. The simulations were done with a fracture either along the cell axes or along the cell boundaries. They failed to show the theoretical basis from which they provided their rules. The rules that they showed used the Peaceman ${ }^{4}$ formula coupled with equivalent radius $\left(r_{w e}\right)$ in case of hydraulic fracture included 
within one cell. In case of a hydraulic fracture extending over several cells, they used what they called a block factor. They provided tables with correlations showing rules to apply for values of transmissibilities to account for hydraulic-fractures passing through several gridblocks.

In 1996 Hegre $^{34}$ studied the simulation of hydraulically fractured horizontal wells and used (a) fine gridding, (b) a computed value of the equivalent radius of the hydraulic fracture coupled with the formula for the Peaceman ${ }^{4}$ radius for horizontal wells, (c) adjustment of transmissibility values for coarse grids with fractures (the new transmissibility values are based on automatically comparing with simulation runs at early time using local grid refinement) and (d) Adjustment of Well Index of centered fractured cells or cells at the tip based on automatically comparing with simulation runs at early time using local grid refinement. 


\section{CHAPTER II}

\section{WELL MODELS AND ARTIFACT WELLBORE STORAGE}

\subsection{Introduction}

It is possible to construct a reservoir model with a grid system that is sufficiently detailed to model near-wellbore behavior. However gridblocks containing wells are usually too coarse to model wells directly (Fig. 2-1). Therefore the calculated pressures in gridblocks containing wells $p_{w b}$ must be corrected to formation face pressure $p_{w f}$. This correction is done using what is known as Peaceman's ${ }^{1}$ equation:

$$
p_{w f}=p_{w b}-\frac{q \mu B}{J_{\text {model }}}
$$

Where $J_{\text {model }}=\frac{0.00708 k h}{\ln (0.208 \Delta x) / r_{w}}$

This above equation is for the radial flow case. It has been developed based on the assumption that steady state pressure profiles occur within the well gridblock. The main idea behind it came from Peaceman ${ }^{1}$ who derived Eq. 2-3. This equation states that the radius $r_{o}$ at which the flowing pressure equaled the average block pressure could be defined for a well gridblock with sides of length $\Delta x$ as

$$
r_{o}=0.208 \Delta x
$$

We re-derived Eq. 2-3 in Appendix A. Peaceman ${ }^{1}$ obtained also numerically from detailed simulation modeling of a square grid around a wellbore that

$$
r_{o}=0.198 \Delta x
$$


Peaceman ${ }^{1,2}$ has also demonstrated that the method can be applied for unsteadystate flow conditions and for the use of rectangular gridblocks of an aspect ratio $\Delta y / \Delta x$ in which case Eq. (2-3) is replaced by Eq. (2-5)

$$
r_{o}=0.14[(\Delta x) \times(\Delta y)]^{0.5}
$$

Peaceman's ${ }^{1,2}$ equations are programmed into any conventional reservoir simulator for the case of radial flow. In this chapter we repeated the same numerical experiments reported by Peaceman ${ }^{1}$ and tried to draw parallels for the case of linear flow. A result was reached that $p_{w f}=p_{w b}$ for the case of linear flow. A more detailed derivation about this conclusion is shown in Appendix B.

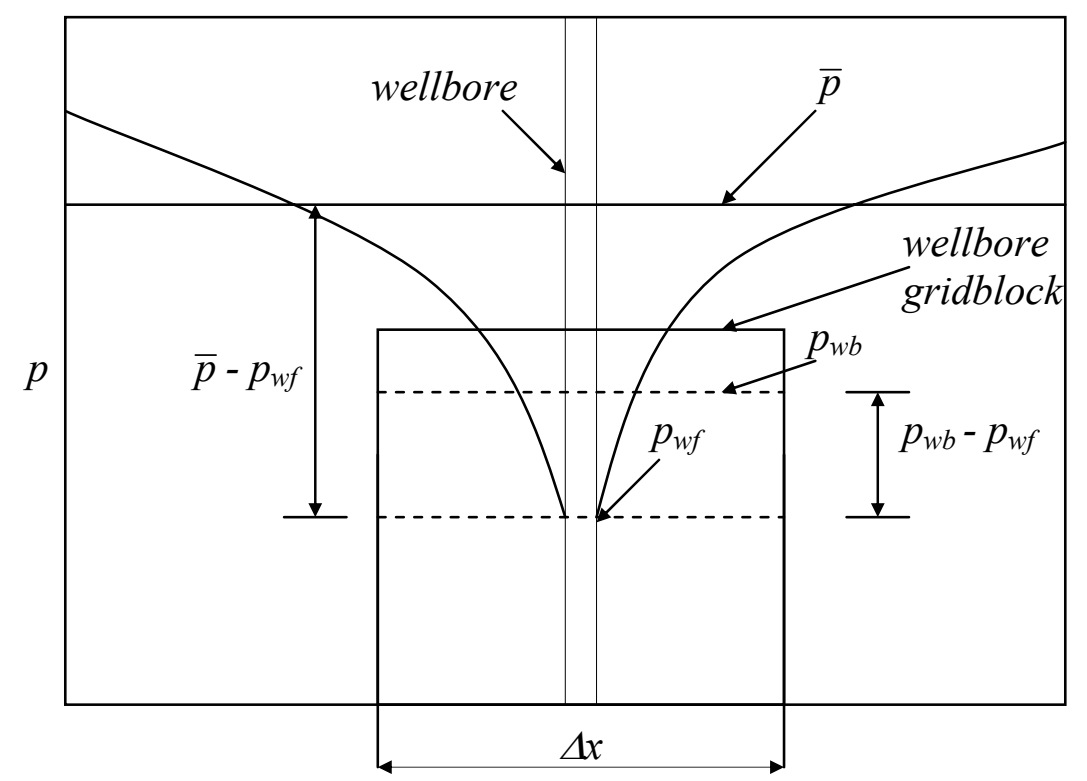

Fig. 2-1 - Schematic of the cross-section of a wellbore gridblock in a reservoir model. 
In addition to the problem of modeling wells in reservoir simulation we are faced with the problem of artifact wellbore storage ${ }^{35}$. This is a time resolution problem where a combination of a tight reservoir of a coarse well gridblock and a high value of diffusivity $\eta$ causes a numerical error at early time.

\subsection{Well Models}

\subsubsection{Well Modeling in Radial Flow}

We attempted using numerical simulation to get the relation between $p_{w b}$ and $p_{w f}$ for the case of radial flow. In doing so we tried to reproduce the results of Peaceman ${ }^{1}$. We consider a single layer homogeneous square-shaped reservoir with uniform thickness $h$ as illustrated in Fig. (2-2). The well was set to produce at a constant rate .We maintained steady state by putting 4 injectors at the corners of the model. The gridding was 99 x 99 cells as illustrated in Fig. (2-3). Table 2-1 summarizes the data used in the simulation run.

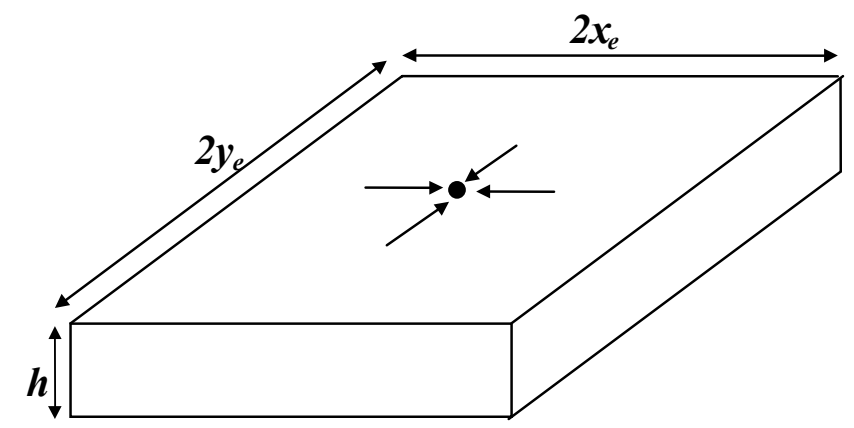

Fig. 2-2 - Radial flow in a homogeneous square reservoir modeled by a twodimensional areal grid system. 


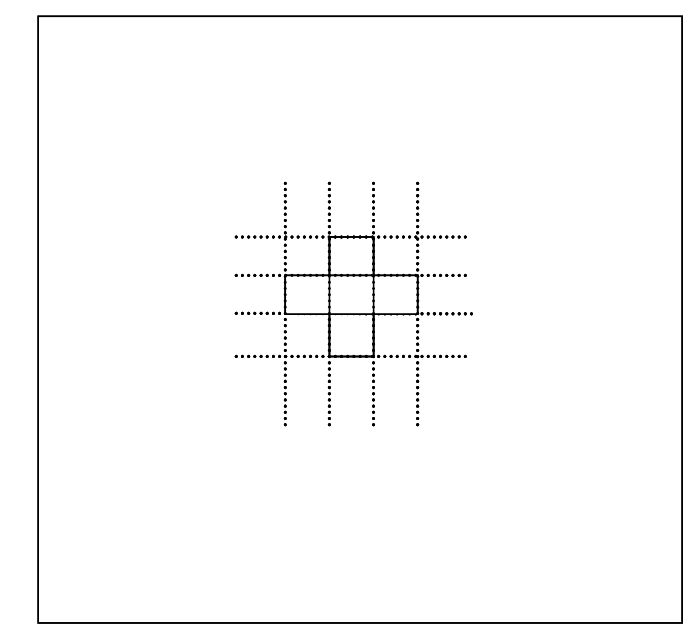

Fig. 2-3 - Top view of a model of a square reservoir. This view shows part of the $99 \mathrm{x}$ 99 cells gridding.

\begin{tabular}{|l|c|}
\hline \multicolumn{2}{|l|}{ Table 2-1 - Reservoir and fluid data for the simulated pressure } \\
drawdown test for the radial flow case & $\cong 80$ \\
\hline Drainage area, Acres & 1,860 \\
Reservoir length $\left(2 x_{e}\right), \mathrm{ft}$ & 1,860 \\
Reservoir length $\left(2 y_{e}\right), \mathrm{ft}$ & 150 \\
Thickness, $(h) \mathrm{ft}$ & 1 \\
Absolute permeability, $(k) \mathrm{md}$ & 0.23 \\
Porosity, $(\phi)$ fraction & 3000 \\
Initial pressure, $\left(p_{i}\right) \mathrm{psi}$ & 1 \\
Oil formation volume factor, $\left(B_{o}\right) \mathrm{RB} / \mathrm{STB}$ & 0.72 \\
Oil viscosity, $\left(\mu_{o}\right) \mathrm{cp}$ & $1.5 \mathrm{E}-05$ \\
Total compressibility, $\left(c_{t}\right) \mathrm{psi}^{-1}$ & 0.25 \\
Wellbore radius, $\left(r_{w}\right) \mathrm{ft}$ & $\mathrm{ft}$ \\
\hline
\end{tabular}


In Fig. (2-4) it is clear that we reached steady state after $t=200$ days. The lower curve is the pressure in well gridblock $(50,50)$ and the upper curves are the pressures for the adjacent gridblocks in the x-direction. We chose any arbitrary time after $t=200$ days and we plotted $p$ vs. $\ln r / \Delta x$. We normalized the value of $r$ to be $r / \Delta x$ and we plotted $p$ vs. $\ln r / \Delta x$ rather than $p$ vs. $\ln r$ to be easier in illustration and deducing results as shown in Fig. (2-5).

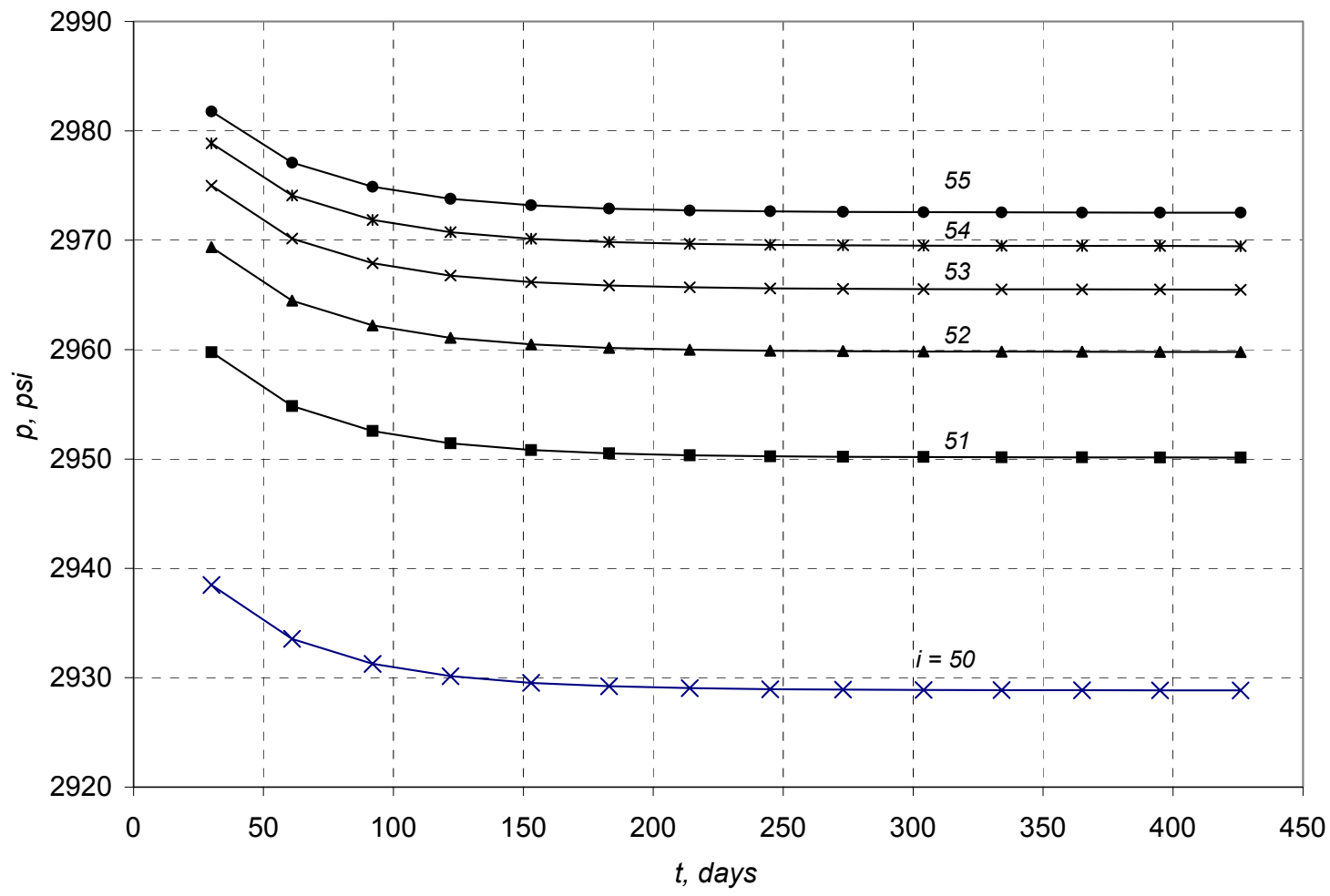

Fig. 2-4 - Simulation results of $p$ vs. $t$ for well gridblock and five adjacent gridblocks. $[i=50$ is the well gridblock $i=51$ is adjacent ...etc. $]$. Notice that lines are parallel after $t$ $=200$ days indicating that we reached steady state. 
For the radial flow case the plot of $p$ vs. $\ln r$ gives a straight line at steady state conditions. Fig. (2-5) shows that all points for the adjacent gridblocks lie on a straight line except for the pressure at the well gridblock. This indicates that $p_{w f} \neq p_{w b}$ for the case of radial flow. If we extend the horizontal line of $p_{w b}$ value to the straight line of $p$ vs. $\ln r$ we will find that the average gridblock pressure $p_{w b}$ equals the flowing pressure at $r_{o}=0.21 \Delta x$. This same result can be concluded from Fig. (2-6) where we plot $p_{i, j}-$ $p_{w b}$ vs. $\ln r / \Delta x$ where $p_{i, j}$ is the pressure in the adjacent gridblocks to the well gridblock.

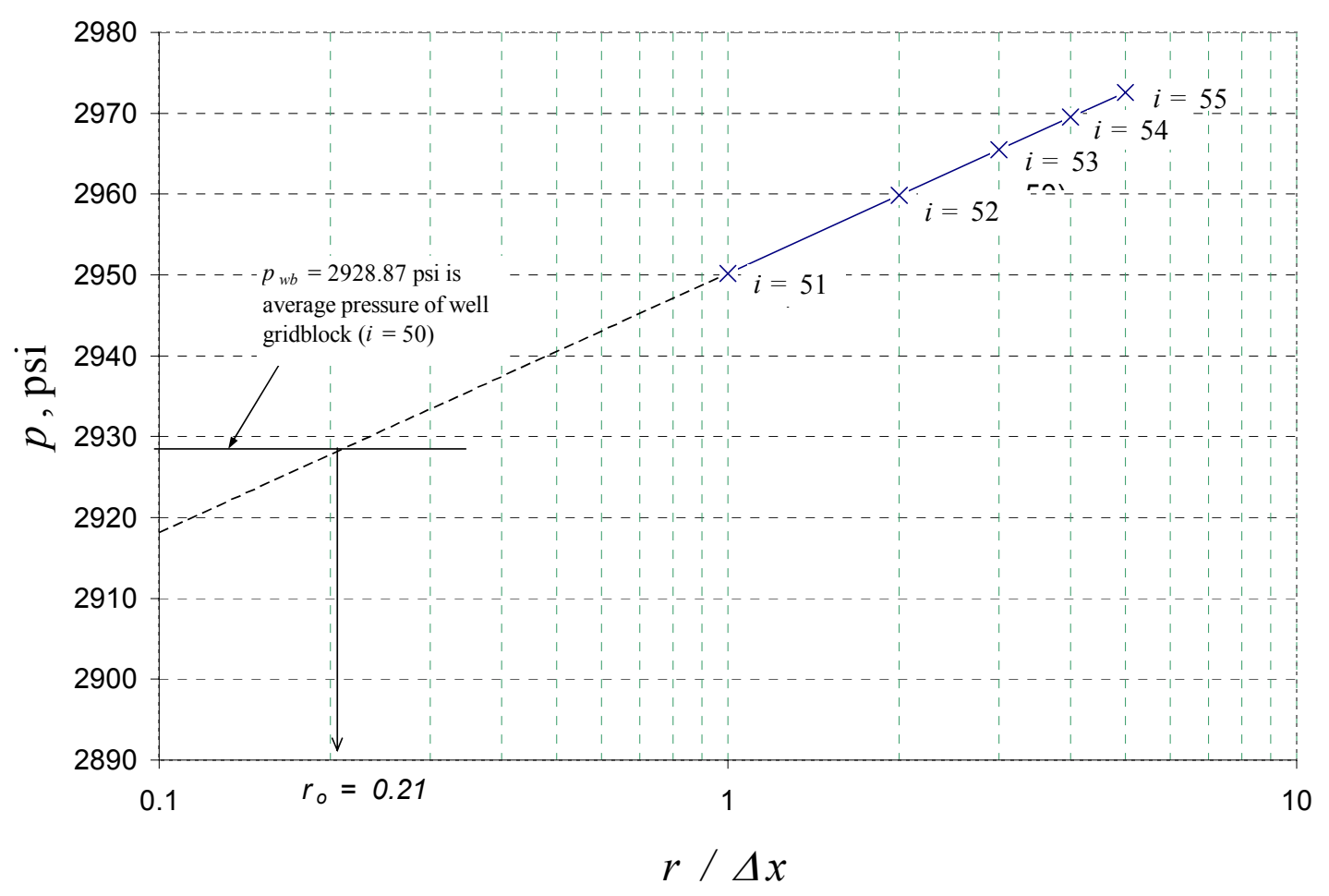

Fig. 2-5 -Simulation results of $p$ vs. $\ln r / \Delta x$ for well gridblock and five adjacent gridblocks appear on the plot. [i=50 is the well gridblock $i=51$ is adjacent ...etc.]. Notice that all results lie on the same straight line except the value of the average pressure of the well gridblock which is equivalent to the analytical solution at $r_{o}=0.21$. 


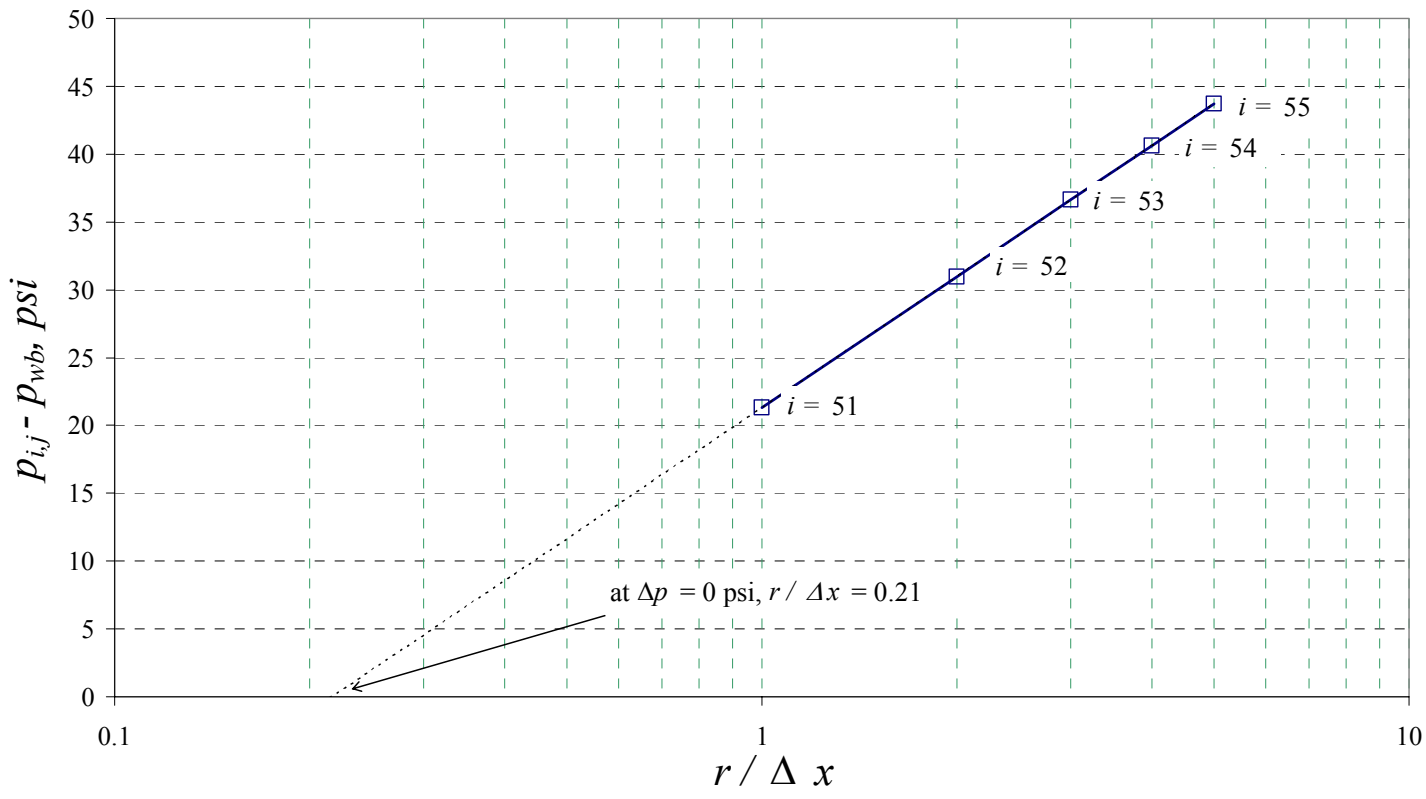

Fig. 2-6 - The plot shows simulation results of $p_{i, j}-p_{w b}$ vs. $\ln r / \Delta x$ for five gridblocks adjacent to well gridblock. [ $\mathrm{i}=50$ is the well gridblock $\mathrm{i}=51$ is adjacent ...etc. ]. Notice that when $\quad p_{i, j}-p_{w b}=0$ the value of $\ln r / \Delta x=0.21$ and not zero. 


\subsubsection{Well Modeling in Linear Flow}

In this section numerical simulation was used to get the relation between $p_{w b}$ and $p_{w f}$ for the case of linear flow. We considered a half linear flow model with uniform thickness $h$ as illustrated in Fig. (2-7). Data used in the simulation run is same as in Table 2-1 but note that $w$ is equivalent to $2 x_{e}$ and $L$ is equivalent to $y_{e}$. The well is set to produce at a constant rate and we maintained steady state by putting 2 injectors at the 2 outer cells of the model. We performed simulation with a 2D full model of 1 x 51 cells where the well gridblock is $(1,25)$.

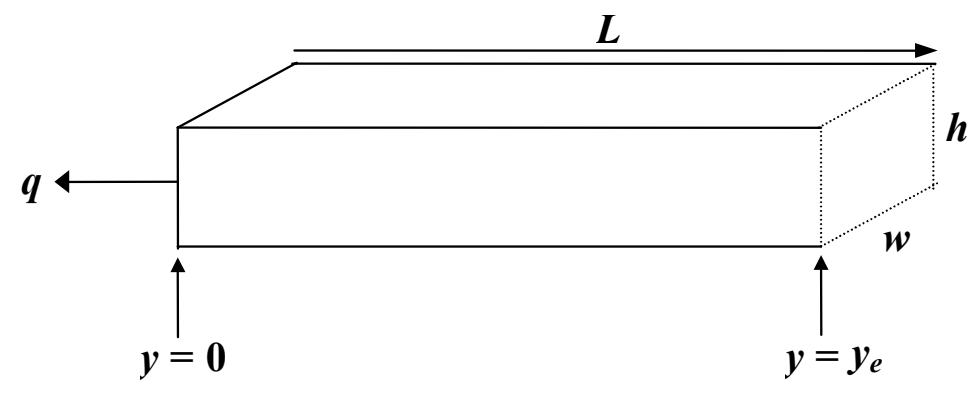

Fig. 2-7 - Sketch of a linear reservoir model (linear slab).

Fig. (2-8) demonstrates that steady state is reached after approximately $\boldsymbol{t}=200$ days. The lower curve is the pressure in well gridblock $(1,25)$ and the upper curves are the pressures for the adjacent gridblocks in the x-direction. We chose any arbitrary time after $\boldsymbol{t}=200$ days and we plot $p$ vs. $y / \Delta y$. We used the normalized value of $y / \Delta y$ and we plotted $p$ vs. $y / \Delta y$ to be easier in illustration and deducing results. 
From fundamentals of reservoir engineering we know that a plot of $\boldsymbol{p}$ vs. $\boldsymbol{y}$ gives a straight line for linear flow at steady-state conditions. Fig. (2-9) shows that all points for adjacent gridblocks lie on a straight line including the pressure of the well gridblock which is at $y / \Delta y=0$. This indicates that $p_{w f}=p_{w b}$ for the case of linear flow. We therefore deduce that there is no concept similar to the Peaceman ${ }^{1}$ radius for linear flow. This same result can be concluded from Fig. (2-10) where we plot $p_{i, j}-p_{w b}$ vs. $\ln y / \Delta y$ where $p_{i, j}$ is the pressure of the adjacent gridblocks to the well gridblock.

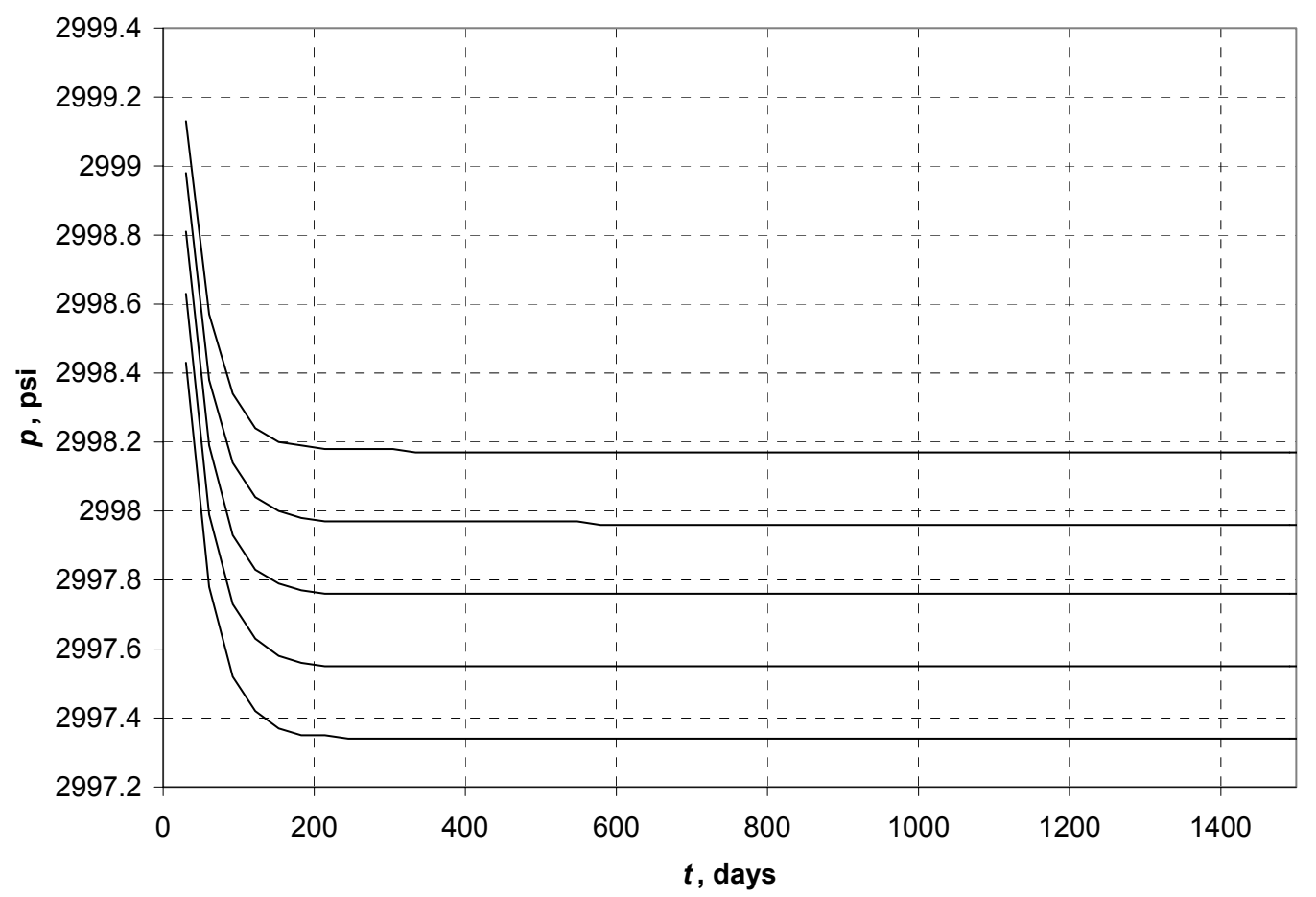

Fig. 2-8 - Plot that shows simulation results of $p$ vs. $t$ for well gridblock and five adjacent gridblocks $[i=25$ is the well gridblock $i=26$ is adjacent ...etc. ]. Notice that lines are parallel after $\mathrm{t}=200$ days indicating that we reached steady state. 


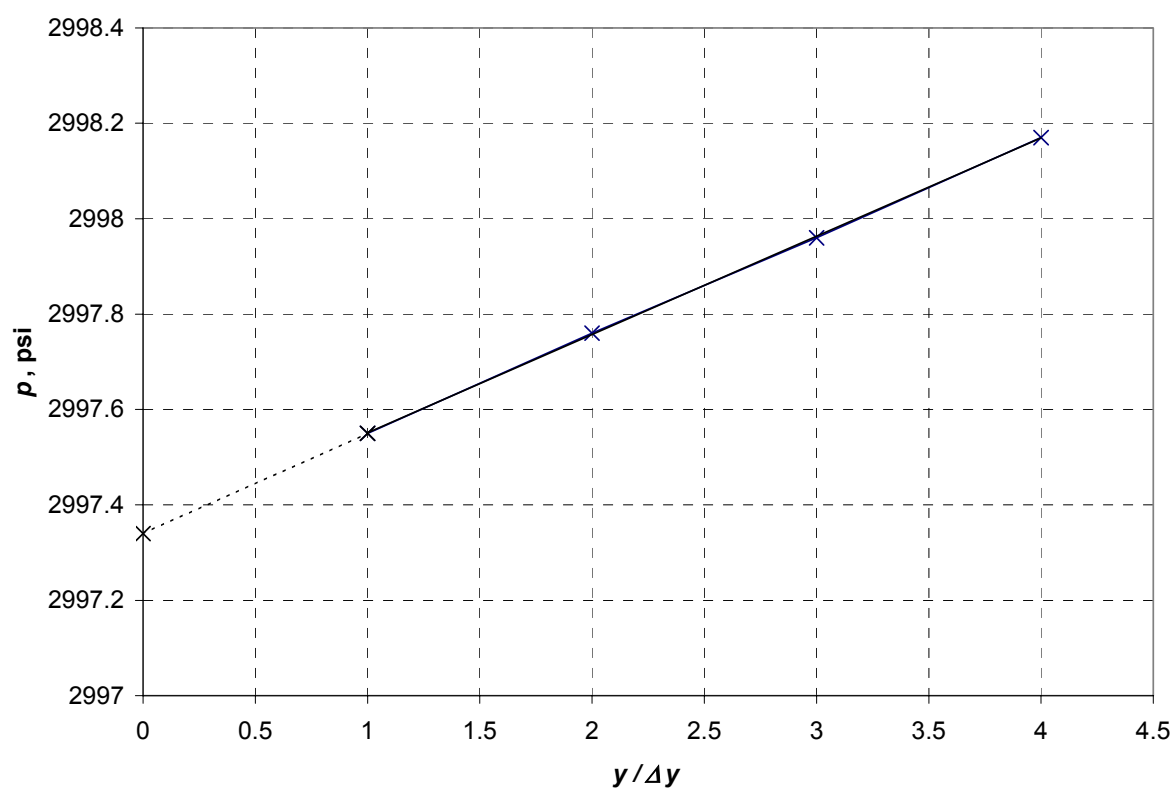

Fig. 2-9 - Plot that shows simulation results of $p$ vs. $y / \Delta y$ for well gridblock and five adjacent gridblocks. [ $i=26$ is the well gridblock, $i=27$ is adjacent ...etc]. Notice that all results lie on the same straight line including the value for the well gridblock.

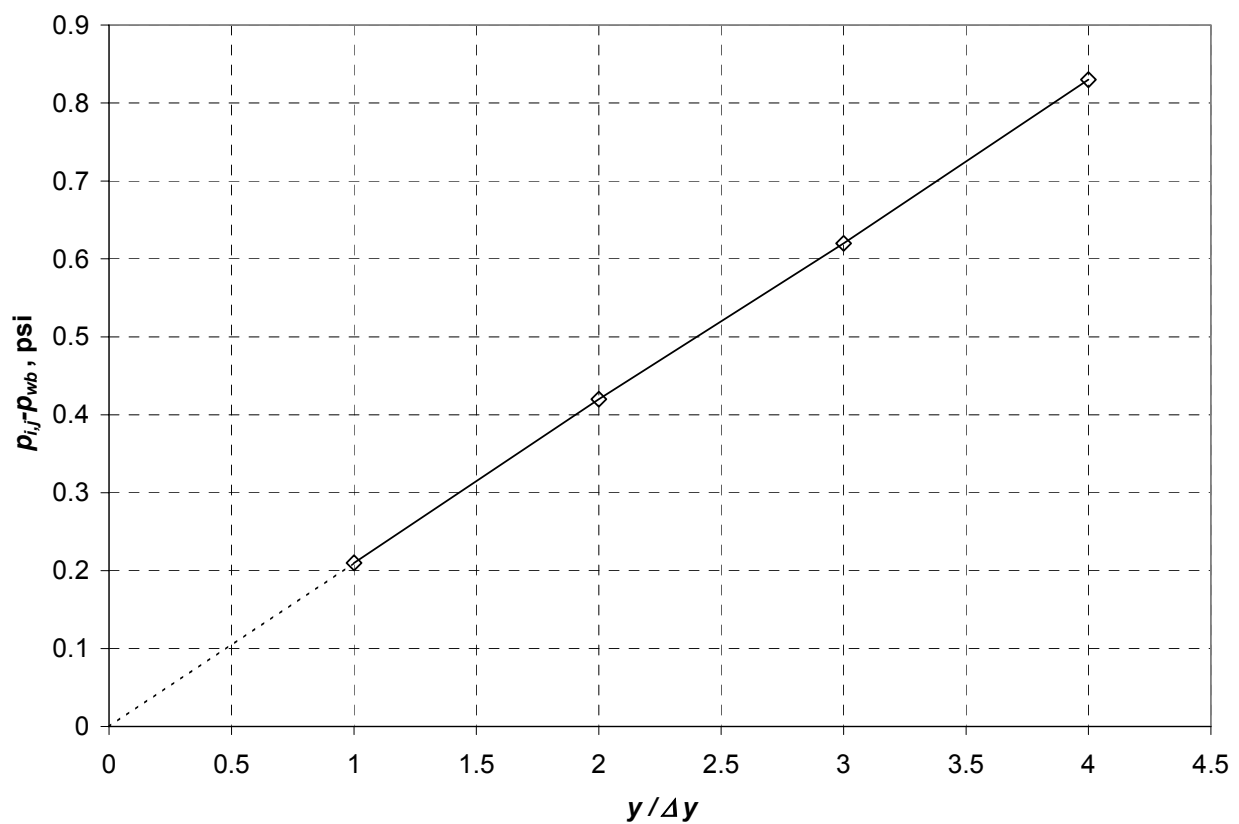

Fig. 2-10 - Plot that shows simulation results of $p_{i, j}-p_{w b}$ vs. $y / \Delta y$ for five gridblocks adjacent to well gridblock. [ $\mathrm{i}=26$ is the well gridblock, $\mathrm{i}=27$ is adjacent ...etc. ]. Notice that when $p_{i, j}-p_{w b}=0$ the extrapolated value of $y / \Delta y=0$. 


\subsection{Artifact Wellbore Storage}

A simulation numerical error is discussed in this section. It occurs at early time and it is common in tight reservoirs that are modeled with wellbore gridblocks that are coarse and which have a high value for diffusivity $\eta$. This combination of a coarse well gridblock and a tight reservoir causes to have what may be described as a long transient period within the well gridblock while the adjacent gridblocks remain at initial pressure. This error is known as artifact wellbore storage ${ }^{35}$. It is named this way because the well gridblock transient effect causes an error of unit slope of the log-log plot of $\Delta p$ vs. $t$. Thus drawing a similarity to the famous wellbore storage of pressure transient analysis. Archer and Yildiz ${ }^{35}$ pointed out that an early time numerical artifact occurred when uniform coarse areal grids are used to simulate pressure transient tests in a conventional reservoir simulator. They believed that there are limitations in Peaceman's ${ }^{1}$ well model equation used in all conventional reservoir simulators. They proposed a new well model formulation to remove the numerical artifact but it still occurred in the level of the pressure derivative. They provided a formula Eq. 2-5 to estimate the earliest minimum time $t_{\min }$ at which the pressure solutions are accurate for a particular grid size. This formula was developed using the concept of radius of investigation. Their work was limited for the case of radial flow.

$t_{\min }=66.67(\Delta x)^{2} \frac{\phi \mu c_{t}}{k}$

It is important to note that the original formula of Eq. 2-5 developed by Archer and Yildiz $^{35}$ had a constant of 1,600 in their work because their unit of $t_{\min }$ was in hours. 


\subsubsection{Artifact Wellbore Storage in Linear Flow}

We considered the Artifact Wellbore Storage for the case of linear flow. A linear flow model of a grid of 1 x 15 is shown in Fig. 2-11. We modeled a square reservoir of drainage area of 80 Acres with different grids 1 x 15, 1 x 25, 1 x 51, and 1 x 193. Fig. 212 compares the analytical and numerical pressure solutions for different grid size for linear flow case. At very early time pressure solutions obtained from the numerical model do not match the analytical solutions. The numerical simulation approaches the analytical solution after some time, which that depends on the grid size. A model with a smaller grid matches the analytical solutions earlier than one with a bigger grid.

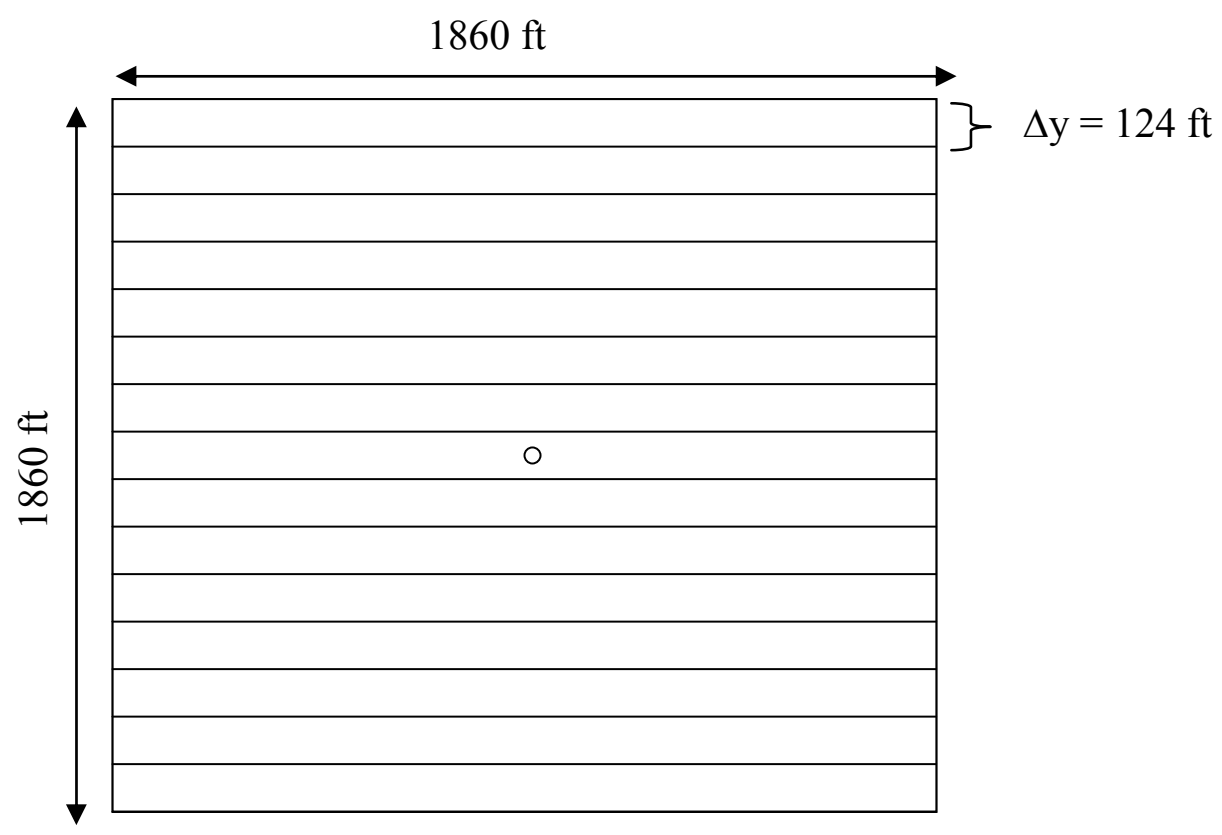

Fig. 2-11 - Square reservoir of a linear model of grid 1 x 15 . 


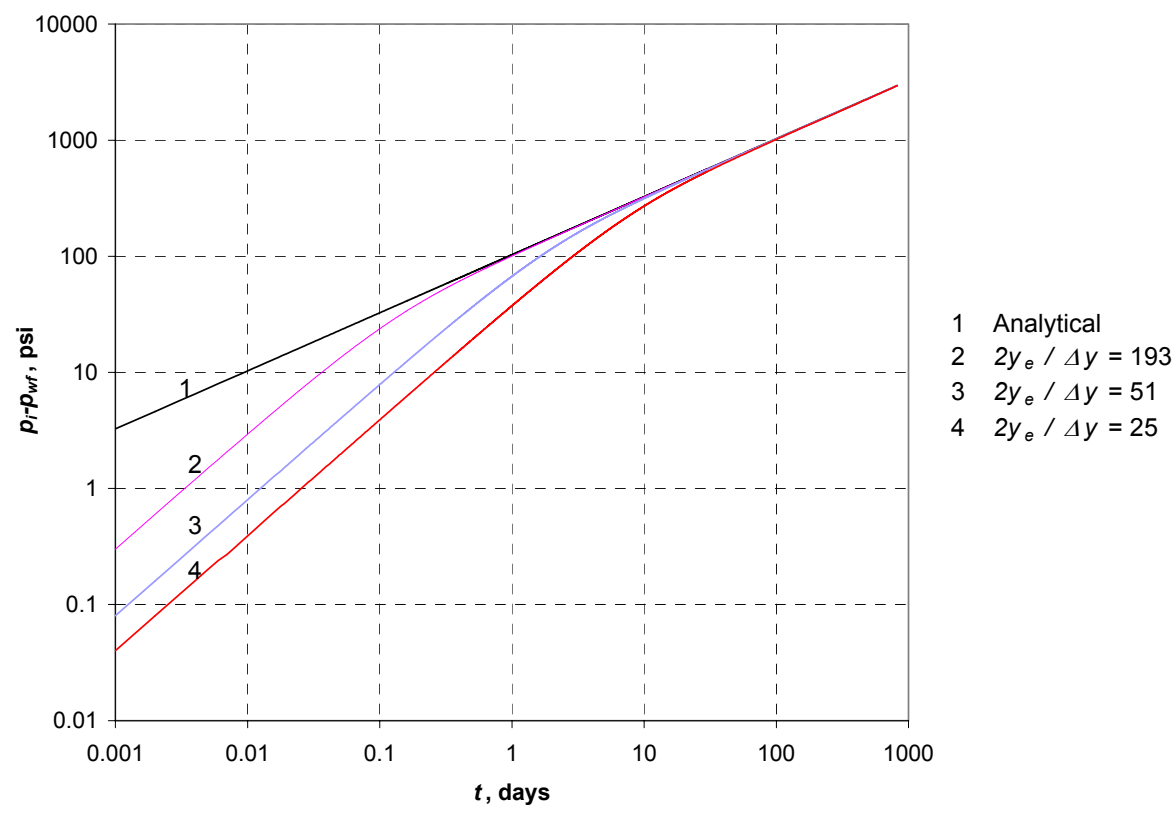

Fig. 2-12 - Plot that shows simulation results of $\log \Delta p$ vs. $\log t$ for gridding of $1 \times 25,1$ $\mathrm{x} 51$, and $1 \times 193$. Notice that the finer grids match the analytical solution at an earlier time.

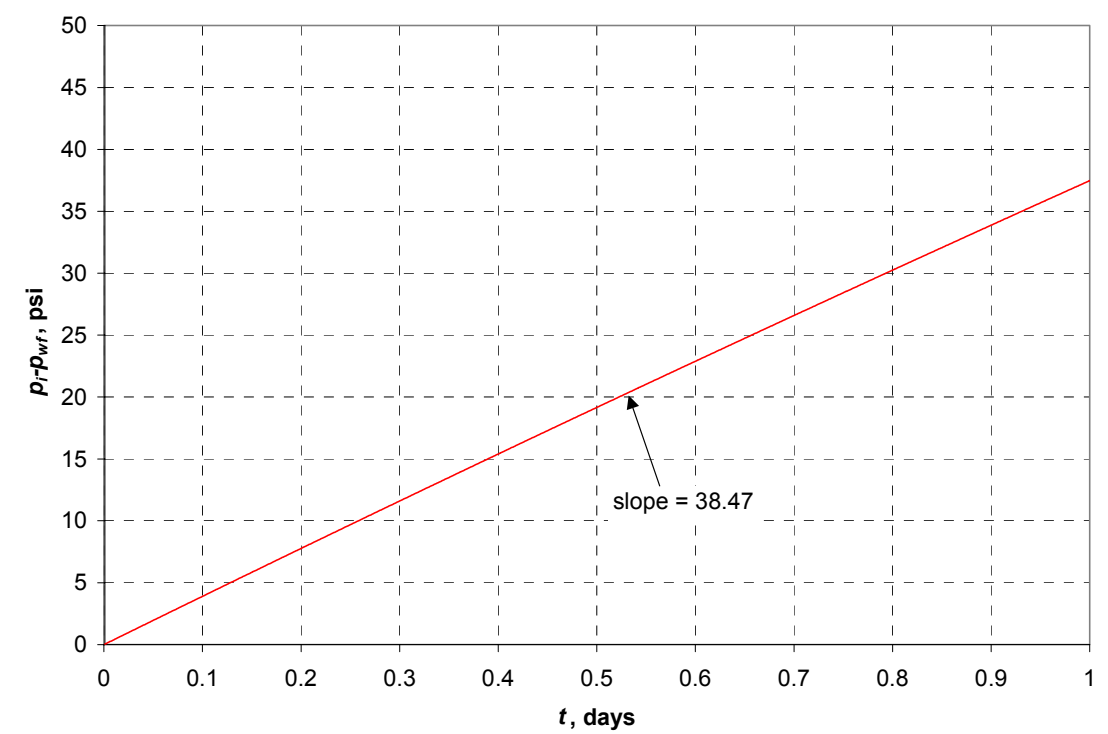

Fig. 2-13 - Simulation results of $\Delta p$ vs. $t$. This is for the case of $1 \times 25$ grid. The slope is found to be equal to $38.47 \mathrm{psi} / \mathrm{ft}$. This slope agrees with the close value of $39.2 \mathrm{psi} / \mathrm{ft}$ obtained when applying Eq. 2-9. 
Based on the simulation results we developed a relation to estimate $t_{\min }$ for the linear case. We determined from Fig. 2-12 that the earliest time at which the pressure solutions are accurate with an error of $5 \%$ and an error of $10 \%$

For the case of $5 \%$ error in $\Delta p$

$$
t_{\min }=217(\Delta x)^{2} \frac{\phi \mu c_{t}}{k}
$$

For the case of $10 \%$ error in $\Delta p$

$$
t_{\min }=118.3(\Delta x)^{2} \frac{\phi \mu c_{t}}{k}
$$

The $\%$ error in $\Delta p$ was calculated using the formula

$\%$ Error $=\frac{(\Delta p)_{\text {analytical }}-(\Delta p)_{\text {simulation }}}{(\Delta p)_{\text {analytical }}}$

And so we apply the above equation at every time step and from the result of the formula at 5\% we can get the constant in Eq. (2-6). We crosschecked the constant obtained in Eq. (2-6) and Eq. (2-7) for the different grids $1 \times 25,1 \times 51$, and $1 \times 193$, to verify that the formula is correct.

It is interesting to note that on plotting $p_{i}-p_{w f}$ vs. $t$ on a Cartesian scale we should expect due to artifact wellbore storage to get the slope to be of

$$
\frac{d p}{d t}=-5.615 \frac{q B}{V_{p} c_{t}}
$$

Where $V_{p}$ is the pore volume of the well gridblock. Fig. 2-13 shows a case of the grid $1 \mathrm{x}$ 25 with a slope of $38.47 \mathrm{psi} / \mathrm{ft}$, which is quite close to the value we got when applying Eq. 2-9, which was $39.2 \mathrm{psi} / \mathrm{ft}$. 
Fig. 2-14 shows a plot of $p$ vs. $x$ at different times for the grid $1 \times 25$. We realize that $p^{\prime}(x)$ is independent of time for values bigger than $t=29$ days which agrees with what we know about this case that $t_{\min }=29.83$ days if we use the formula for a $5 \%$ error and so this is further evidence that there is no effect from artifact wellbore storage after this time.

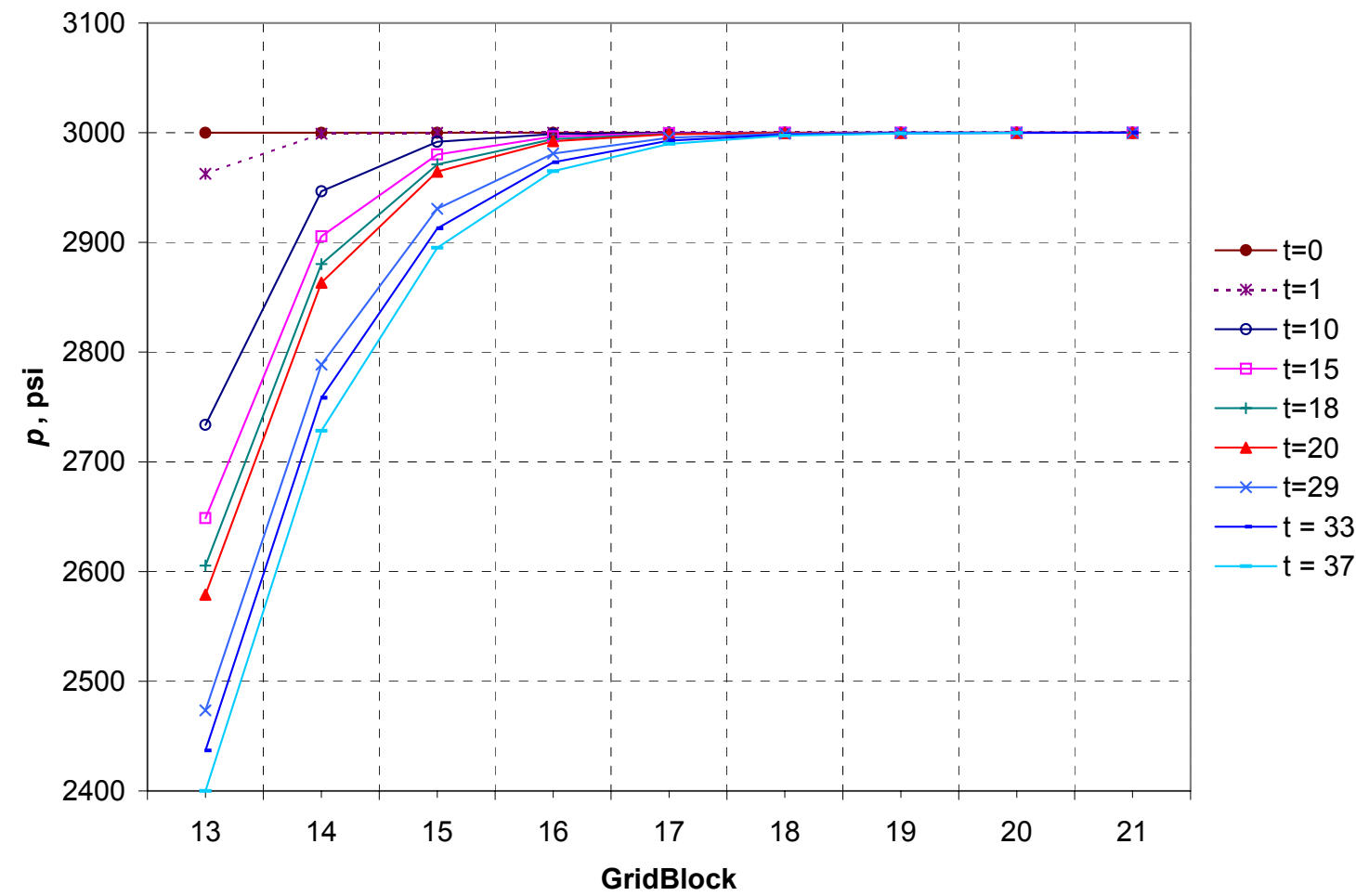

Fig. 2-14 - Plot that shows simulation results of $p$ vs. $x$ at different times. This is for the case of $1 \times 25$ grid. Notice that $p^{\prime}(x)$ is independent of time for values greater than $t=$ 29 days which means there is no effect of artifact wellbore storage after this time. 


\section{CHAPTER III}

\section{MODELING HYDRAULIC FRACTURES WITH UNIFORM FINE GRIDS}

\subsection{Introduction}

Non-uniform fine gridding is conventionally used for research purposes ${ }^{28}$. The objective of this chapter is to test the use of the uniform grid versus the use of the nonuniform grid (Fig. 3-1). In this chapter, ways to simulate hydraulically fractured wells using uniform fine grids were investigated. Several grid sets were used and grid sensitivity analysis was performed in order to determine the best way to simulate both infinite and finite conductivity hydraulic fracture cases.
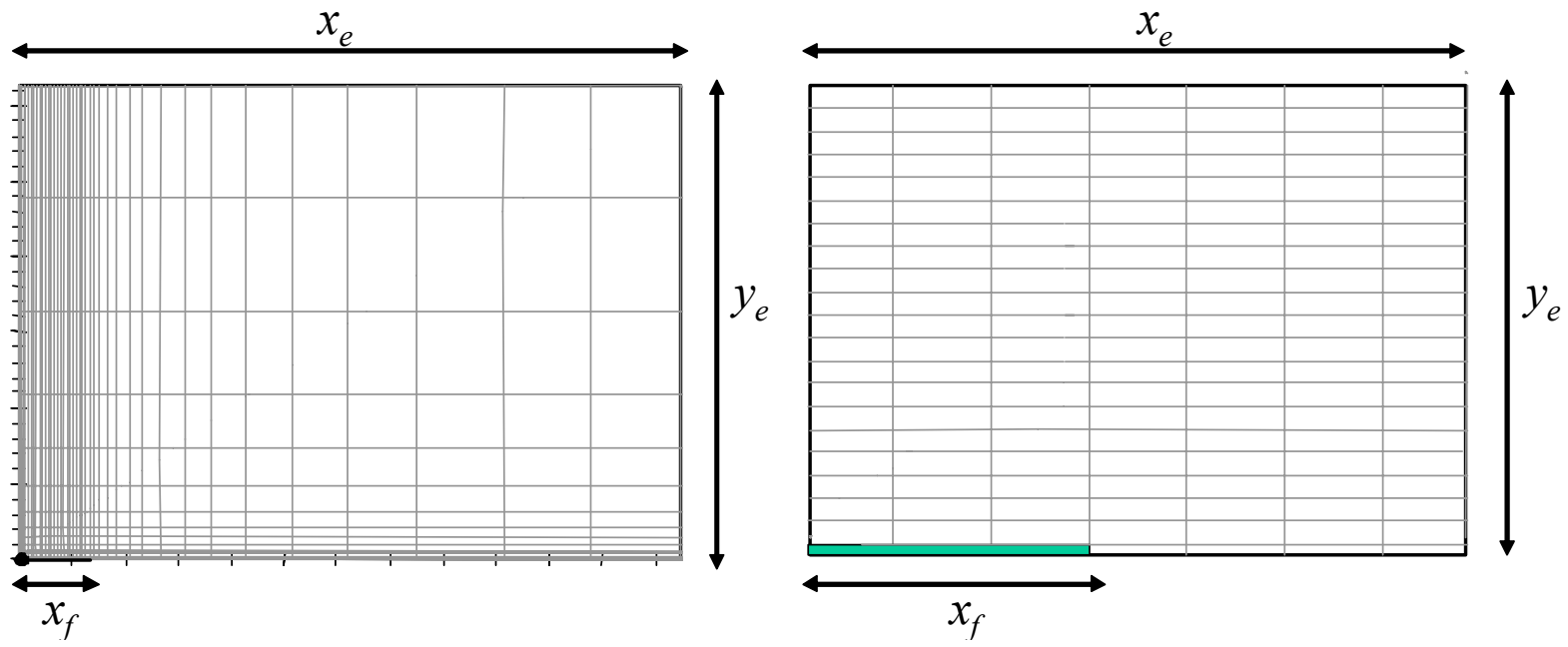

Fig. 3-1 - Schematic of a non-uniform fine grid compared to a uniform fine grid for the case of a quarter model. 
Analytical solutions developed by Gringarten et al. ${ }^{19}$ and Cinco-Ley et al. ${ }^{21}$ were used in this chapter as the benchmark to know the best way to simulate every specific case. The error was shown as a deviation from the performance of the analytical solution on the plot of $p_{D}$ vs. $t_{D x f}$. This error was found to happen during the transient period and at early time. The error extended to later time when a grid was used that is not fine enough. The error ended at very early times as finer grids were used.

It was found in this chapter that in general when simulating cases for infinite conductivity fracture or cases of finite conductivity fracture of high fracture conductivity that it is sufficient to have more gridblocks (finer grids) only for the gridblocks in the direction perpendicular to the fracture and not for the gridblocks in the direction along the fracture. On the contrary when simulating cases for finite conductivity fracture of low fracture conductivity it was found that there is a need to have more gridblocks (finer grids) for the gridblocks in both the direction perpendicular and the direction parallel to the hydraulic fracture.

Since for cases with the hydraulic fracture conductivity of small value, we need to use very fine grids to obtain accurate results. Therefore, in those specific cases it was concluded that it is preferable to use the non-uniform grid since it has the advantage of having fewer gridblocks for our model.

Grid sensitivity was conducted to make sure the uniform gridding gives results with acceptable numerical error using a reasonable number of grid blocks. 
The performance of a reservoir is affected by the value of the dimensionless fracture conductivity $F_{C D}$. In this dissertation $F_{C D}$ is defined as

$$
F_{C D}=\frac{k_{f} w_{f}}{k x_{f}}
$$

There is another definition also common in the literature, which adds a $\pi$ in the denominator of equation (3-1). A hydraulic fracture with a value of $F_{C D}$ greater than 500 is considered to be of infinite conductivity according to Agarwal ${ }^{23}$. Cinco-Ley ${ }^{21}$ considered a hydraulic Fracture to be of infinite conductivity if the value of $F_{C D}$ greater than $100 \pi$.

In this chapter, a uniform grid had a constant value of $\Delta \mathrm{x}$ and another constant value of $\Delta y$ throughout the model. There were two exceptions for this rule of constant $\Delta \mathrm{x}$ and constant $\Delta \mathrm{y}$. The first exception is "the cells that represent the hydraulic fracture and the cells that are adjacent to those fracture cells in the x-direction". These cells must always have a constant $(\Delta y)^{\prime}$ as shown in Fig. 3-2. The value of $(\Delta y)$ ' is the value of the width of the hydraulic fracture which is usually about $0.02 \mathrm{ft}$. The second exception is "the cells adjacent to the well gridblock in the y-direction" as shown also in Fig. 3-2. These cells had a negligible small value $(\Delta \mathrm{x})^{\prime}$ and its sole purpose was to have a symmetric model in the $\mathrm{x}$-direction around the wellbore. This symmetry was especially important when we had a fracture not extended until end of reservoir $\left(x_{f} / x_{e}<1\right)$. Fig. 32 is an illustration of a model with a uniform gridding of $9 \times 11$ where we have 8 constant values of $\Delta \mathrm{x}$ and 10 constant values of $\Delta y$. 


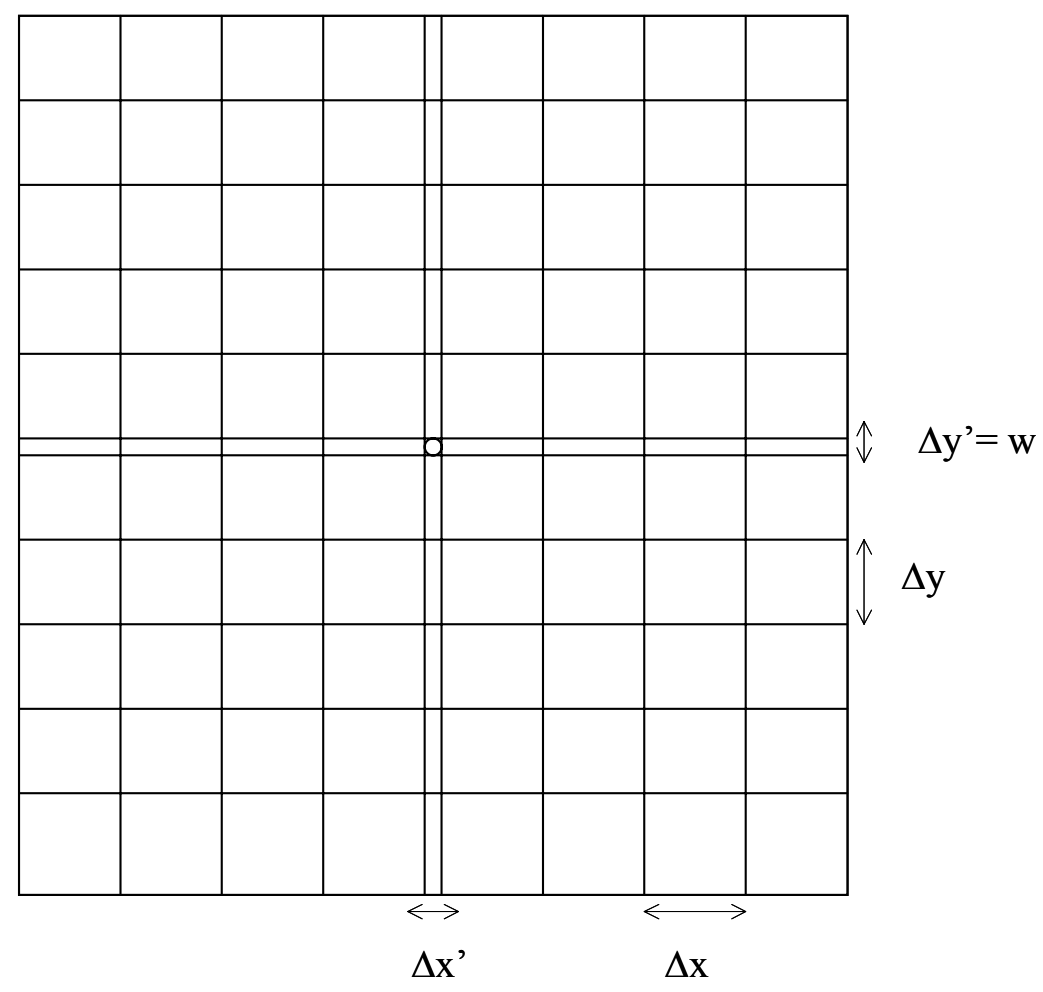

Fig. 3-2 - Uniform fine gridding of 9 x 11 cells of a hydraulic fracture model.

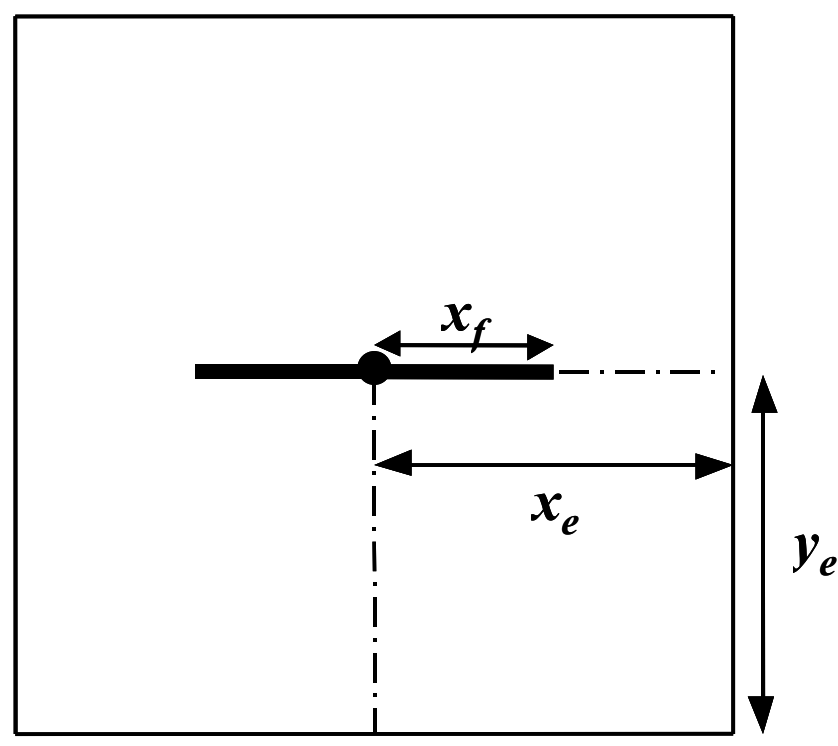

Fig. 3-3 - Schematic of a typical hydraulic fracture model of a square reservoir $\left(x_{e}=y_{e}\right)$. 
An arbitrary reservoir data set (Table 3-1) of an 80-Acre hydraulically fractured square oil reservoir (Fig. 3-3) was used for all the simulation runs that were undergone in this chapter.

\begin{tabular}{|l|c|}
\hline \multicolumn{2}{|c|}{ Table 3-1 - Reservoir and fluid data for the simulated case } \\
\hline Drainage area, acres & $\approx 80$ \\
Reservoir half length $\left(x_{e}\right), \mathrm{ft}$ & 930 \\
Reservoir half length $\left(y_{e}\right), \mathrm{ft}$ & 930 \\
Thickness $(h), \mathrm{ft}$ & 150 \\
Absolute permeability $(k), \mathrm{md}$ & 0.1 \\
Porosity $(\phi)$, fraction & 0.23 \\
Initial pressure $\left(p_{i}\right), \mathrm{psi}$ & 3000 \\
Oil production rate $\left(q_{o}\right), \mathrm{STB}$ & 5 \\
Oil formation volume factor $\left(B_{o}\right), \mathrm{RB} / \mathrm{STB}$ & 1 \\
Oil viscosity $\left(\mu_{o}\right), \mathrm{cp}$ & 0.72 \\
Total compressibility $\left(c_{t}\right), \mathrm{psi}{ }^{-1}$ & $1.5 \mathrm{E}-05$ \\
\hline
\end{tabular}

The results of the simulation runs are reported in real pressure and time. We plot the pressure change versus time on a log-log scale. Following are the dimensionless variables used to compare the numerical solutions with the analytical solutions.

$$
\begin{aligned}
& p_{D}=\frac{k h\left(p_{i}-p_{w f}\right)}{141.2 q B \mu} \\
& t_{D x_{f}}=\frac{0.00633 k t}{\phi \mu c_{t} x_{f}^{2}} \ldots .
\end{aligned}
$$




\begin{tabular}{|c|c|c|c|c|c|}
\hline \multicolumn{6}{|c|}{ Table 3-2-Summary of 20 cases simulated using gridding of 41 x 193 cells } \\
\hline Case \# & $F_{C D}$ & $x_{f} / x_{e}$ & $x_{f}$ & $k_{f}$ & Comment \\
\hline 1 & 500 & 1 & 930 & $2,325,000$ & Accurate \\
\hline 2 & 500 & 0.8 & 744 & $1,860,000$ & Accurate \\
\hline 3 & 500 & 0.5 & 465 & $1,162,500$ & Accurate \\
\hline 4 & 500 & 0.3 & 279 & 697,500 & Accurate \\
\hline 5 & 500 & 0.1 & 93 & 232,500 & Accurate except at early Dimensionless time \\
\hline 6 & 10 & 1 & 930 & 46,500 & Accurate \\
\hline 7 & 10 & 0.8 & 744 & 37,200 & Accurate \\
\hline 8 & 10 & 0.5 & 465 & 23,250 & Accurate \\
\hline 9 & 10 & 0.3 & 279 & 13,950 & Accurate \\
\hline 10 & 10 & 0.1 & 93 & 4,650 & Accurate except at early Dimensionless time \\
\hline 11 & 1 & 1 & 930 & 4,650 & Accurate \\
\hline 12 & 1 & 0.8 & 744 & 3,720 & Accurate \\
\hline 13 & 1 & 0.5 & 465 & 2,325 & Accurate \\
\hline 14 & 1 & 0.3 & 279 & 1,395 & Accuracy Lower than Cases \# 11, 12 and 13 \\
\hline 15 & 1 & 0.1 & 93 & 465 & Accurate except at early Dimensionless time \\
\hline 16 & 0.1 & 1 & 930 & 465 & Not Accurate \\
\hline 17 & 0.1 & 0.8 & 744 & 372 & Not Accurate \\
\hline 18 & 0.1 & 0.5 & 465 & 232.5 & Not Accurate \\
\hline 19 & 0.1 & 0.3 & 279 & 139.5 & Not Accurate \\
\hline 20 & 0.1 & 0.1 & 93 & 46.5 & Not Accurate \\
\hline
\end{tabular}




\subsection{Simulation of Twenty Cases of Hydraulic Fractures of Different $F_{C D}$ 's and $x_{f}$ 's}

The log-log plot of $p_{D}$ vs. $t_{D x f}$ shown in Fig. 3-4 shows a family of simulated constant rate type-curves for a square shaped reservoir model that is hydraulically fractured. All simulations were done using a set of uniform fine grids. It demonstrates the performance of hydraulically fractured cells with different values of dimensionless fracture conductivity $\left(F_{C D}\right)$. For each $F_{C D}$ case there are different ratios of $x_{f} / x_{e}$. The results in Fig. 3-4 matched in most cases the plot reported by Meng ${ }^{36}$ who basically simulated all the twenty cases of different $x_{f} / x_{e}$ shown in Table 3-2. Those cases that showed a poor match were not plotted but they were reported in Table 3-2.

Fig. 3-4 shows the fact that the change in the hydraulic fracture conductivity has an effect only in the transient period while the change in the length of fracture with respect to the reservoir has an effect only in the pseudo-steady state flow period. The gridding used here for all these cases was of 41 x 139 cells with a uniform grid size of $\Delta \mathrm{x}=46.5$ and $\Delta \mathrm{y}=9.6875$ with the two exceptions of $(\Delta y)^{\prime}=w$ and the negligible small value of $(\Delta x)^{\prime}$ that were explained earlier in this chapter (Fig. 3-2). 


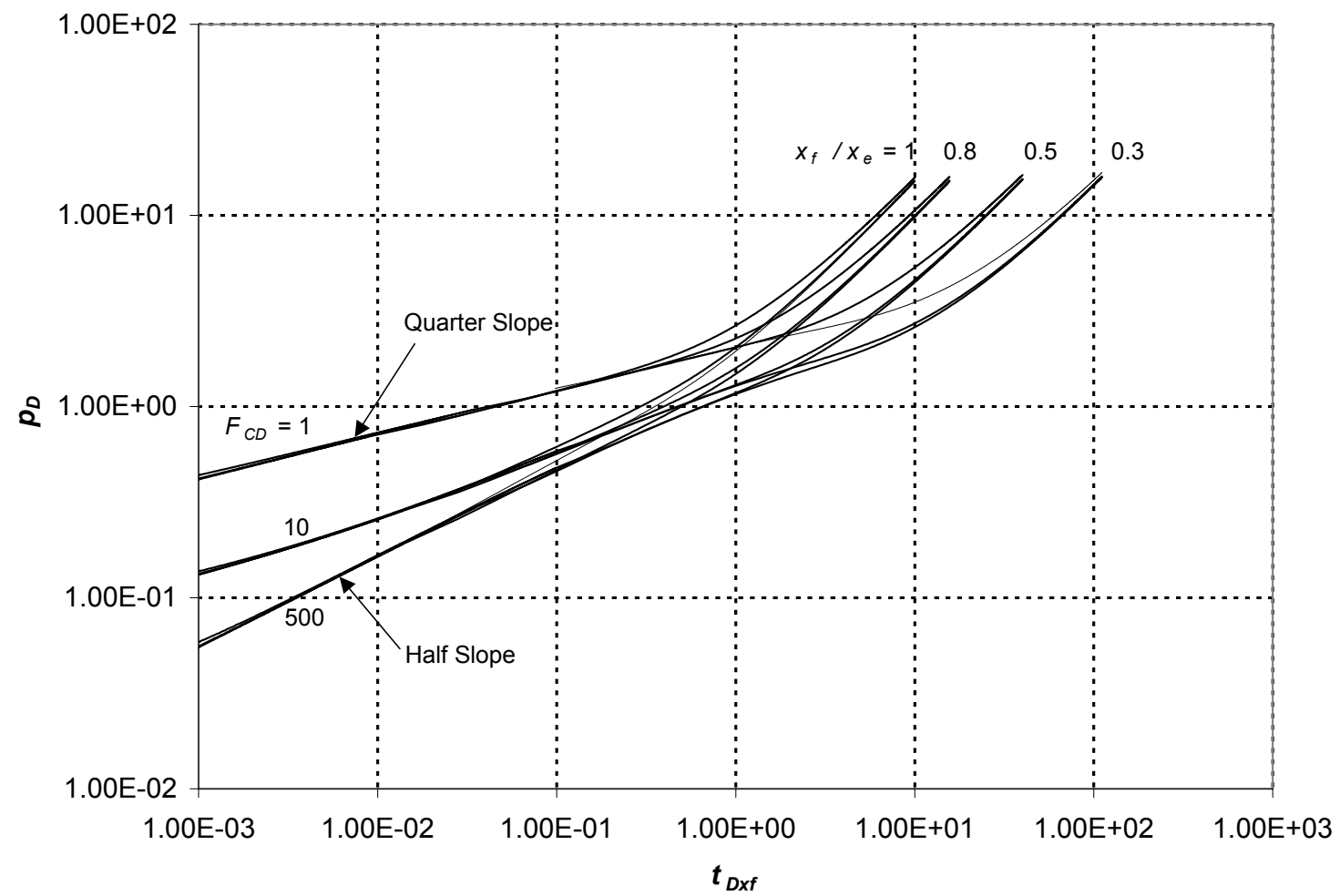

Fig. 3-4 - Plot showing a family of constant rate type curves simulated with a set of uniform fine grids in the $\mathrm{x}$ and $\mathrm{y}$ directions of $41 \mathrm{x} 193$ cells. Accuracy is good for the range shown on the plot. All simulated cases had an error at $t_{D}<10^{-3}$. Simulated cases of $F_{C D}<1$ gave a significant error during transient for all ratios of $x_{f} / x_{e}$. Cases of $x_{f} / x_{e}=$ 0.1 gave a large error during transient for all $F_{C D}$ values. 
The results on Fig. 3-4 show that at early time from $t_{D x f}=10^{-3}$ to $t_{D x f}=10^{-1}$ we see the transient period and then we move to a transition period until we hit the reservoir boundaries (pseudo-steady state flow period). The pressure behavior in the pseudosteady state flow period depends on how much the hydraulic fracture was extended in the reservoir. It should be noted that pressure behavior at this late time of pseudo-steady state flow period is independent of the hydraulic fracture characteristics (infinite conductivity or finite-conductivity) as can be seen on Fig. 3-4. It is worth also to note that at early time the case of $F_{C D}=1$ shows a quarter slope on this log-log plot indicating existence of bilinear flow while the case of $F_{C D}=500$ shows a half slope at early time indicating the existence of linear flow.

The results on Fig. 3-4 are accurate for the range of parameters shown on the plot. Erroneous results appeared to happen for cases of $x_{f} / x_{e}<0.3$ or for cases of $F_{C D}<$ 1 at early $t_{D}$. We see on Fig. 3-4 that all cases of different $x_{f} / x_{e}$ but all have $F_{C D}=1$ converge to the same line of quarter slope. There is one line that is slightly higher which is for the case of $x_{f} / x_{e}=0.3$. When we tried to plot the cases of $F_{C D}=0.1$ there was significant error that is not shown on Fig. 3-4 but is reported in Table 3-2.

This error occurs at the same time $t$ for the same $F_{C D}$ value but this error appears exaggerated or appears for the smaller values of $t_{D x f}$. This happens because the definition of $t_{D x f}$ depends on half-length of hydraulic fracture $\left(x_{f}\right)$ that exists in the denominator so as we have a smaller $\left(x_{f}\right)$ the error that occurs at early time is shifted on the axis to occur at later dimensionless time $t_{D x f}$. This last point will be highlighted and explained later in this chapter. 


\subsection{Grid Sensitivity for Case of $F_{C D}>500$ Where $x_{f}=x_{e}$}

In this section a case of $F_{C D}=1075$ where $x_{f} / x_{e}=1$ was simulated by a $1 \mathrm{D}$ model since the case studied is of a hydraulic fracture of infinite conductivity $\left(F_{C D}>\right.$ $500)$ and the fracture extends until the boundaries of the reservoir $\left(x_{f} / x_{e}=1\right)$. This case is that of linear flow which has a known analytical solution of closed form ${ }^{37,38}$.

$$
p_{D}=\frac{\pi}{2}\left[\frac{1}{3}\left(\frac{y_{e}}{x_{e}}\right)+\left(\frac{x_{e}}{y_{e}}\right) t_{D x e}\right]-\frac{1}{\pi}\left(\frac{y_{e}}{x_{e}}\right) \sum_{n=1}^{\infty}\left(\frac{1}{n^{2}}\right) \exp \left[-n^{2} \pi^{2}\left(\frac{x_{e}}{y_{e}}\right)^{2} t_{D x e}\right] .
$$

The definition of $t_{D x f}$ in (3-2) has been replaced by the definition of $t_{D x e}$

$$
t_{D x_{e}}=\frac{0.00633 k t}{\phi \mu c_{t} x_{e}^{2}}
$$

Fig. 3-5 shows a comparison between three simulation runs and the analytical solution. The first simulation run is for a uniform gridding of $1 \times 25$ cells. The second simulation run is for a uniform gridding of $1 \times 193$ cells. The third simulation run is for a non-uniform gridding of $79 \times 33$ cells. It appears clear from the plot that the uniform gridding of $1 \times 193$ cells gives a perfect match with the analytical solution while the non-uniform gridding of $79 \times 33$ cells showed a slight error. The uniform gridding of 1 x 25 cells showed no match with the analytical solution at early time.

Any non-uniform gridding mentioned in this dissertation will follow the usual complex grid system that is frequently used for research purposes. This complex grid system suggested to have geometrically spaced grids for regions near the well and the fracture tip for the grids in the direction of the fracture. It also suggested to have geometrically spaced grids for the grids in the direction perpendicular to the fracture ${ }^{18}$. 


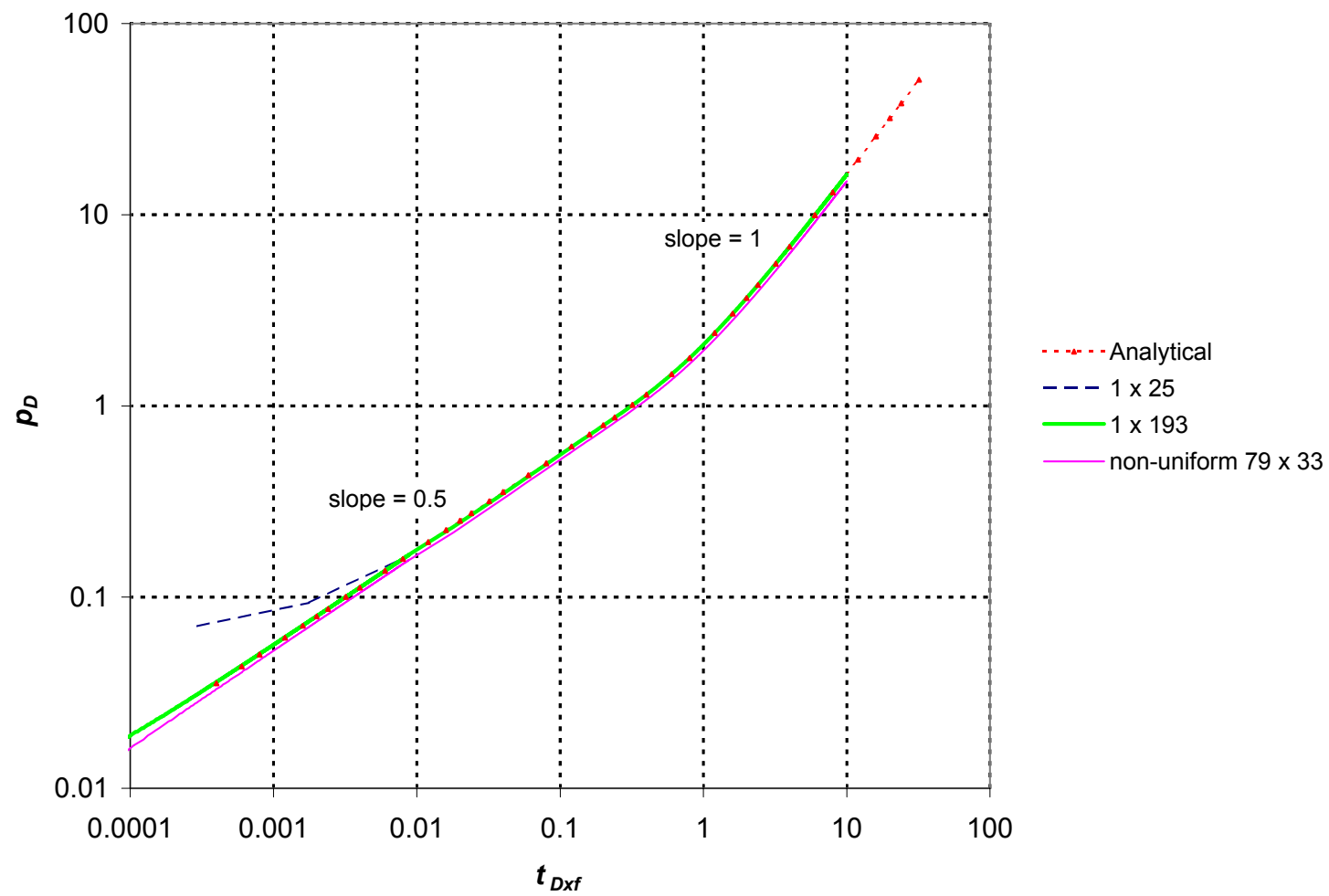

Fig. 3-5 - A comparison between results of three simulations for the case of $F_{C D}>500$ where $x_{f}=x_{e}$. We notice that finer grids in the direction perpendicular to the fracture result in a match with the analytical solution. 


\subsection{Grid Sensitivity for Case of $F_{C D}=500$ Where $x_{f}<x_{e}$}

Recalling what was already mentioned in section 3.2 (when discussing the accuracy of the 20 cases simulated with the gridding of 41 x 193 cells) there was an error at early $t_{D}$ for the cases of $\boldsymbol{x}_{\boldsymbol{f}} / \boldsymbol{x}_{\boldsymbol{e}}<0.3$ that was reported in Table 3.2 but not shown in

Fig. 3-4. It was mentioned that this error at early $t_{D}$ is due to a shift in the axis when using $t_{D x f}$ since $t_{D x f}$ definition has the $x_{f}$ term in its denominator. To clarify this point we took a closer look at the three simulated cases of $\boldsymbol{x}_{f} / \boldsymbol{x}_{\boldsymbol{e}}=0.50 .2$ and 0.1 using the gridding of 41 x 193 cells and compared it to Gringarten ${ }^{19}$ Analytical solution as shown in Fig. 3-6 and Fig. 3-7. In addition to the log-log plot $p_{D}$ vs. $t_{D x f}$ shown on Fig. 3-5. The $\log -\log$ plot of $p_{i}-p_{w f}$ vs. $t$ is shown on Fig. 3-7.

In Fig. 3-6 the cases of $\boldsymbol{x}_{\boldsymbol{f}} / \boldsymbol{x}_{\boldsymbol{e}}=0.5$ and $\boldsymbol{x}_{\boldsymbol{f}} / \boldsymbol{x}_{\boldsymbol{e}}=0.2$ showed a match with the analytical solution while the case of $\boldsymbol{x}_{\boldsymbol{f}} / \boldsymbol{x}_{\boldsymbol{e}}=0.1$ showed an error at early time as reported before in Table 3.2 for the log-log plot $p_{D}$ vs. $t_{D x f}$.

In Fig. 3-7 the log-log plot of $p_{i}-p_{w f}$ vs. $t$ showed that the error for all the cases (deviation from the half slope straight line of linear flow) was seen to end at the same time. This proves the shifting effect that was mentioned earlier. The case of $\boldsymbol{x}_{\boldsymbol{f}} / \boldsymbol{x}_{\boldsymbol{e}}=0.1$ has a smaller $\boldsymbol{x}_{\boldsymbol{f}}$ and therefore the dimensionless time $t_{D x f}$ where error ends is of a big value that can appear on the plot for the range of $t_{D x f}$ values chosen. The cases of $\boldsymbol{x}_{\boldsymbol{f}} / \boldsymbol{x}_{\boldsymbol{e}}$ $=0.5$ and 0.2 have a bigger $\boldsymbol{x}_{\boldsymbol{f}}$ and therefore the dimensionless time $t_{D x f}$ where error ends is of a small value that couldn't appear on the plot for the range of $t_{D x f}$ values chosen. 


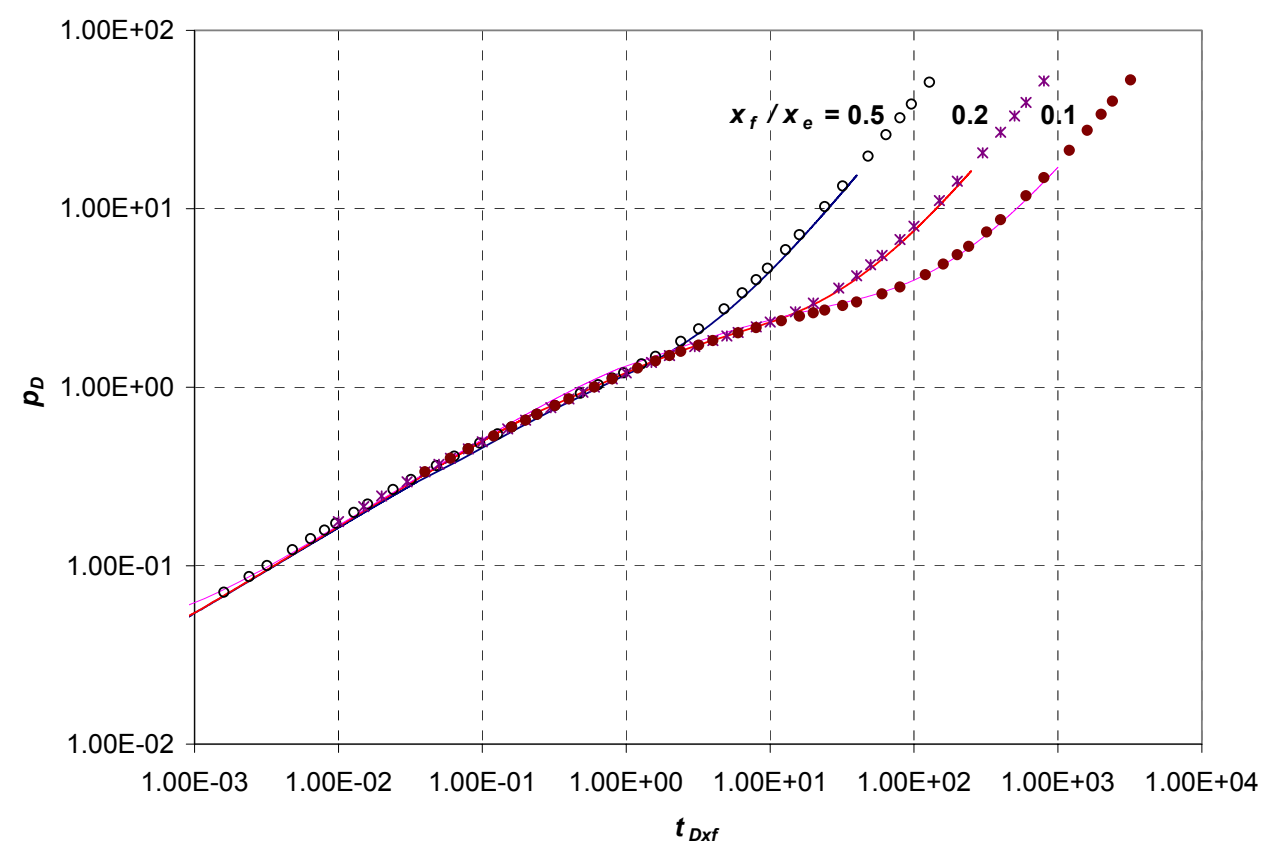

Fig. 3-6 - Three simulations of a uniform fine grid of different $\boldsymbol{x}_{\boldsymbol{f}} / \boldsymbol{x}_{\boldsymbol{e}}$ ratios compared on a $t_{D s f}$ basis showing a match with the analytical solution except for the case of $\boldsymbol{x}_{\boldsymbol{f}} / \boldsymbol{x}_{\boldsymbol{e}}=0.1$.

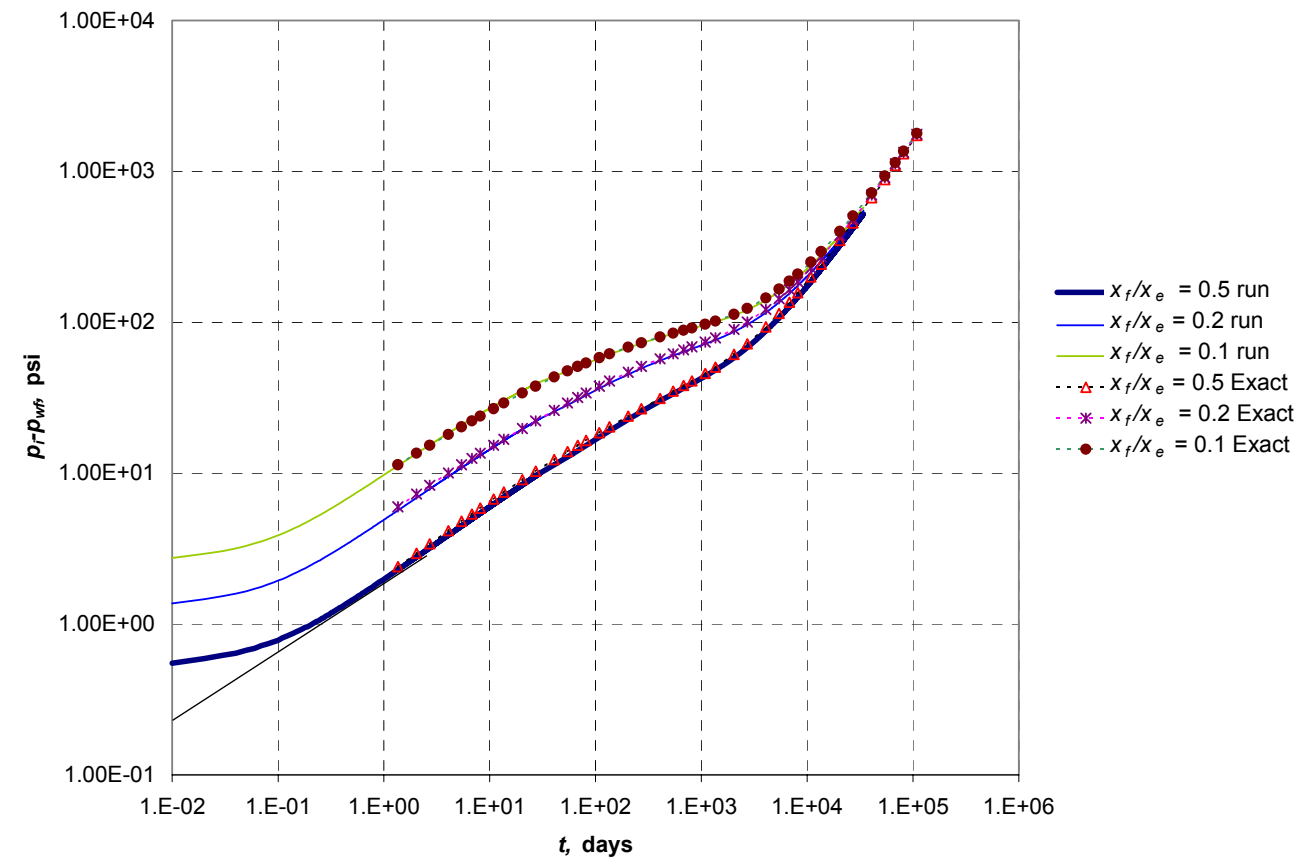

Fig. 3-7 -Three simulations of different ratios of $x_{f} / x_{e}$ compared on a $t$ basis indicating that the error starts at the same time regardless of the $x_{f} / x_{e}$ ratio. 


\subsection{Grid Sensitivity for Case of Infinite Conductivity Fracture Where $\boldsymbol{x}_{\boldsymbol{f}} / \boldsymbol{x}_{\boldsymbol{e}}=0.2$}

Fig. 3-8 shows three simulated cases of $\boldsymbol{F}_{\boldsymbol{C D}}=500$ and $\boldsymbol{x}_{\boldsymbol{f}} / \boldsymbol{x}_{\boldsymbol{e}}=0.2$ of different gridding. These three cases were compared to the Gringarten et al. ${ }^{19}$ exact analytical solution. The upper curve on Fig. 3-8 represents the results of the simulation of the gridding of $21 \times 193$ cells and the simulation of the gridding of $41 \times 193$ cells, which had their lines coinciding on top of each other. These cases showed more deviation from the exact solution than the simulation of the gridding of $21 \times 385$ cells, which is the lower curve that has a small deviation from the analytical solution slope equal to half.

Fig. 3-8 shows that the error at early time can be eliminated in the case of $\boldsymbol{F}_{\boldsymbol{C D}}=$ 500 by having finer grids in the direction perpendicular to the fracture and is not necessarily affected by the coarsening or refining of the grids in the direction along the fracture. There just must be enough gridblocks in the direction along the fracture to specify how far the fracture is extended in the reservoir $\left(\boldsymbol{x}_{\boldsymbol{f}} / \boldsymbol{x}_{\boldsymbol{e}}\right.$ ratio).

It is noticed in Fig. 3-8 that the simulation case of the gridding of $21 \times 385$ cells matches the analytical solution at $\mathrm{t}>0.2$ days. The reason for this error can be explored from Fig. 3-9 where we plotted the gridblock pressures of a group of cells adjacent to the well gridblock in the direction perpendicular to the hydraulic-fracture. It shows the pressure vs. distance away from the fracture at different time's. We notice clearly that the lines show a typical parallel performance after $\mathrm{t}>0.2$ days indicating that $p^{\prime}(x)$ is independent of time for values of $t>0.2$ days. This indicates that for $t<0.2$ there is an effect of cell storage that caused an error, which is very similar to the concept of the 
wellbore storage discussed in chapter II except that the latter is just for the well gridblock.

In Fig. 3-10 the sensitivity of the gridding an Infinite fracture conductivity was tested for the same ratio of fracture extension $\boldsymbol{x}_{\boldsymbol{f}} / \boldsymbol{x}_{\boldsymbol{e}}=0.2$ but of a lower fracture conductivity of $100 \pi$. Five simulation runs were performed using different gridding in the direction perpendicular to the fracture and the Cinco-Ley ${ }^{21}$ analytical solution was used as the reference to check accuracy. Fig. 3-10 shows that the case of the finest grids of $25 \times 97$ cells had the slightest deviation from the analytical solution while the coarsest case with least number of gridblocks of $25 \times 25$ cells had the largest deviation from the analytical solution.

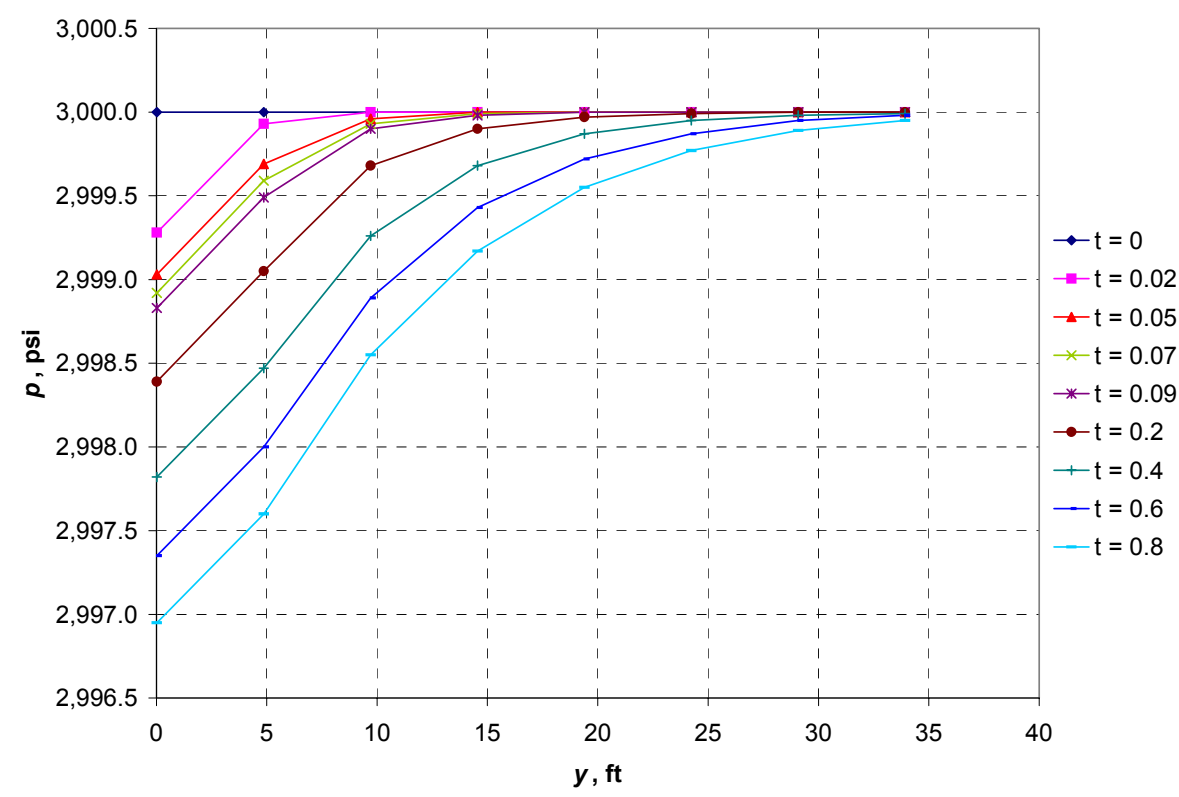

Fig. 3-8 - Three simulations of $F_{C D}=500$ and $x_{f} / x_{e}=0.2$ compared to the analytical solution showing that the finer grids are important only in the direction perpendicular to the hydraulic fracture for the case simulated. 


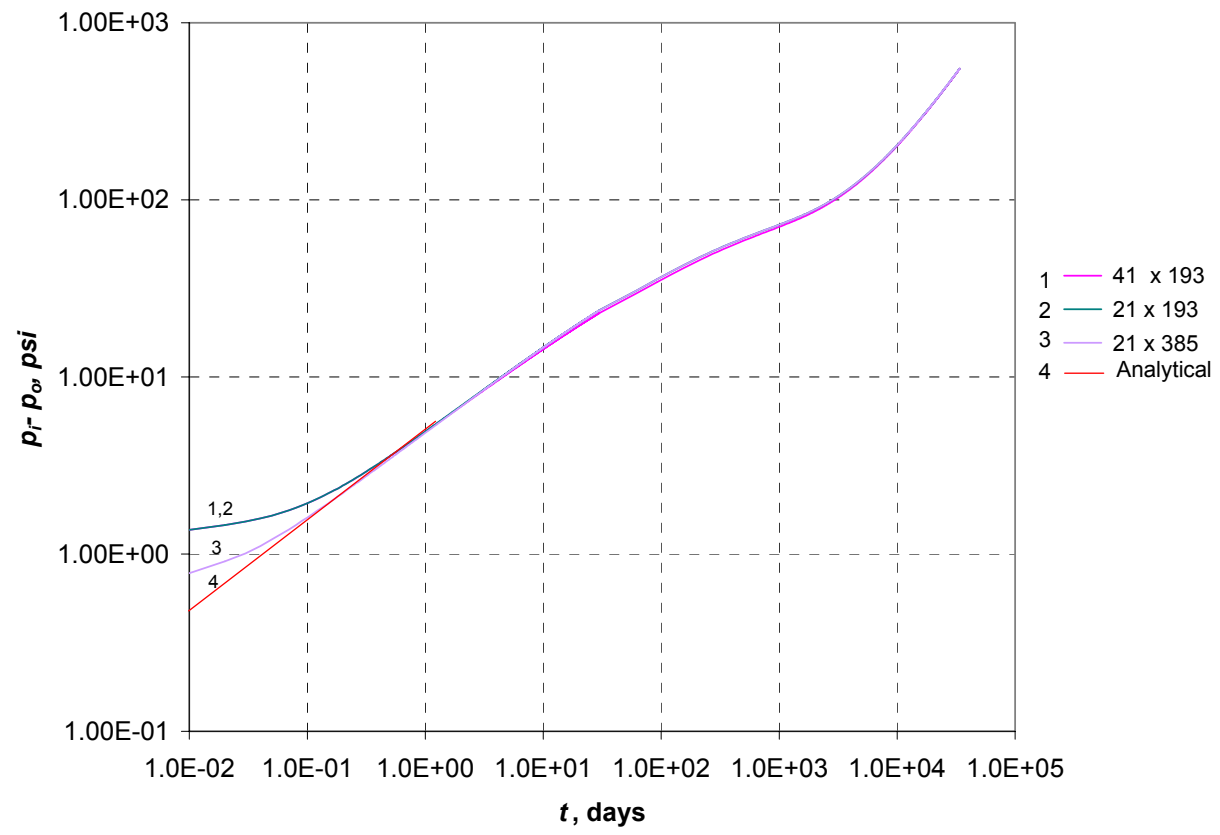

Fig. 3-9 $-p$ vs. $y$ for the gridblocks of the case of $21 \times 385$ gridding showing that at late time the pressure profiles are parallel indicating that the artifact wellbore storage ended. 


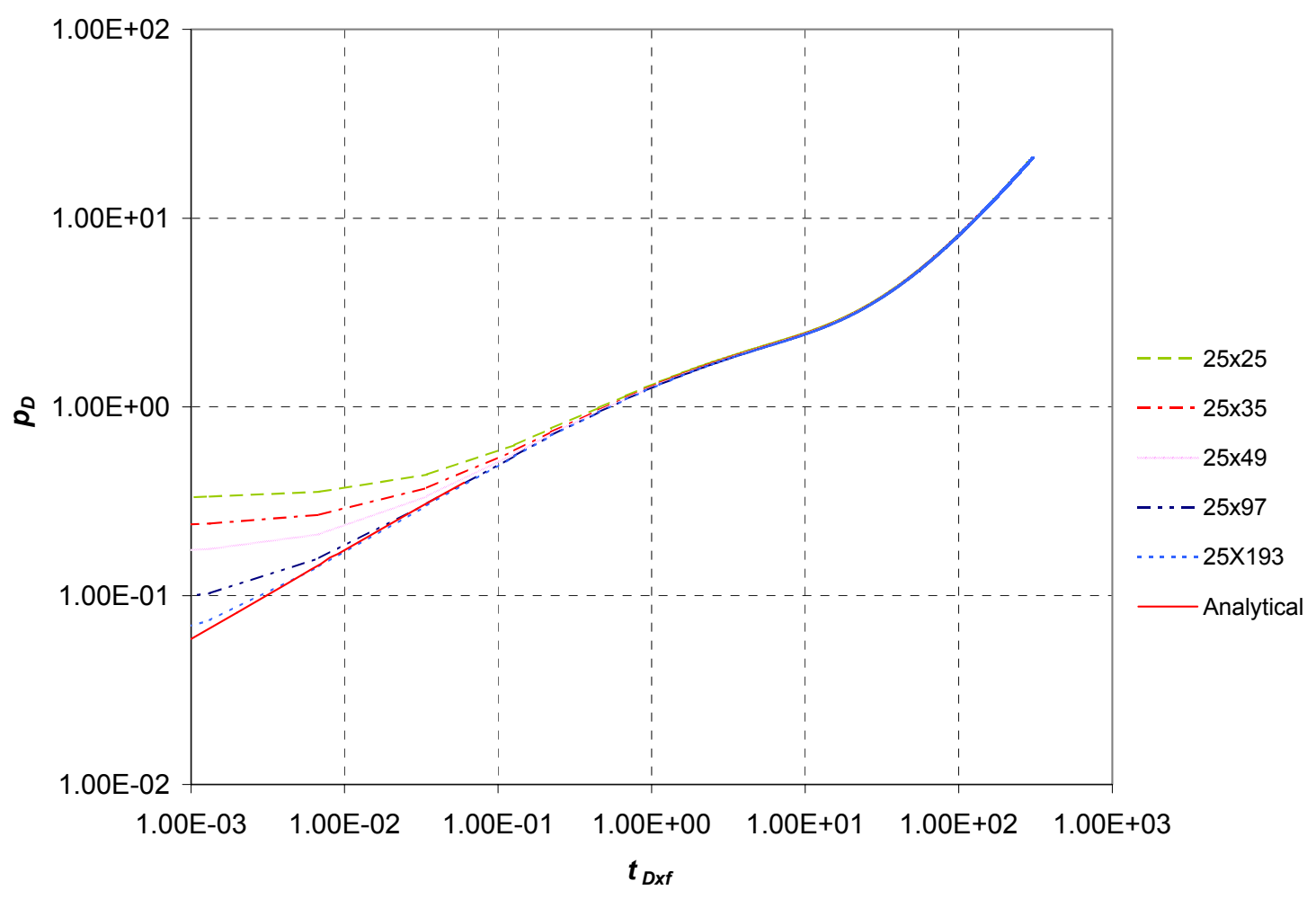

Fig. 3-10 - Six simulations for $F_{C D}=100 \pi$ and $x_{f} / x_{e}=0.2$ compared to analytical solution indicating that finer grids in the direction perpindicular to the fracture gives the best match to the analytical solution. 


\subsection{Grid Sensitivity for Case of $\boldsymbol{F}_{C D}=\pi$ Where $x_{f} / \boldsymbol{x}_{\boldsymbol{e}}=0.2$}

Recalling Fig. 3-4 earlier in this chapter we deduced that a low fractureconductivity and a small ratio of $\boldsymbol{x}_{\boldsymbol{f}} / \boldsymbol{x}_{\boldsymbol{e}}$ is likely to have an error at early $t_{D}$. In this section three simulation gridding cases will be tested for a finite-fracture conductivity of $F_{C D}=\pi$, where $x_{f} / x_{e}=0.2$ and a comparison to the Cinco-Ley et al. ${ }^{21}$ analytical solution will be performed. It is obvious from Fig. 3-11 that the least error at early time is for the uniform fine gridding of $45 \times 193$ cells followed by the case $25 \times 193$ cells which had a bigger deviation from the analytical solution. The simulation of the case of the gridding of $25 \times 25$ cells showed the biggest error. These results proof that for the case of a finite-conductivity fracture the gridding is important in both the direction perpendicular to the fracture and along the fracture.

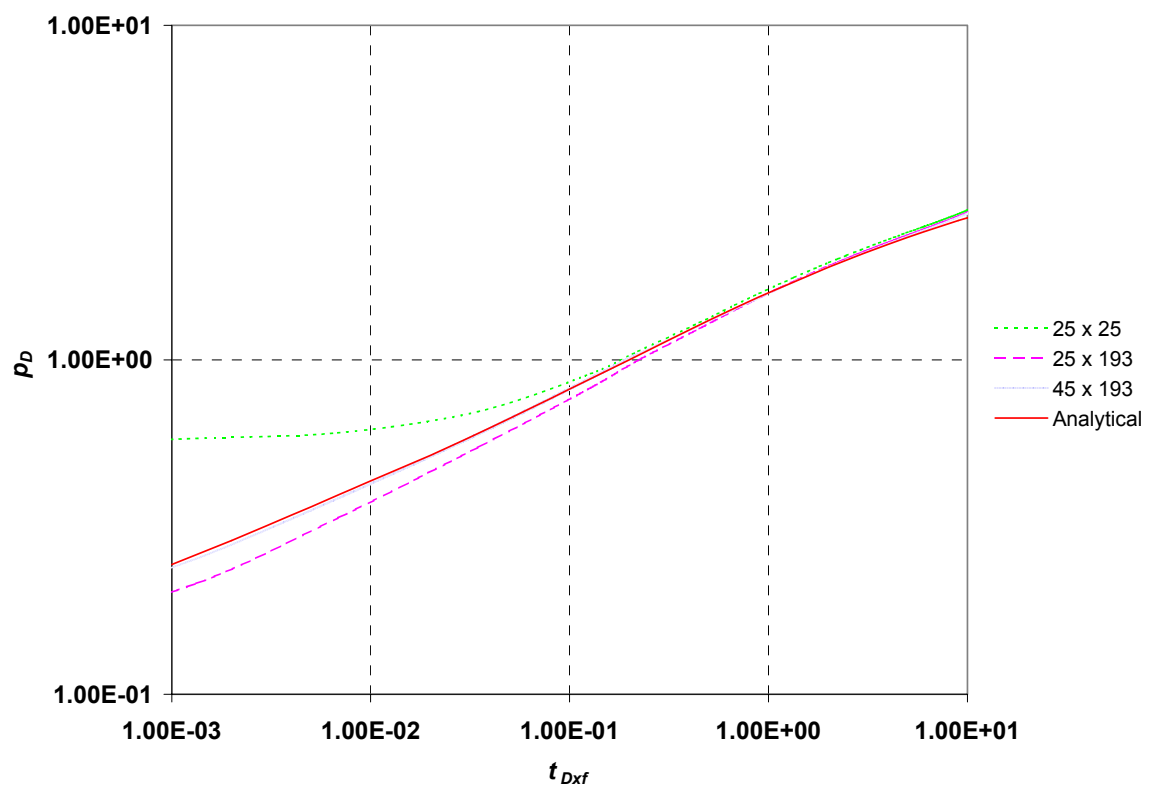

Fig. 3-11 - Grid sensitivity for the case of $F_{C D}=\pi$ where $x_{f} / x_{e}=0.2$ indicating that finer grids are needed in both the direction perpindicular and parallel to the fracture to give the best match to the analytical solution. 


\subsection{Grid Sensitivity for Cases of $F_{C D}=100 \pi 10 \pi$ and $\pi$ Where $x_{f} / x_{e}=0.1$}

A match was tried for any of the case of $F_{C D}=100 \pi 10 \pi$ and $\pi$ where $\boldsymbol{x}_{\boldsymbol{f}} / \boldsymbol{x}_{\boldsymbol{e}}=$ 0.1 with Cinco-Ley et $a l .^{21}$ analytical solution using a uniform grid but wasn't successful because probably very fine grids were needed. However, the using of a non-uniform grid of 79 x 33 cells gave a good match at early time shown in Fig. 3-12. The failure of match using a uniform fine grid further proves the point that we mentioned earlier that for the cases of $\boldsymbol{x}_{\boldsymbol{f}} / \boldsymbol{x}_{\boldsymbol{e}}<0.3$ there was an error at early $t_{D x f}$. The cases of $\boldsymbol{x}_{\boldsymbol{f}} / \boldsymbol{x}_{\boldsymbol{e}}<0.3$ were also reported in Table 3.2 but not shown in Fig. 3-4.

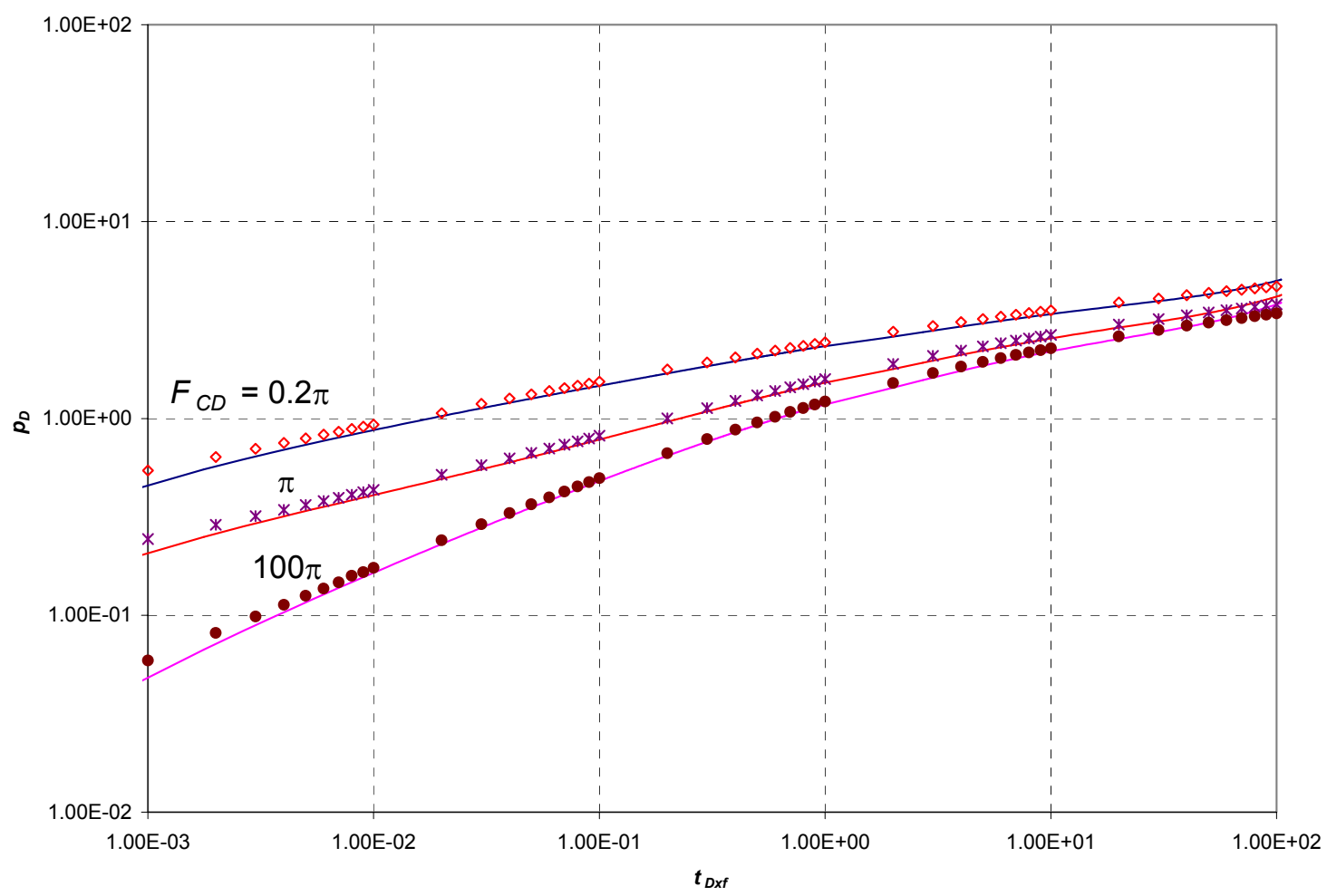

Fig. 3-12 - Grid sensitivity for cases of $F_{C D}=100 \pi 10 \pi$ and $\pi$ where $x_{f} / x_{e}=0.1$ using a non-uniform grid of $79 \times 33$ cells. 


\section{CHAPTER IV}

\section{MODELING HYDRAULIC FRACTURES IN COARSE GRIDBLOCKS}

\subsection{Introduction}

A single hydraulic fracture is conventionally modeled for research purposes using fine grids (Fig. 4-1). In actual field models of tight gas reservoirs, there can be several wells with hydraulic fractures. These hydraulic fractures are usually very long. They can extend in length to be more than a thousand feet. These long hydraulic fractures extend for several gridblocks in a simulation model (Fig. 4-2). Therefore, it is

very difficult to use fine grids to simulate these actual field models. Many authors ${ }^{31,33}$ suggested the replacement of the hydraulic fracture by an effective wellbore radius but this technique is only valid when the hydraulic fracture does not extend beyond the boundaries of one gridblock. There were also some attempts by some authors ${ }^{30,32,34}$ to modify transmissiblities of the gridblocks, which contain hydraulic fractures however these attempts were done for hydraulically fractured horizontal wells. In addition, these attempts had several rules of thumb that had no basic theory behind them.

In this chapter, ways are showed to model hydraulic fractures in coarse gridblocks. Pseudo-permeability values were used to account for the hydraulic fracture passing through the coarse gridblock. An alternative way that was also shown in this chapter was to modify the transmissibilities of the gridblocks that contain the hydraulic fracture. 


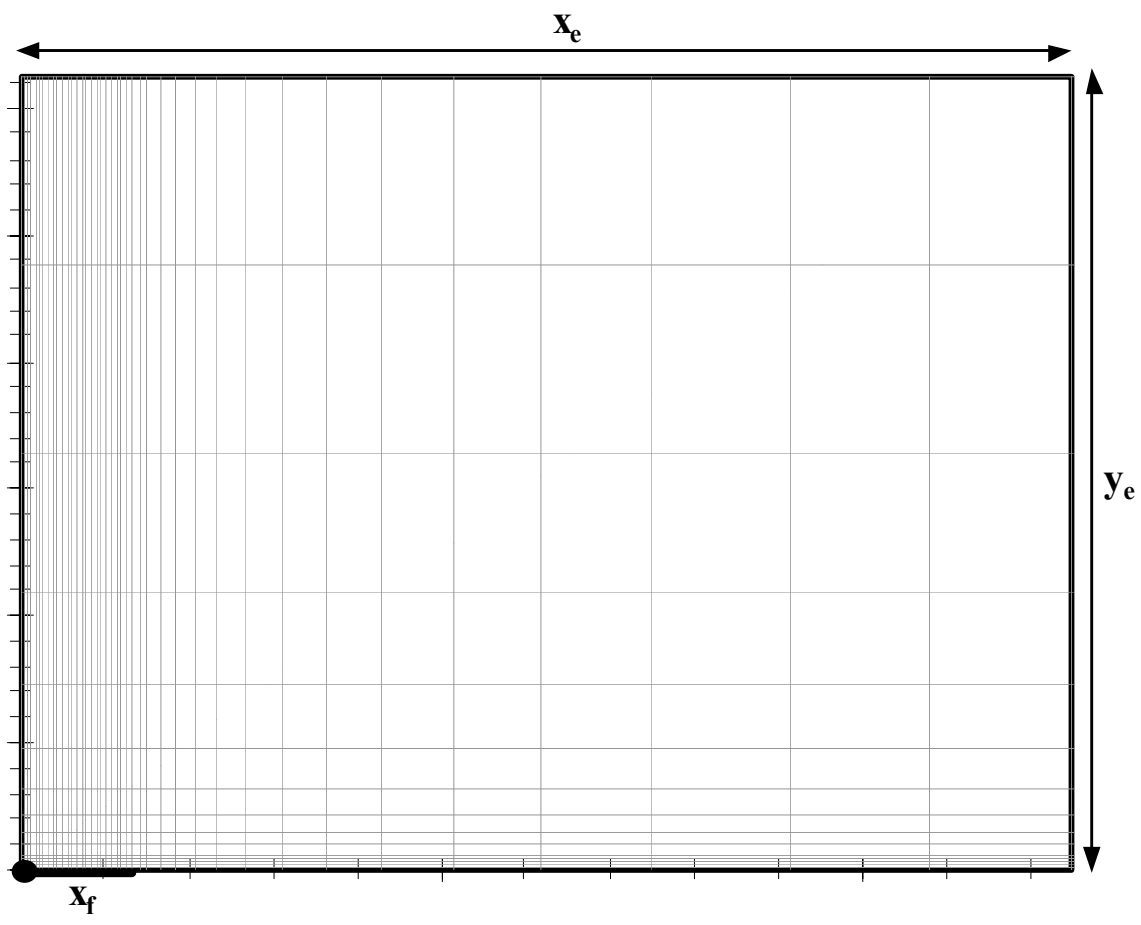

Fig. 4-1 -Quarter model of a single hydraulic fracture using the conventional fine grid. 


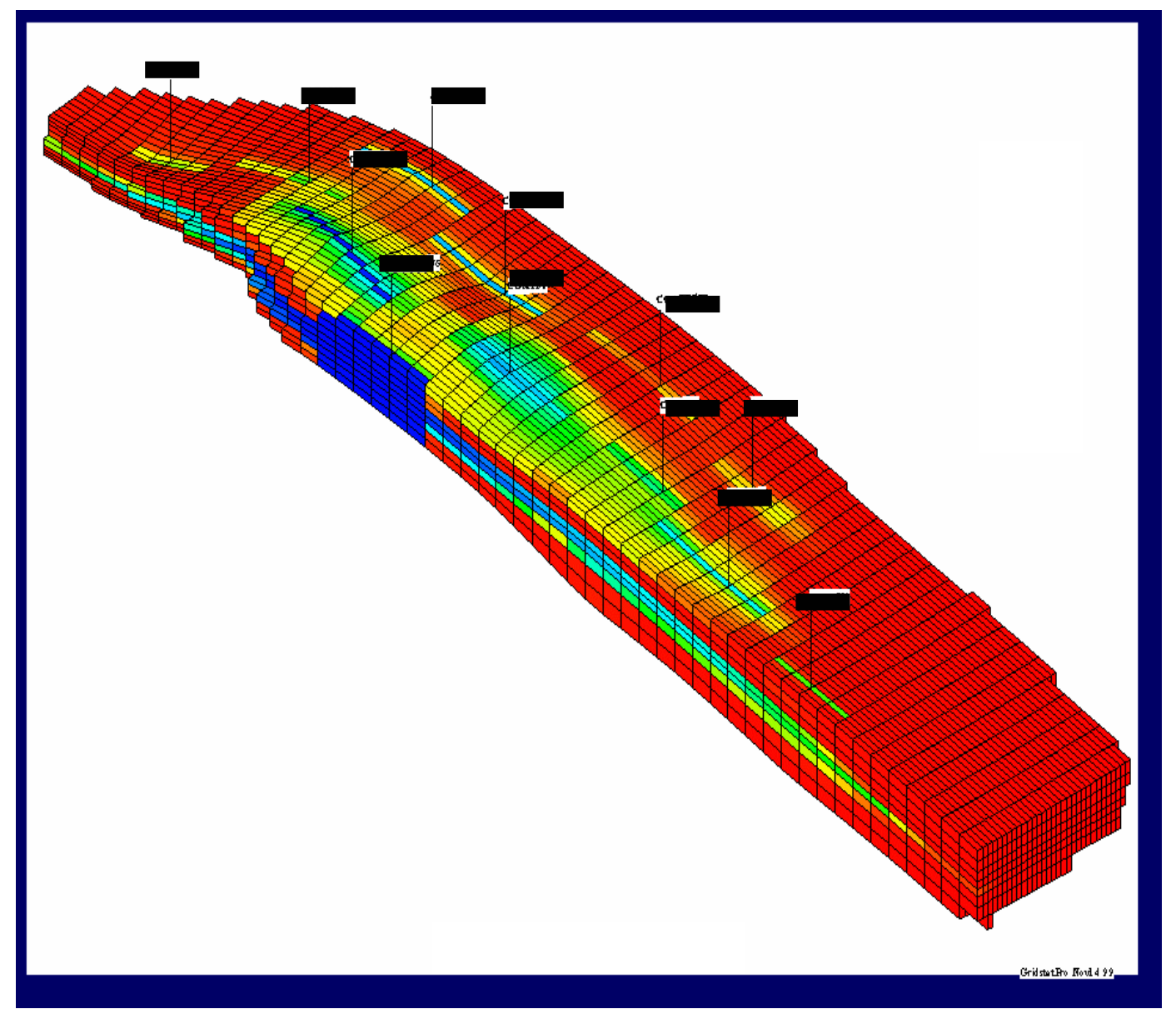

Fig. 4-2 - An example of a field model with several wells with hydraulic fractures. 
In this chapter, the use of the coarse gridblock caused the issue of artifact wellbore storage discussed in Chapter II to emerge. As in Chapter II, there was an error at early time that was experienced on the log-log plot of $p_{D}$ vs. $t_{D x f}$ for the cases of modeling hydraulic fractures in coarse gridblocks. It was also shown that the formula's accounting for minimum time, which were showed in Chapter II also applied for coarse scale simulation. Further, there was a sensitivity analysis of the amount of error that was seen when coarse scale simulation was used for both the infinite conductivity and finite conductivity hydraulic fractures. It was also shown that the concept of minimum time and the formula's developed in Chapter II only applied for coarse scale simulation of infinite conductivity hydraulic fractures with very high fracture conductivity $\left(F_{C D}\right)$.
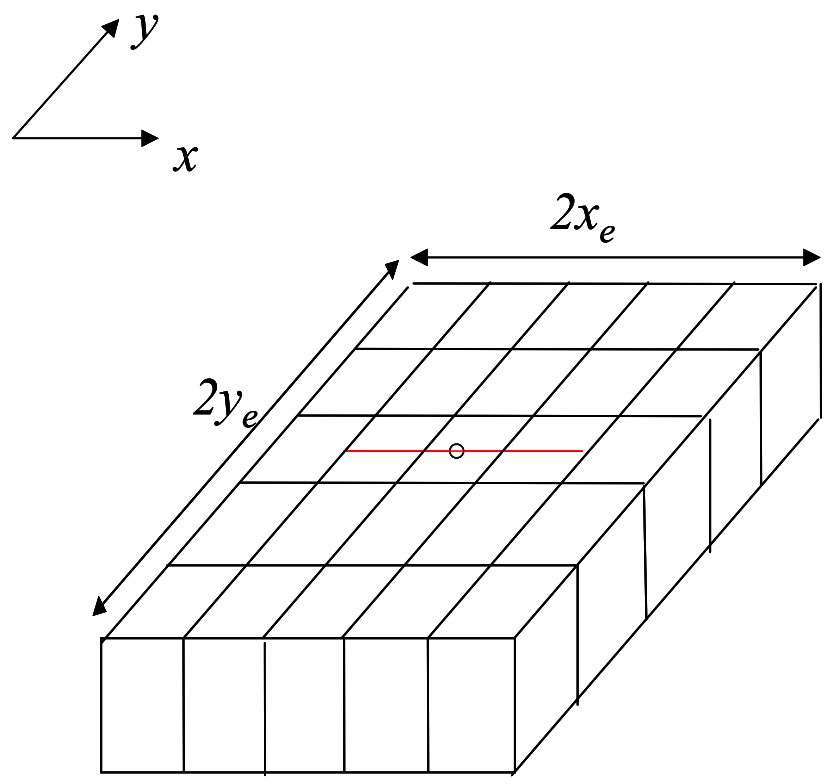

Fig. 4-3 - An example of a hydraulic fracture passing through coarse gridblocks. 


\subsection{Modeling Hydraulic Fractures in Coarse Blocks Using Pseudo-Permeabilities}

Our objective in this section was to show how to model a single hydraulic fracture that passes through coarse gridblocks as shown in Fig. 4-3. The formula's shown below in Eq. 4-1 and Eq. 4-3 were derived for the pseudo-permeability in the xdirection (direction along the fracture) and in the y-direction (direction perpendicular to the fracture) respectively for the coarse gridblocks that have hydraulic fractures passing through them. Derivations were shown in Appendix C.

$\tilde{k}_{x}=\frac{k(\Delta y-w)+k_{f} w}{\Delta y}$

Since the value of $(\Delta y-w) \cong \Delta y$ then Eq. $4-1$ can be reduced to

$$
\begin{aligned}
& \tilde{k}_{x} \cong k+\frac{k_{f} w}{\Delta y} \ldots \ldots \ldots . . . \\
& \tilde{k}_{y}=\frac{\Delta y}{\left[\frac{w}{k_{f}}+\frac{\Delta y}{k}-\frac{w}{k}\right]}
\end{aligned}
$$

Since the value of $(\Delta y-w) \cong \Delta y$ and $\frac{w}{k_{f}} \cong 0$ then Eq. $4-3$ can be reduced to

$\widetilde{k}_{y} \cong k$

These pseudo-permeability values were entered into the simulator to account for the hydraulic fracture passing through the coarse gridblocks in the physical model. These formulas were derived by comparing the physical model to the finite difference model using the basic rules of averaging of linear beds in series and linear beds in parallel. 


\subsection{Modeling Hydraulic Fractures in Coarse Blocks Using Transmissibility Multipliers}

In this section, another method to model a single hydraulic fracture that passes through coarse gridblocks was used. This method was simply to adjust the transmissibilities of the gridblocks that have the fracture passing through them in the physical model using a transmissibility multiplier. $\mathrm{CMG}^{39}$ simulator that was used to conduct this study used the word "TRANSI" as an abbreviation for the transmissibility multiplier in the x-direction. The formula for TRANSI for the gridblocks shown in Fig. 4.3 (where the fracture extends through the gridblock) was found to be $T R A N S I \cong \frac{\widetilde{k}}{k}$

For a gridblock where a hydraulic fracture was not extended until the end of that block (Fig. 4.4) the formula for TRANSI for that specific gridblock was found to be

$$
\operatorname{TRANSI}=\frac{\tilde{k} \Delta x}{k\left[\frac{\Delta x}{2}+a\right]+\tilde{k}\left(\left[\frac{\Delta x}{2}-a\right]\right)}
$$

Symbol " $a$ " is the distance that the hydraulic fracture extends in either direction from the edge of the gridblock. The side view of the blocks shown in Fig. 4.5 show that $a$ can be positive or negative. Derivation for Eq. 4-6 is shown in Appendix D. TRANSI adjusts the transmissibility between the specified gridblock and the adjacent gridblock on the right hand side. Therefore, Eq. 4-6 could be used between the gridblocks A and B in Fig. 4.5 but can not be used between $\mathrm{C}$ and $\mathrm{D}$. This right hand side rule may be specified to be left hand side in a different simulator and so Eq. 4-6 would not be valid in that case. 


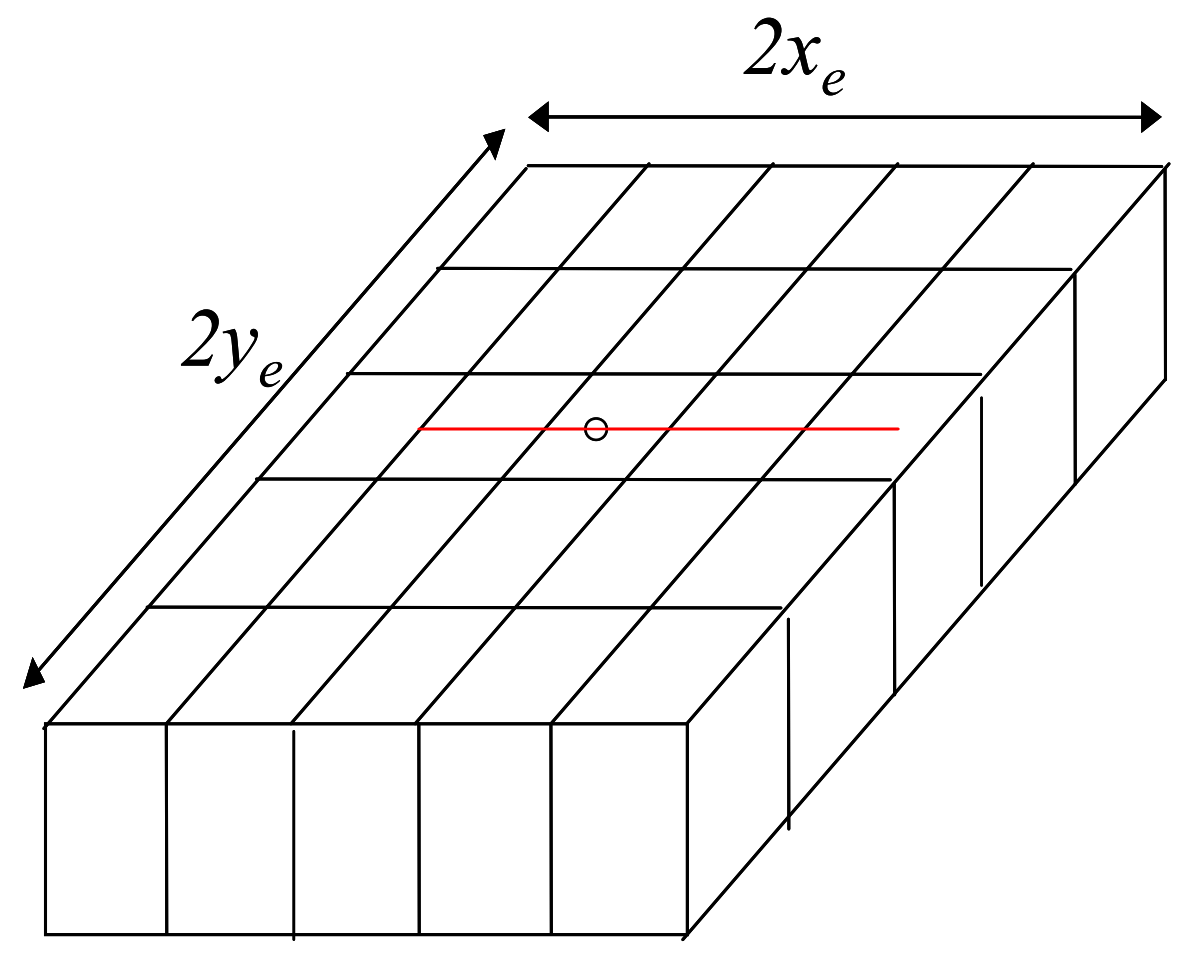

Fig. 4-4 - An example of a hydraulic fracture not extended till the end of the gridblock.

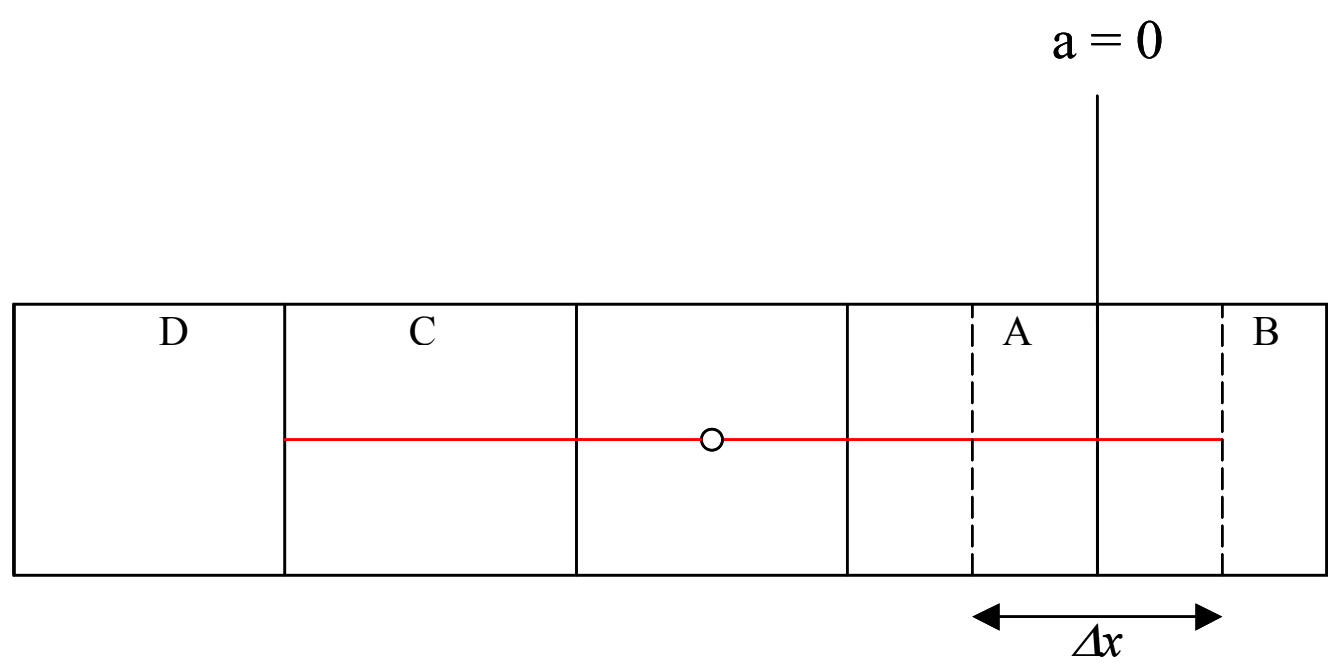

Fig. 4-5 - Top view of a hydraulic fracture not extended till the end of the gridblock. 


\subsection{Simulation Results and Matching Analytical Solutions}

The techniques showed earlier were used to simulate hydraulic fractures in coarse grid blocks. All cases simulated had grid sets such that $\Delta x=\Delta y$. The nomenclature for the grid sets was such that a 2D- Model which has gridding of 5 x 5 was named as a grid set of $2 x_{e} / \Delta x=5$ as shown in Fig. 4-6. For a case that has gridding of $15 \times 15$ it was named as a grid set of $2 x_{e} / \Delta x=15$ and so on. All cases simulated were for a square reservoir of 80 acres with the properties specified in Table 4-1. The only property that varied from case to case was either the fracture length or the dimensionless fracture conductivity as shown in Table 4-2.

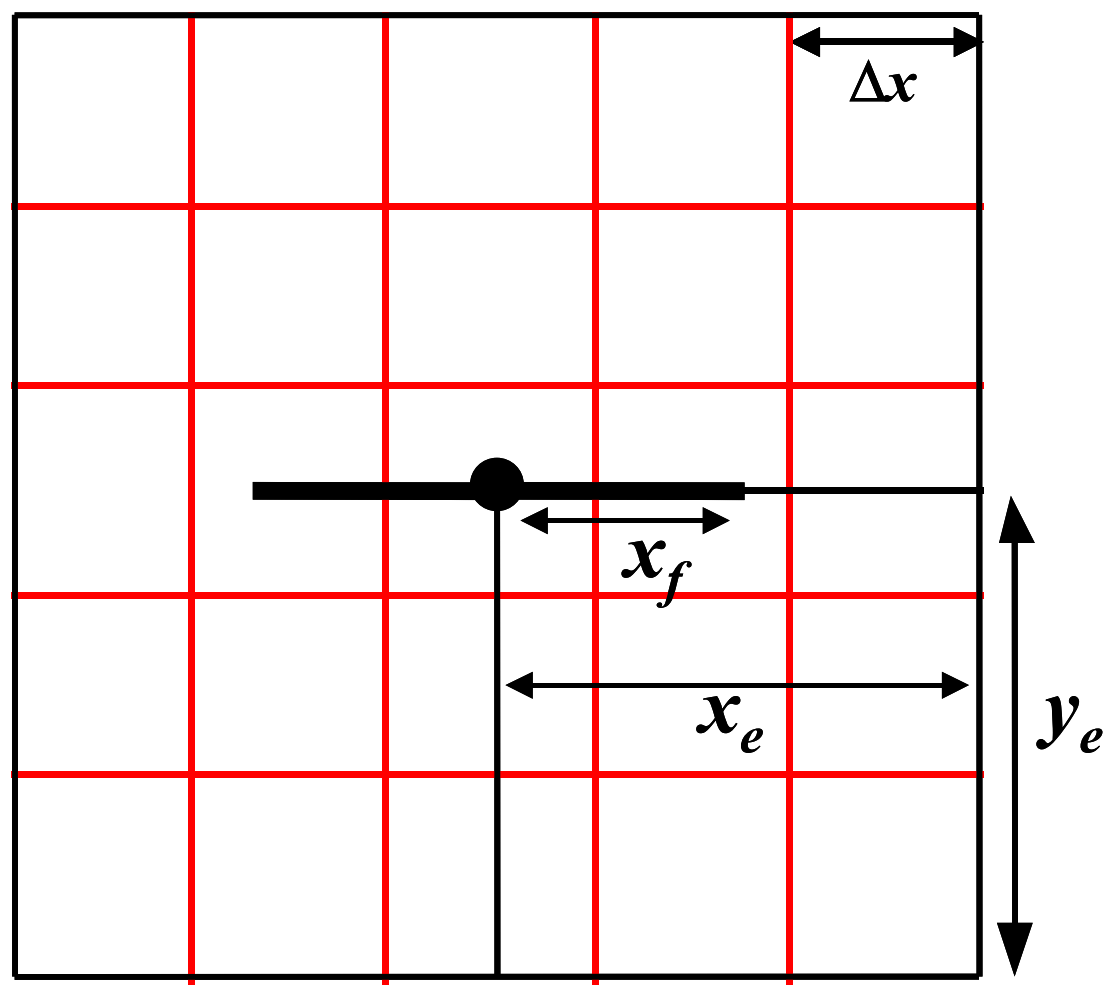

Fig. 4-6 - An 80 acre square reservoir with gridding of $2 x_{e} / \Delta x=5$. 
Table 4-1 - Main data for the simulated cases

Drainage Area Acres

$\cong 80$

$2 x_{e} \mathrm{ft}$

1,860

$2 y_{e} \mathrm{ft}$

1,860

Thickness $(h) \mathrm{ft}$

150

Absolute Permeability $(k) \mathrm{mD}$

0.1

Porosity $(\phi)$ fraction

0.23

Initial Pressure $\left(p_{i}\right)$ psi

Oil Formation Volume Factor $\left(B_{o}\right) \mathrm{RB} / \mathrm{STB}$

3,000

Oil Viscosity $\left(\mu_{o}\right) \mathrm{cp}$

1

0.72

Total compressibility $\left(c_{t}\right) \mathrm{psi}^{-1}$

$1.5 \mathrm{E}-05$

Table 4-2 - Data for the different cases

Case \# 1
$F_{C D}=50,000$
$x_{e} / x_{f}=1$

Case \#2
$F_{C D}=100 \pi$
$x_{e} / x_{f}=1$

Case \# 3

$F_{C D}=50,000$

$x_{e} / x_{f}=5$

Table 4-3 - Data for the different grid sets for case \# 1

\begin{tabular}{|c|c|c|c|}
\hline $2 x_{e} / \Delta \boldsymbol{x}$ & $\Delta \boldsymbol{x} \mathbf{f t}$ & $\tilde{k}$ md & TRANSI \\
97 & 19.17 & 482,510 & $4,825,100$ \\
49 & 37.96 & 122,510 & $1,225,100$ \\
25 & 74.4 & 62,510 & 625,100 \\
5 & 372 & 12,510 & 125,100 \\
1 & 1,860 & 2,510 & 25,100 \\
\hline
\end{tabular}




\subsubsection{Simulation of Case \# $1, F_{C D}=50,000$, and $x_{e} / x_{f}=1$}

The first case to be simulated was for an infinite conductivity fracture of $x_{e} / x_{f}=1$ as noted in Table 4.2 There were five different grid sets used for this case which are shown in Table 4-3. The five different grid sets will have values of $2 x_{e} / \Delta x=97,49,25$, 5, and 1 but all with the same properties shown in Table 4-1. A plot of the results for five different simulations on the Log-Log plot of $p_{D}$ vs. $t_{D x f}$ is shown in Fig. 4-7. These simulations are compared to the exact analytical solution. The exact analytical solution which for this case is the basic linear flow solution described in Chapter II and is the Gringarten et al. ${ }^{19}$ solution for infinite conductivity hydraulic fracture for the case of $x_{e} / x_{f}$ $=1$.

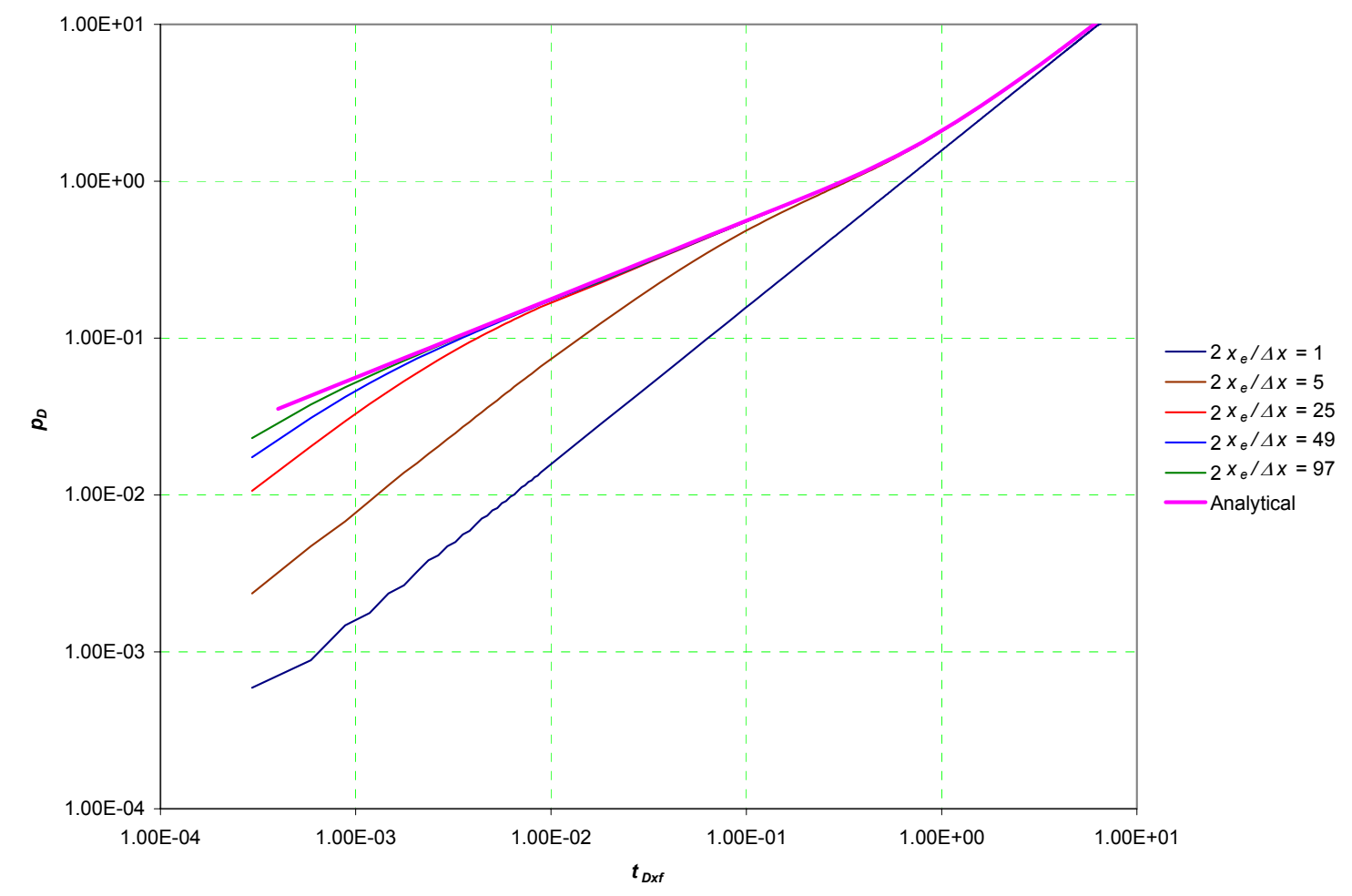

Fig. 4-7 - The log-log plot of $p_{D} v s . t_{D x f}$ for different grid sets of case \# 1 . 
It is obvious from Fig. 4-7 that there is significant error for the coarser grid sets. The grid set of $2 x_{e} / \Delta x=97$ matches the analytical solution at much earlier time than the grid set of $2 x_{e} / \Delta x=5$. The one grid block set of $2 x_{e} / \Delta x=1$ gave a unit slope at all times and matched the analytical solution only in the pseudo-steady state region very late in time.

It is also noticeable from Fig. 4-7 that for all simulation cases that the early period that has error forms a unit slope at early time. This unit slope is due to artifact wellbore storage discussed in Chapter II and it was found to end at the minimum time from the formula that was developed in Chapter II.

\begin{tabular}{|c|c|c|c|}
\hline \multicolumn{4}{|c|}{ Table 4-4 - Data for the different grid sets for case \# 2} \\
\hline $\mathbf{2} \boldsymbol{x}_{\boldsymbol{e}} / \boldsymbol{\Delta x}$ & $\boldsymbol{\Delta} \boldsymbol{x} \mathbf{f t}$ & $\tilde{k}$ md & TRANSI \\
97 & 19.17 & $1,523.77$ & $15,237.7$ \\
49 & 37.96 & 769.79 & $7,697.9$ \\
25 & 74.4 & 392.8 & 3,928 \\
5 & 372 & 78.64 & 786.4 \\
1 & 1,860 & 15.81 & 158.1 \\
\hline
\end{tabular}




\subsubsection{Simulation of Case \# $2, F_{C D}=100 \pi$, and $x_{e} / x_{f}=1$}

The second case to be simulated was for a finite conductivity fracture of $F_{C D}=$ $100 \pi$ and where $x_{e} / x_{f}=1$ as noted in Table 4.2. There were five different grid sets used for this case, which are shown in Table 4-4. The five different grid sets will have values of $2 x_{e} / \Delta x=97,49,25,5$, and 1 but all with the same properties shown in Table 4-1. A plot of the results for 5 different simulations on the log-log plot of $p_{D}$ vs. $t_{D x f}$ is shown in Fig. 4-8. It also shows a comparison to the exact analytical solution. The exact analytical solution which for this case is the Cinco-Ley et $a .^{21}$ solution for finite conductivity hydraulic fracture of $F_{C D}=100 \pi$.

It is obvious from Fig. 4-8, which is very similar to Fig. 4-7 that there is significant error for the coarser grid sets. The grid set of $2 x_{e} / \Delta x=97$ matches the analytical solution at much earlier time than the grid set of $2 x_{e} / \Delta x=5$. The one grid block set $2 x_{e} / \Delta x=1$ gave a unit slope at all times and matched the analytical solution only in the pseudo-steady state region very late in time.

However, in Fig. 4-8 the early period that has the error doesn't form a unit slope at the early time as shown in Fig. 4-7. This comparison may be clearer in Fig. 4-9 where we compare Case \# 1 and Case \# 2 for the grid set of $2 x_{e} / \Delta x=25$. We obviously see from Fig. 4-9 that the unit slope appears only for high values of fracture-conductivity. Several other cases rather than case \# 2 where tested which were all of infinite fracture conductivity $F_{C D}>500$ but not so large and none of these cases gave the unit slope due to the formation of a gradient in the hydraulic-fracture. 


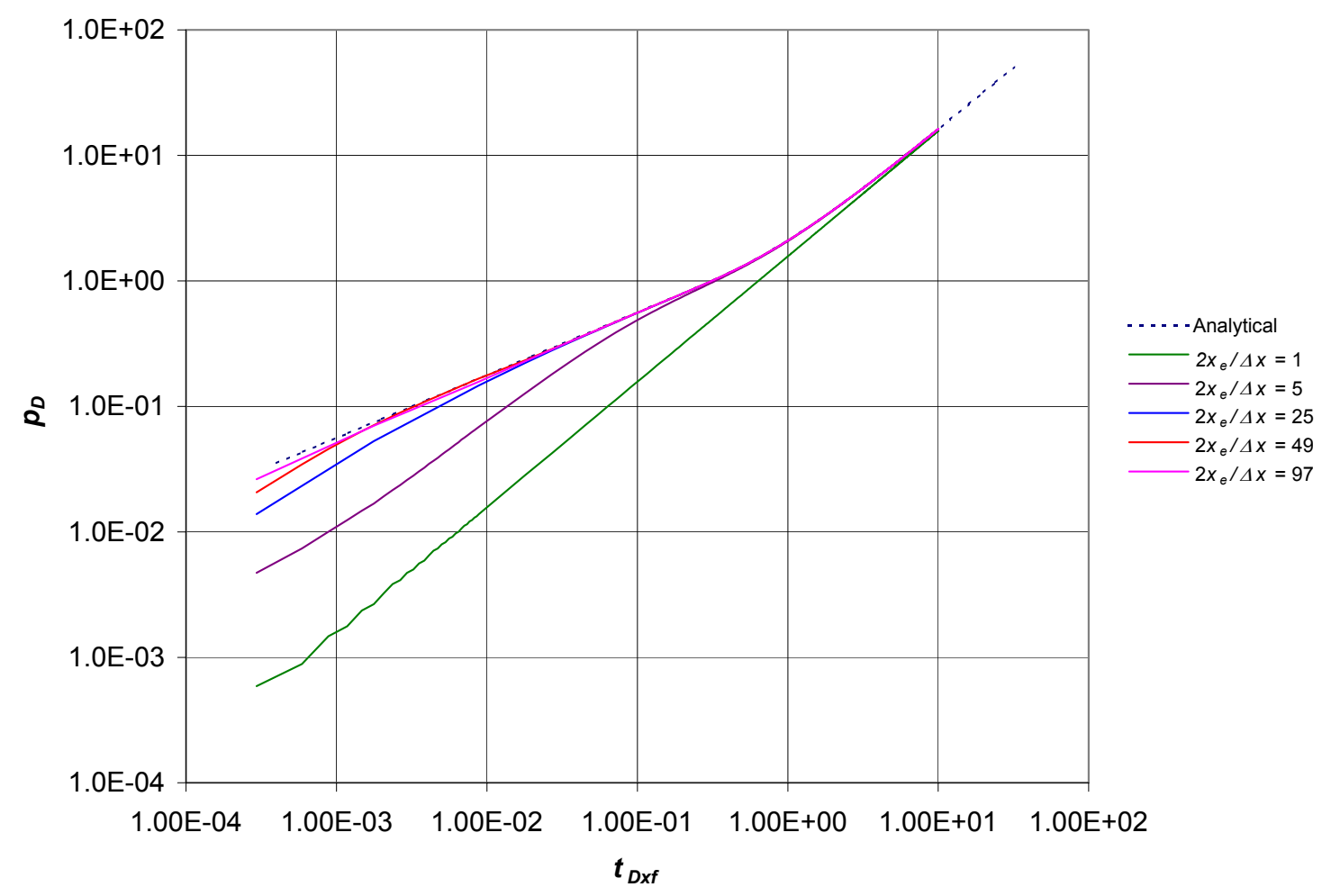

Fig. 4-8 - The log-log p1ot of $p_{D} v s . t_{D x f}$ for different grid sets of case \# 2 .

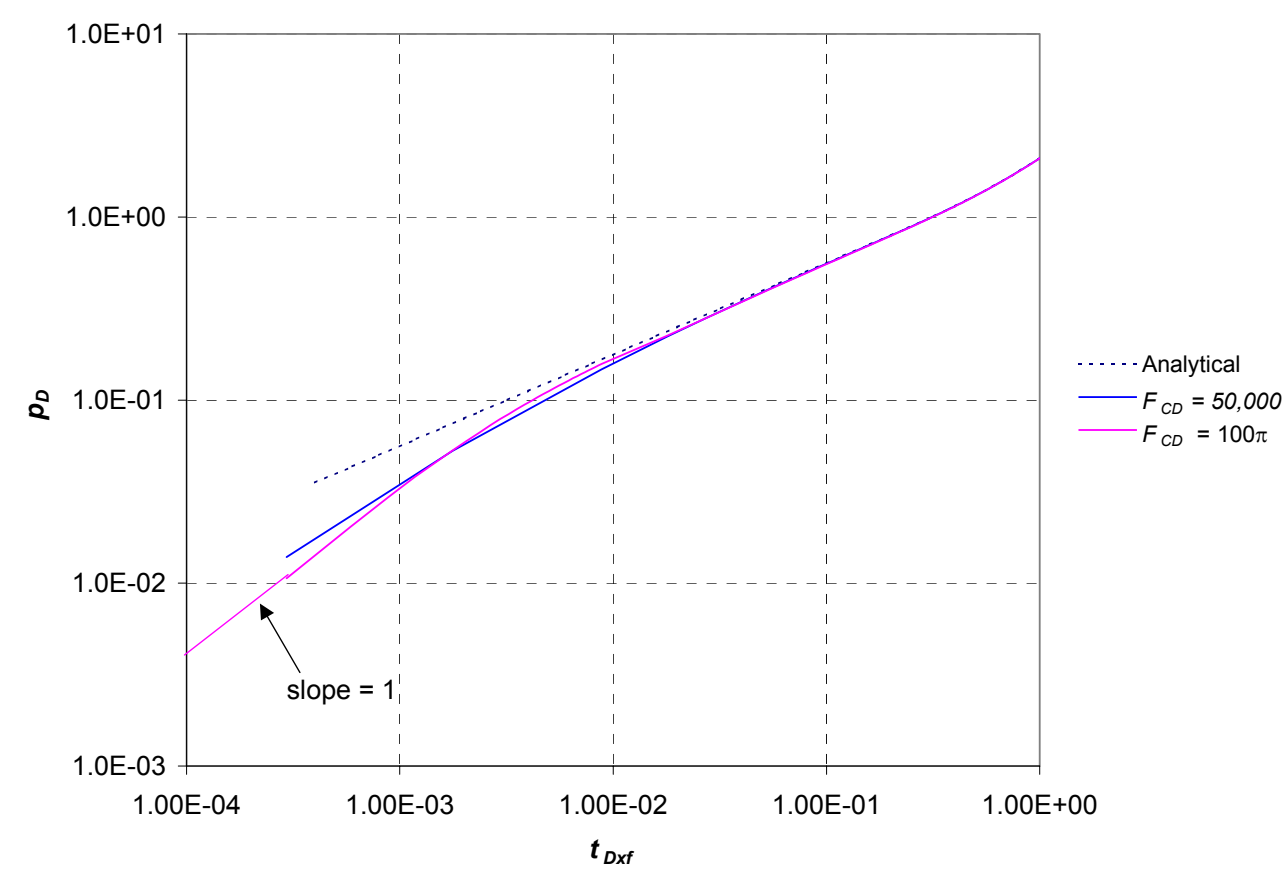

Fig. 4-9 - The log-log plot of $p_{D} v s$. $t_{D x f}$ for comparison of cases \# 1 and \# 2 . 


\subsubsection{Simulation of Case \# 3, $F_{C D}=50,000$, and $x_{e} / x_{f}=5$}

The third case to be simulated was for an infinite conductivity hydraulic fracture of $F_{C D}=50,000$ and where $x_{e} / x_{f}=5$ as noted in Table 4.2. There were three different grid sets used for this case, which are shown in Table 4-5. The three different grid sets will have values of $2 x_{e} / \Delta x=9749255$ and 1 but all with the same properties shown in Table 4-1. A plot of the results for 3 different simulations on the Log-Log plot of $p_{D}$ vs. $t_{D x f}$ is shown in Fig. 4-10. It also shows a comparison to the exact analytical solution. The exact analytical solution which for this case is the Gringarten et al. ${ }^{19}$ solution for infinite conductivity fracture of $x_{e} / x_{f}=5$.

As in the previous two cases, there is significant error for the coarser grid sets. The grid set of $2 x_{e} / \Delta x=97$ matches the analytical solution at much earlier time than the grid set of $2 x_{e} / \Delta x=5$. The unit slope behavior is also obvious in Fig. 4-10.

\begin{tabular}{|c|c|c|c|}
\hline \multicolumn{4}{|c|}{ Table 4-5 - Data for the different grid sets for case \# 3 } \\
\hline $2 \boldsymbol{x}_{\boldsymbol{e}} / \Delta \boldsymbol{x}$ & $\Delta \boldsymbol{x} \mathbf{f t}$ & $\widetilde{k}$ md & TRANSI \\
95 & 19.58 & 47,510 & 475,100 \\
35 & 53.14 & 17,510 & 175,100 \\
25 & 74.4 & 12,510 & 125,100 \\
\hline
\end{tabular}




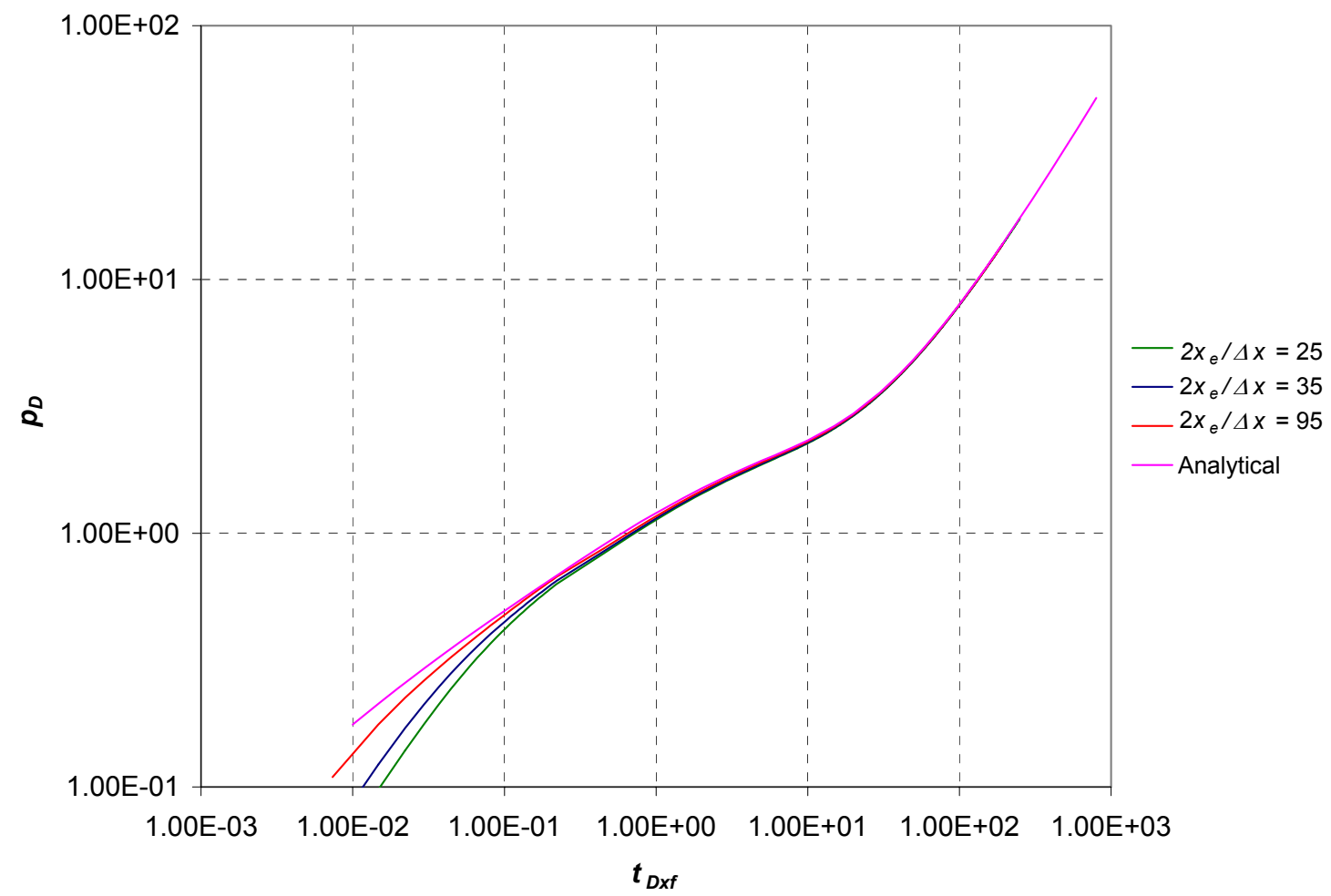

Fig. 4-10 - The log-log p1 ot of $p_{D} v s$. $t_{D x f}$ for different grid sets of Case \# 3. 


\subsection{Analysis of Early Time Error}

In this section, the early time error causing the unit slope will be shown in a quantified manner for the different grid sets of case \# 1. Three arbitrary dimensionless times in the transient period are chosen to show the error in dimensionless pressure as shown in Table 4-6. One arbitrary dimensionless time was chosen in the pseudo-steady state period and the error was shown as a deviation from the dimensionless productivity index $\left(J_{D}\right)$ as shown in Table 4-7.

\section{Table 4-6- Percentage of error in dimensionless pressure during transient period}

\begin{tabular}{|c|c|c|c|c|c|}
\hline$t_{D \times f}$ & $2 x_{e} / \Delta x=1$ & $2 x_{e} / \Delta x=5$ & $2 x_{e} / \Delta x=25$ & $2 x_{e} / \Delta x=49$ & $2 x_{e} / \Delta x=97$ \\
\hline 0.0012 & $97.12 \%$ & $85.10 \%$ & $38.00 \%$ & $15.89 \%$ & $6.76 \%$ \\
\hline 0.08 & $74.81 \%$ & $16.82 \%$ & $1.46 \%$ & $1.11 \%$ & $0.99 \%$ \\
\hline 1.2 & $21.64 \%$ & $0.79 \%$ & $-0.05 \%$ & $-0.08 \%$ & $-0.09 \%$ \\
\hline
\end{tabular}

\section{Table 4-7- Percentage of error in dimensionless productivity index $\left(J_{D}\right)$}

\begin{tabular}{|c|c|c|c|c|}
\hline$t_{D x f}$ & $2 x_{e} / \Delta x=5$ & $2 x_{e} / \Delta x=25$ & $2 x_{e} / \Delta x=49$ & $2 x_{e} / \Delta x=97$ \\
\hline 10 & $4.19 \%$ & $0.19 \%$ & $0.02 \%$ & $0.02 \%$ \\
\hline
\end{tabular}

The $\%$ error in $p_{D}$ is calculated using the following formula :

$\%$ error $=\frac{\left(p_{D}\right)_{\text {analytical }}-\left(p_{D}\right)_{\text {simulation }}}{\left(p_{D}\right)_{\text {analytical }}}$

The $\%$ error in $J_{D}$ is calculated using the following formula:

\%error $=\frac{\left(J_{D}\right)_{\text {analytical }}-\left(J_{D}\right)_{\text {simulation }}}{\left(J_{D}\right)_{\text {analytical }}}$ 
The definition of the dimensionless productivity index $J_{D}$ is

$J_{D}=\frac{141.2 q B \mu}{k h\left(\bar{p}-p_{w f}\right)}=\frac{1}{\left[\frac{\pi}{6}\left(\frac{y_{e}}{x_{e}}\right)\right]}$

which is originally deduced from the productivity index from the linear flow case ${ }^{37,38}$ as follows

$$
J=\frac{q}{\bar{p}-p w f}=\frac{k h}{141.2 B \mu\left[\frac{\pi}{6}\left(\frac{y_{e}}{x_{e}}\right)\right]}
$$

We conclude from Table 4-6 regarding Case \# 1 that had a match with the analytical solution before reaching the pseudo-steady state period that using a coarse grid block can cause a significant error in the transient period while Table 4-7 shows that there is not so much error in the pseudo-steady state period. 


\section{CHAPTER V}

\section{SUMMARY AND DISCUSSION}

In this chapter, we will present a summary of how to simulate and interpret results of hydraulically fractured reservoirs using coarse grids. We will also show how all the work in this dissertation applies to gas reservoirs. The last part of this chapter will discuss ideas of future research work that can be built on the results of this study.

\subsection{Summary of Steps to Create a Model of Coarse Scale Simulation}

For a 2D single well model of $\Delta x=\Delta y$ of an anisotropic homogeneous reservoir of permeability $k$ that has a hydraulic fracture the $\mathrm{x}$-direction:

1) Input the reservoir permeability $k$ in your simulator into all the gridblocks of the model including the gridblocks that have hydraulic fractures passing through them.

2) Change the transmissibility multiplier in the $x$-direction for all the gridblocks that have a hydraulic fracture passing through them. The value for the transmissibility multiplier that should be entered for the gridblocks that have hydraulic fractures

passing through them completely till an adjacent gridblock is TRANSI $\cong \frac{\widetilde{k}}{k}$

where $\tilde{k}=\frac{k(\Delta y-w)+k_{f} w}{\Delta y}$

3) Change the transmissibility multiplier in $\mathrm{x}$-direction for all the gridblocks that have a hydraulic fracture passing through them not completely till the adjacent 
gridblock to a value of TRANSI $=\frac{\tilde{k} \Delta x}{k\left[\frac{\Delta x}{2}+a\right]+\tilde{k}\left(\left[\frac{\Delta x}{2}-a\right]\right)}$ where

$\widetilde{k}=\frac{k(\Delta y-w)+k_{f} w}{\Delta y}$ and " $a$ " is the distance that the hydraulic fracture extends

in either direction from the surface of the gridblock.

4) Keep the transmissibility multiplier in the y-direction for all the gridblocks the same default value of one and do not change it.

\subsection{Example Calculation}

For a model of an 80 acre square reservoir of $\Delta x=\Delta y$ of an anisotropic homogeneous reservoir. The properties used in this example were:

1. Reservoir permeability $k=0.1 \mathrm{md}$.

2. Reservoir dimensions are $x_{e}=y_{e}=930 \mathrm{ft}$.

3. A hydraulic fracture of $x_{e} / x_{f}=5$ and $F_{C D}=5,000$.

4. The arbitrary grid set of $25 \times 25$ was used which can be also called $2 x_{e} / \Delta x=$ 25.

We deduce that $x_{f}=x_{e} / 5=186 \mathrm{ft}$ and therefore that $k_{f}=F_{C D} k x_{f} / w=4,650,000 \mathrm{md}$.

Also, $2 x_{e} / \Delta x=25$ and therefore $2 x_{e} / \Delta x=1,860 / 25=74.4 \mathrm{ft}$. Since $x_{e} / x_{f}=5$ then $2 x_{f} /$ $\Delta x=25$ and therefore $\mathrm{a}=0$ so step 3 in part 5.1 is not applicable.

Following the steps in part 5.1 as follows:

1) Input the reservoir permeability $k=0.1$ in your simulator into all the gridblocks of the model including the gridblocks that have hydraulic fractures passing through them. 
2) Change the transmissibility multiplier in the $x$-direction for all the gridblocks that have a hydraulic fracture passing through them.

$$
\begin{aligned}
& \widetilde{k}=\frac{k(\Delta y-w)+k_{f} w}{\Delta y}=\frac{0.1(74.4-0.02)+46,500,00(0.02)}{74.4}=1,250.99 \mathrm{md} \\
& T R A N S I \cong \frac{\tilde{k}}{k}=12,509.9 .
\end{aligned}
$$

3) Keep the transmissibility multiplier in the y-direction for all the gridblocks the same default value of one and do not change it.

\subsection{Summary of Steps to Interpret Results of Coarse Scale Simulation}

1) The use of coarse grid models will cause the results of the simulation of the constant production case to have a numerical error of unit slope on the log-log plot of $\Delta p=p_{i}-p_{w f}$ Vs. $t$

2) The error on the log-log plot of $\Delta p$ s. $t$ ends at a minimum time

$$
t_{\min }=217(\Delta x)^{2} \frac{\phi \mu c_{t}}{k}
$$

Where we will have only a $5 \%$ error in the correct value of $\Delta p$.

3) The conclusion from that we deduce from the above step is that we can not match any data before the minimum time specified in the above step on performing history matching using coarse scale simulation.

\subsection{Application of the Work in the Dissertation for Gas Reservoirs}

When dealing with gas reservoirs all steps of coarse scale modeling and interpreting that were shown in previous two sections are valid. The only difference is that results of the simulation of the constant production case to have a numerical error of unit slope on the 
$\log -\log$ plot of $\Delta m(p)=m\left(p_{i}\right)-m\left(p_{w f}\right)$ vs. $t$ where $\Delta m(p)$ is real gas pseudopressure that was defined by Al-Hussainy et al. ${ }^{40}$ as follows:

$$
m(p)=2 \int_{p_{o}}^{p} \frac{p}{z \mu} d p
$$

All the analytical solutions that were used for matching are numerical results can be easily modified for gas flow. Simply to obtain gas solutions $p_{w D}$ is replaced by $m_{w D}$ in the liquid solutions. The $m_{w D}$ parameter can be defined as follows:

$$
m_{w D}=\frac{k h\left\lfloor m\left(p_{i}\right)-m\left(p_{w f}\right)\right\rfloor}{1424 q g T}
$$

The dimensionless time can be defined in function of the initial fluid properties as follows:

$$
t_{D x_{f}}=\frac{0.00633 k t}{\left(\phi \mu c_{t}\right)_{i} x_{f}^{2}}
$$

\subsection{Recommendations for Future Work}

1. Investigating the effect of artifact wellbore storage on the history match and on the simulation forecast.

2. Extending the work for modeling coarse grids for layers (3D model).

3. Investigating the case of producing with constant $p_{w f}$ with coarse grids. 


\section{CHAPTER VI}

\section{CONCLUSIONS}

1. A new method to simulate a single hydraulic fracture passing through several coarse gridblocks was developed and documented. This method specifies transmissibility multipliers to be entered into the simulator to account for the presence of the fracture in the coarse gridblock. The method developed applies anywhere whether the fracture ends at the center of the gridblock or any arbitrary distance within the grid block. The new method was successfully tested by matching it to the analytical solution for the constant rate case. However, there was a numerical error at early time.

2. The numerical error that exists at early time was found to have a unit slope on the log-log plot of $\Delta p$ vs. $t$ but this unit slope is only present for high values of $F_{C D}$. For lower values of $F_{C D}$ (including of course the finite conductivity hydraulic fractures) an error exists but not of unit slope. Two formulas were developed to estimate the time at which the numerical error is reduced to only $10 \%$ and to $5 \%$ error compared to the analytical solution.

3. Uniform fine gridding can yield as good results as non-uniform fine gridding when simulating models of reservoirs with hydraulic fractures especially for cases that have infinite conductivity fractures since gridding seems to be 
important only in the direction perpendicular to the fracture and not in the direction along the fracture. This is not the case for finite conductivity fractures where gridding seemed to be important in both directions along and perpendicular to the fracture. 


\section{NOMENCLATURE}

\section{Variables}

$$
\begin{aligned}
& A \quad=\text { cross-sectional area to flow, }\left[\mathrm{ft}^{2}\right] \\
& B \quad=\text { gas formation volume factor, }[\mathrm{rb} / \mathrm{stb}] \\
& C \quad=\text { wellbore storage coefficient, }[\mathrm{bbl} / \mathrm{psi}] \\
& C_{D} \quad=\text { dimensionless wellbore storage coefficient } \\
& c_{t} \quad=\text { total system compressibility, }\left[\mathrm{psia}^{-1}\right],\left[=c_{g} S_{g}+c_{o} S_{o}+c_{w} S_{w i}+c_{f}\right] \\
& c_{w b}=\text { wellbore fluid compressibility, }\left[\mathrm{psia}^{-1}\right] \\
& F_{C D}=\text { dimensionless fracture conductivity }\left[=k_{f} w / k x_{f}\right] \\
& h \quad=\text { net reservoir thickness, [ft] } \\
& \bar{h} \quad=\text { average net reservoir thickness, [ft] } \\
& k=\text { permeability of the reservoir, [md] } \\
& \bar{k} \quad=\text { average permeability of the reservoir, [md] } \\
& \tilde{k}=\text { required permeability to model skin effect, [md] } \\
& k_{f} \quad=\text { fracture permeability (fracture referred to bulk volume), [md] } \\
& k_{h} \quad=\text { horizontal permeability, [md] } \\
& k_{v} \quad=\text { vertical permeability, [md] } \\
& k_{x}=\text { permeability in } \mathrm{x} \text {-direction, [md] } \\
& k_{y} \quad=\text { permeability in y-direction, [md] } \\
& x=x \text { direction } \\
& L=\text { Length of linear reservoir, [ft] } \\
& p \quad=\text { absolute pressure, }[\mathrm{psia}] \\
& p_{i} \quad=\text { initial reservoir pressure, }[\mathrm{psia}] \\
& p_{w D}=\text { dimensionless pressure at the wellbore } \\
& p_{w b}=\text { well gridblock pressure, [psia] } \\
& p_{w f} \quad=\text { flowing bottomhole pressure, [psia] } \\
& q \quad=\text { production rate, }[\mathrm{stb} / \mathrm{D}]
\end{aligned}
$$




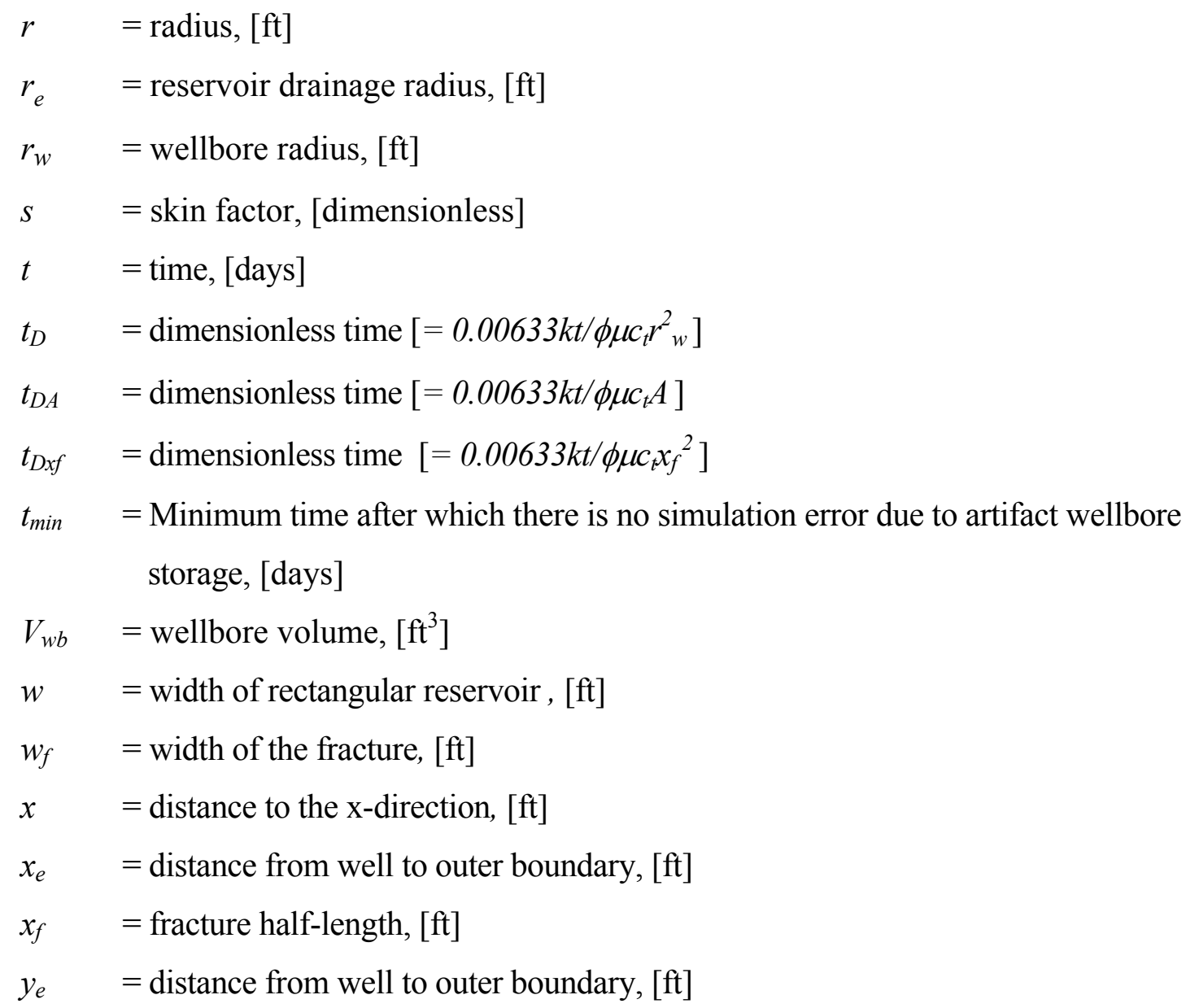

\section{Subscripts}

$D \quad=$ dimensionless

$f \quad=$ fracturel

\section{Greek Symbols}

$$
\begin{array}{ll}
\phi & =\text { porosity, }[\text { fraction] } \\
\mu & =\text { viscosity, }[\mathrm{cp}] \\
\Delta p & =\text { pressure change, [psia] } \\
\Delta p_{s} & =\text { pressure change caused by skin effect, [psia] } \\
\Delta x & =\text { grid size in } \mathrm{x} \text {-direction, }[\mathrm{ft}] \\
\Delta y & =\text { grid size in y-direction, }[\mathrm{ft}] \\
\pi & =\text { constant }
\end{array}
$$




\section{REFERENCES}

1. Peaceman, D.W.: "Interpretation of Well-Block Pressures in Numerical Reservoir Simulation," paper SPE 6893, presented at the SPE-AIME $52^{\text {nd }}$ Annual Fall Technical Conference and Exhibition, Denver, Colorado, Oct. 1977.

2. Peaceman, D.W.: "Interpretation of Well-Block Pressures in Numerical Reservoir Simulation with Non Square Grid Blocks and Anisotropic Permeability," paper SPE 10528, presented at the 1982 SPE Symposium on Reservoir Simulation Fall, New Orleans, Louisiana, Jan. 31-Feb. 3, 1983.

3. Peaceman, D.W.: "Interpretation of Well-Block Pressures in Numerical Reservoir Simulation - Part 3: Some Additional Well Geometries," paper SPE 16976, presented at the $62^{\text {nd }}$ SPE Annual Fall Technical Conference and Exhibition, Dallas, Texas, Sept. 1987.

4. Peaceman, D.W.: "Representation of a Horizontal Well in Numerical Reservoir Simulation," paper SPE 21217, presented at the 11th SPE Symposium on Reservoir Simulation, Anaheim, California, Feb. 1991.

5. Peaceman, D.W.: "Further Discussion of Productivity of a Horizontal Well," SPERE (February 1991) 149.

6. Peaceman, D.W.: "A New Method for Representing Multiple Wells with Arbitrary Rates in Numerical Reservoir Simulation," paper SPE 29120, presented at the13th SPE Symposium on Reservoir Simulation, San Antonio, Texas, Feb. 1995.

7. Babu, D.K., Odeh, A.S., Al-Khalifa, A.J., and McCann, R.C.: "The Relation Between Wellblock and Wellbore Pressure in Numerical Simulation of Horizontal Wells -General Formulas for Arbitrary Well Locations in Grids," SPERE (February 1991) 324.

8. Mochizuki, S.: Well Productivity for Arbitrarily Inclined Well," paper SPE 29133 , presented at the $13^{\text {th }}$ SPE Symposium on Reservoir Simulation, San Antonio, Texas, Feb. 1995.

9. Chen, G., Tehrani, D.H., and Peden, J.M.: "Calculation of Well Productivity in a Reservoir Simulator (1)," paper SPE 29121, presented at the $13^{\text {th }}$ Symposium on Reservoir Simulation, San Antonio, Texas, Feb.1995. 
10. Chen, G., Tehrani, D.H., and Peden, J.M.: "Calculation of Well Productivity in a Reservoir Simulator (2)," paper SPE 29932, presented at the International Meeting of Petroleum Engineering, Beijing, China, Nov.1995.

11. Sharpe, H.N., and Ramesh, B.A.: Development and Validation of a Modified Well Model Equation for Non Uniform Grids with Application to Horizontal Well and Coning Problems," paper SPE 24896, presented at the 67th SPE Annual Technical Conference and Exhibition, Washington, DC, Oct. 1992.

12. Ding Y., Renard, G., and Aristegui, C.: "New Representation of Wells in Numerical Reservoir Simulation," paper SPE 25248, presented at the 12th Symposium on Reservoir Simulation, New Orleans, Louisiana, Feb. 28 - March 3, 1993.

13. Wan, J., Penmatcha, V.R., Arbabi, S., and Aziz, K.: "Effects of Grid Systems on Predicting Horizontal Well Productivity," paper SPE 46228, presented at the SPE West Regional Meeting and Exhibition, Bakersfield, California, May 1998.

14. Prats, M., Hazebroek, P., and Strickler, W.R.: "Effect of Vertical Fractures on Reservoir Bahavior-Compressible-Fluid Case," SPEJ (June 1962) 87.

15. Prats, M. and Levine, J.S.: "Effect of Vertical Fractures on Reservoir BehaviorResults on Oil and Gas Flow," JPT (Oct. 1963) 1119.

16. Russell, D.G. and Truitt, N.E.: "Transient Pressure Behavior in Vertically Fractured Reservoirs," JPT (Oct. 1964) 1159.

17. Wattenbarger, R.A. and Ramey, H.J., Jr.: "Well Test Interpretation of Vertically Fractured Gas Wells," JPT (May 1969) 625; Trans., AIME, 246.

18. Morse, R.A. and Von Gonten, D.: "Productivity of Vertically Fractured Wells Prior to Stabilized Flow," paper SPE 3631 presented at the 1971 Annual Technical Conference and Exhibition, New Orleans, Louisiana, 3-6 October.

19. Gringarten, A.C., Ramey, H.J.Jr., and Raghavan, R.: "Pressure Analysis for Fractured Wells," paper SPE 4051 presented at the 1972 Annual Fall Meeting SPE-AIME, San Antonio, Texas, 8-11 October.

20. Gringarten, A.C., Ramey, H.J.Jr., and Raghavan, R.: “Applied Pressure Analysis for Fractured Wells," JPT (July 1975) 887.

21. Cinco-Ley, H., Samaniego, F.V, and Dominguez, N.: "Transient Pressure Behavior for a Well with a Finite-Conductivity Vertically Fracture," SPEJ (Aug. 1978) 253. 
22. Cinco-Ley, H. and Samaniego, V.F.: "Effect of Wellbore Storage and Damage on the Transient Pressure Behavior of Vertically Fractured Wells," paper SPE 6752 presented at the 1977 Annual Fall Technical Conference and Exhibition SPE-AIME, Denver, Colorado, 9-12 October.

23. Agarwal, R.G., Carter, R.D., and Pollock, C.B.: "Evaluation and Performance Prediction of Low-Permeability Gas Wells Stimulated by Massive Hydraulic Fracturing," JPT (March 1979) 362; Trans., AIME, 267.

24. Cinco-Ley, H. and Samaniego, F.V.: "Transient Pressure Analysis for Fractured Wells," JPT (September 1981) 1749.

25. Narasimhan, T.N. and Palen, W.A.: "A Purely Numerical Approach for Analyzing Fluid Flow to a Well Intercepting a Vertical Fracture ", paper SPE 7983 presented at the 1979 California Regional Meeting of SPE-AIME, Ventura, California, 18-20 April.

26. Bostic, J.N., Agarwal, R.G., and Carter, R.D.: "Combined Analysis of Post Fracturing Performance and Pressure Buildup Data for Evaluating an MHF Gas Well," paper SPE 8280 presented at the 1979 Annual Fall Technical Conference and Exhibition SPE-AIME, Las Vegas, Nevada, 23-26 September.

27. Cinco-Ley, H. and Samaniego, V.F.: "Transient Pressure Analysis: Finite Conductivity Fracture Case Versus Damaged Fracture Case," paper SPE 10179 presented at the 1981 Annual Fall Technical Conference and Exhibition, San Antonio, Texas, 5-7 October.

28. Bennett, C.O., Reynolds, A.C., Raghavan, R., and Elbel, J.L.: "Performance of Finite-Conductivity, Vertically Fractured Wells in Single-Layer Reservoirs," SPEFE (Aug. 1986) 399.

29. Ding, Y.: "Modeling of Fractured Wells in Reservoir Simulation," paper SPE 36668 presented at the 1996 Annual Technical Conference and Exhibition, Denver, Colorado, 6-9 October.

30. Ngheim, L.D., Jr.: “Waterflooding Increases Gas Recovery, ”JPT (October 1989) 1102.

31. Schulte, W.M.: "Production from a Fractured Well with Well Inflow Limited to Part of the Fracture Height," SPE Production Engineering (Sept. 1986) 333.

32. Roberts, B.E., van Engen, H., and van Kruysdijk, C.P.J.W.: "Productivity of Multiply Fractured Horizontal Wells in Tight Gas Reservoirs," paper SPE 23113 
presented at the 1991 Offshore Europe Conference. Aberdeen, Scotland, Sept. 36.

33. Lefevre, D., Pellissier, G., and Sabathier, J.C.: "A New Reservoir Simulation System for a Better Reservoir Management," paper SPE 25640 presented at the 1993 SPE Middle East Annual Fall Meeting, Manama, Bahrain, April 3-6.

34. Hegre, T.M.: "Hydraulically Fractured Horizontal Well Simulation" paper SPE 35506 presented at the 1996 European 3-D Reservoir Modelling Conference, Stavanger, Norway, April 16-17.

35. Archer, R.A. and Yildiz, T.T.: "Transient Well Index for Numerical Well Test Analysis," paper SPE 71572 presented at the 2001 Annual Fall Technical Conference and Exhibition SPE, Houston, Texas, 30 September-3 October.

36. Meng, H-Z., Proano, E.A., Buhidma, I.M., and Mach, J.M.: "Production Systems Analysis of Vertically Fractured Wells," paper SPE/DOE 10842 presented at the 1982 SPE/DOE Unconventional Gas Recovery Symposium held in Pittsburgh, Pennsylvania, May 16-18.

37. Miller, F.G.: "Theory of Unsteady-State Influx of Water in Linear Reservoirs," Journal of the Institute of Petroleum (Nov. 1956) Volume 48, No. 467, 365.

38. Nabor, G.W. and Barham, R.H.: “Linear Aquifer Behavior,” JPT (May 1964) 561 .

39. “CMG”, Version 2002.1 Revision 4, Computer Modelling Group, 1978-2002.

40. Al-Hussainy, R., Ramey, H.J., Jr., and Crawford, P.B.: "The Flow of Real Gas through Porous Media," JPT (May 1966) 624. 


\section{APPENDIX A \\ DERIVATION TO SHOW RELATION BETWEEN $p_{w f}$ and $p_{w b}$ IN RADIAL \\ FLOW}

\section{$\underline{\text { Re-deriving the Peaceman }}{ }^{1}$ radius equation $\left(r_{o}\right)$}

The steps of the derivation of the Peaceman ${ }^{1}$ radius equation is not quite clear in his paper, so we attempted to re-derive it in more detail.

\section{Finite Difference Equation}

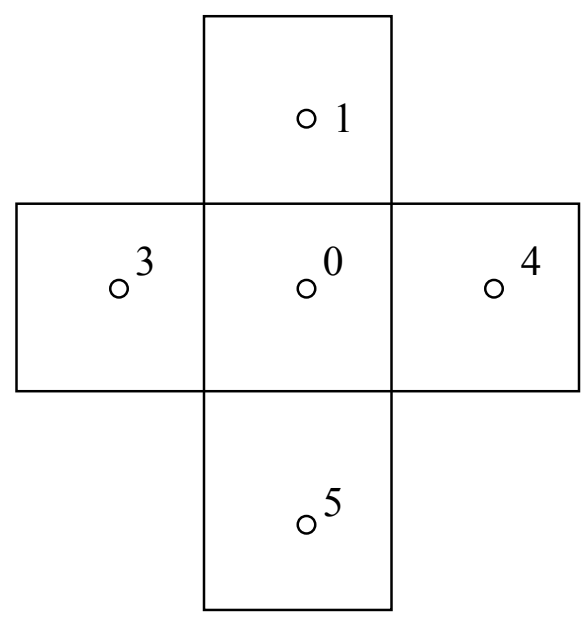

$\Delta a \Delta p^{n+1}=\frac{V_{p} c_{t}}{\Delta t}\left(p^{n+1}-p^{n}\right)+q$

We will assume that we have equal pressures from all directions $=\mathrm{p} 1$ from east, west , north and south.

For steady-state case, we cancel the first term on R.H.S of the equation

$4 \frac{0.00633}{5.615} \frac{k h \Delta x}{B \mu} \frac{\left(p_{1}-p_{0}\right)}{\Delta y}=q$ 
where area $=h \Delta x$, and $\Delta y$ is the distance between 2 grid blocks in the north-south direction.

Re-arranging equation

$4 \frac{-1}{2 \Pi}\left(\frac{2 \Pi}{1} \frac{0.00633}{5.615} \frac{k h}{B \mu}\right) \frac{\Delta x}{\Delta y}\left[\left(p_{i}-p_{1}\right)-\left(p_{i}-p_{0}\right)\right]=q$

$4 \frac{-1}{2 \Pi}\left(\frac{1}{141.2} \frac{k h}{B \mu}\right) \frac{\Delta x}{\Delta y}\left[\left(p_{i}-p_{1}\right)-\left(p_{i}-p_{0}\right)\right]=q$

From the definition of $P_{D}=f\left(t_{D}\right)$, we know that

$\frac{k h}{141.2 q B \mu}\left(p_{i}-p_{1}\right)-\left(p_{i}-p_{0}\right)=p_{D 1}-p_{D 0}$

Therefore, re-arranging equation, and assuming that $\Delta y=\Delta x$

$p_{D 1}-p_{D 0}=\frac{-\pi}{2}$

\section{$\underline{\text { Analytical Equation (Exact) }}$}

$\frac{k h}{141.2 B \mu} \frac{\left(p_{1}-p_{w f}\right)}{\ln \frac{\Delta x}{r_{w}}}=q$

$-\ln \frac{\Delta x}{r_{w}}=\frac{k h}{141.2 q B \mu}\left[\left(p_{i}-p_{1}\right)-\left(p_{i}-p_{w f}\right)\right]$

From the definition of $P_{D}=f\left(t_{D}\right)$, we know that

$$
\begin{aligned}
& \frac{k h}{141.2 q B \mu}\left(p_{i}-p_{1}\right)-\left(p_{i}-p_{w f}\right)=p_{D 1}-p_{D w f} \\
& p_{D 1}-p_{D w f}=-\ln \frac{\Delta x}{r_{w}}
\end{aligned}
$$

We can repeat the same steps for the equations from (7) to (10), but for the desired location $\mathrm{r}_{0}$ of the proposed $p_{o}$, that replaces $p_{1}$, where $p_{o}$ is the location of the supposed pressure of the material balance average of the cell.

We will obtain an analogous equation to that of equation (11), but for that "desired" location. 
$p_{D 0}-p_{D w f}=-\ln \frac{r_{o}}{r_{w}}$

Subtracting equation (12) from equation (11),

$$
p_{D 1}-p_{D 0}=\ln \frac{r_{0}}{\Delta x}
$$

Substituting equation (6) into equation (12),

$\ln \frac{r_{o}}{\Delta x}=-\frac{\pi}{2}$ which can be rewritten as $\frac{r_{o}}{\Delta x}=e^{\frac{-\pi}{2}}$

\section{Conclusion:}

The average pressure of the cell is exactly at a distance $0.208 \Delta \mathrm{x}$ of the grid block, and there is called Peaceman ${ }^{1}$ radius $r_{o}$. 


\section{APPENDIX B}

DERIVATION TO SHOW THAT $p_{w f}=p_{w b}$ IN LINEAR FLOW

\section{Deriving the equation for average pressure location $\left(\Delta v_{o}\right)$ in linear flow}

Finite Difference Equation

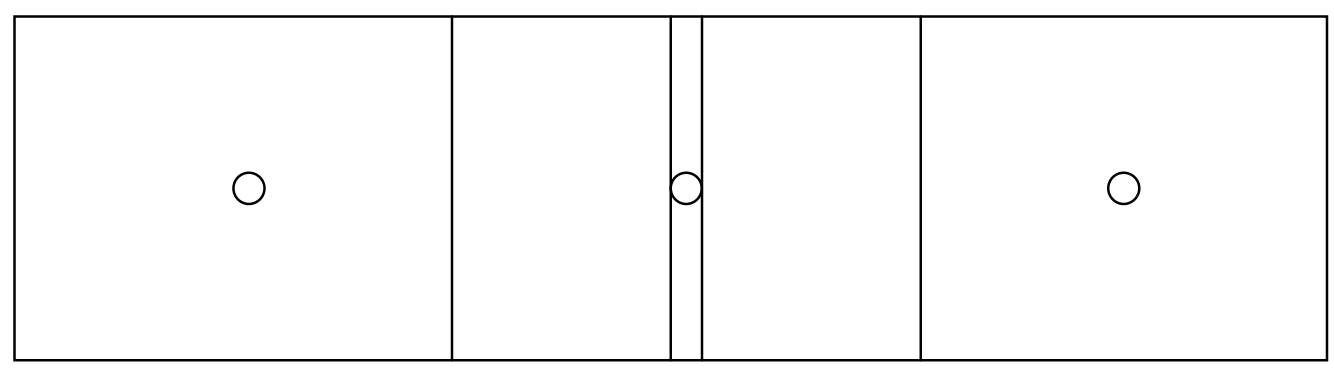

$\Delta a \Delta p^{n+1}=\frac{V_{p} c_{t}}{\Delta t}\left(p^{n+1}-p^{n}\right)+q$

For steady-state case, we cancel the first term on R.H.S of the equation

$2 \frac{0.00633}{5.615} \frac{k h \Delta x}{B \mu} \frac{\left(p_{1}-p_{0}\right)}{\Delta y}=q$

where area $=h \Delta x$, and $\Delta y$ is the distance between 2 grid blocks in the north-south direction.

Re-arranging equation

$$
\begin{aligned}
& 2 \frac{-1}{2 \pi}\left(\frac{2 \pi}{1} \frac{0.00633}{5.615} \frac{k h}{B \mu}\right) \frac{\Delta x}{\Delta y}\left[\left(p_{i}-p_{1}\right)-\left(p_{i}-p_{0}\right)\right]=q \\
& 2 \frac{-1}{2 \pi}\left(\frac{1}{141.2} \frac{k h}{B \mu}\right) \frac{\Delta x}{\Delta y}\left[\left(p_{i}-p_{1}\right)-\left(p_{i}-p_{0}\right)\right]=q
\end{aligned}
$$

From the definition of $p_{D}=f\left(t_{D}\right)$, we know that 
$\frac{k h}{141.2 q B \mu}\left(p_{i}-p_{1}\right)-\left(p_{i}-p_{0}\right)=p_{D 1}-p_{D 0}$

Therefore, re-arranging equation

$$
p_{D 1}-p_{D 0}=-\pi \frac{\Delta y}{\Delta x}
$$

\section{$\underline{\text { Analytical Equation (Exact) }}$}

$$
\begin{aligned}
& \frac{0.00633}{5.615} \frac{k(2 h \Delta x)}{B \mu} \frac{\left(p_{1}-p_{f}\right)}{\Delta y}=q \\
& \frac{-2}{2 \Pi}\left(\frac{2 \Pi}{1} \frac{0.00633}{5.615} \frac{k h}{B \mu}\right) \frac{\Delta x}{\Delta y}\left[\left(p_{i}-p_{1}\right)-\left(p_{i}-p_{f}\right)\right]=q \\
& \frac{-2}{2 \Pi}\left(\frac{1}{141.2} \frac{k h}{B \mu}\right) \frac{\Delta x}{\Delta y}\left[\left(p_{i}-p_{1}\right)-\left(p_{i}-p_{f}\right)\right]=q
\end{aligned}
$$

From the definition of $P_{D}=f\left(t_{D}\right)$, we know that

$$
\begin{aligned}
& \frac{k h}{141.2 q B \mu}\left(p_{i}-p_{1}\right)-\left(p_{i}-p_{f}\right)=p_{D 1}-p_{D f} \\
& p_{D 1}-p_{D f}=-\pi \frac{\Delta y}{\Delta x}
\end{aligned}
$$

We can repeat the same steps for the equations from (7) to (11), but for the desired location $\Delta \mathrm{y}_{0}$ of the proposed $p_{o}$, that replaces $p_{1}$, where $p_{o}$ is the location of the supposed pressure of the material balance average of the cell.

We obtain an analogous equation to that of equation (11), but for that "desired" location.

$$
P_{D 0}-P_{D f}=-\pi \frac{\Delta y_{o}}{\Delta x}
$$

Subtracting equation (12) from equation (11), 
$P_{D 1}-P_{D 0}=-\pi \frac{\left(\Delta y-\Delta y_{0}\right)}{\Delta x}$

Substituting equation (6) into equation (13),

$-\pi \frac{\Delta y}{\Delta x}=-\pi \frac{\left(\Delta y-\Delta y_{0}\right)}{\Delta x}$

Which will be reduced to $\Delta \mathrm{y}_{0}=0$

\section{Conclusion:}

The average pressure of the cell is exactly at the center of the grid block, and there is no concept that is similar to the Peaceman ${ }^{1}$ radius as in case of radial flow. 
APPENDIX C

DERIVATION OF PSEUDO VALUES OF $K$ FOR MODELING COARSE GRIDS

General diagram of the gridblocks $A_{1}, A_{2}, B_{1}$ and $B_{2}$

\begin{tabular}{|l|l|l|l|l|l|l|l|l|l|l|}
\hline & & & & & & & & & & \\
\hline & & & & & & & & & & \\
\hline & & & & & & & & & & \\
\hline & & & $\mathrm{A}_{2}$ & & & & & & & \\
\hline & & & 0 & & & \\
\hline & & & & & & & & & & \\
\hline & & & & & & & & & & \\
\hline & & & & & & & & & & \\
\hline & & & & & & & & & & \\
\hline & & & & & & & & & & \\
\hline
\end{tabular}




\section{Calculating pseudo permeability in y-direction:}

For grid blocks $A_{1}$ and $A_{2}$ in the general diagram:

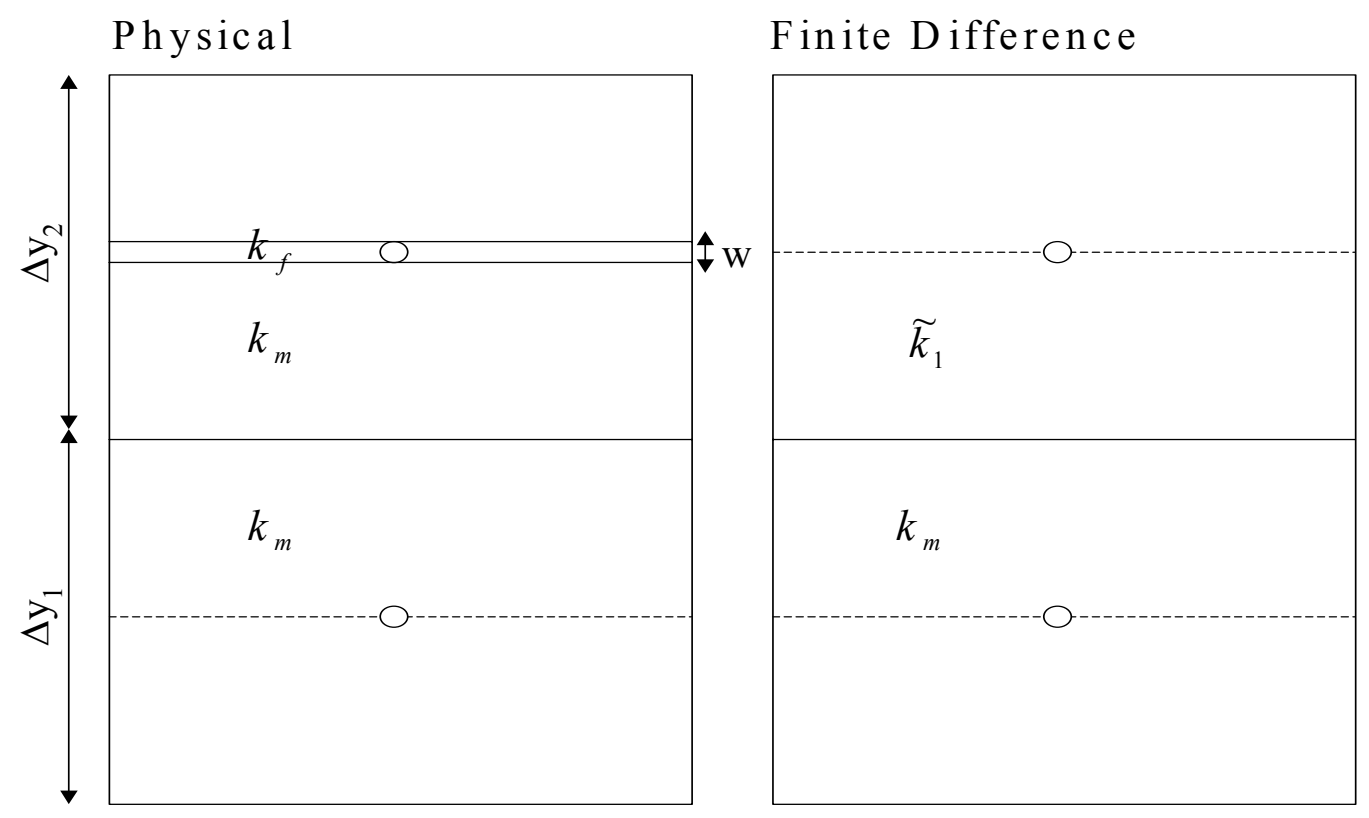

We know that flow is in series, and thus we use harmonic average where:

$k_{y_{\text {avg }}}=\frac{\sum L_{i}}{\sum\left(L_{i} / K_{i}\right)}$

From the drawing of physical blocks, we see that

$$
k_{y_{\text {avg }}}=\frac{\frac{w}{2}+\left(\frac{\Delta y_{1}}{2}-\frac{w}{2}\right)+\frac{\Delta y_{2}}{2}}{\frac{w / 2}{k_{f}}+\left(\frac{\Delta y_{1} / 2-w / 2}{k_{m}}\right)+\frac{\Delta y_{2}}{2 k_{m}}}
$$

which is reduced to 


$$
k_{y_{\text {avg }}}=\frac{\frac{\Delta y_{1}+\Delta y_{2}}{2}}{\frac{w / 2}{k_{f}}+\left(\frac{\frac{\Delta y_{1}+\Delta y_{2}}{2}-w / 2}{k_{m}}\right)}
$$

If $\Delta \mathrm{y}_{1}=\Delta \mathrm{y}_{2}=\Delta \mathrm{y}$

Then equation (1) becomes $k_{y_{\text {avg }}}=\frac{\Delta y}{\frac{w}{2 k_{f}}+\left(\frac{2 \Delta y-w}{k_{m}}\right)}$

Which is the physical equation.

We will now equate the same $\mathrm{k}_{\mathrm{y}}$ avg. but from the actual simulator grid blocks .

We will use the same harmonic equation as above,

$$
k_{y_{\text {avg }}}=\frac{\frac{\Delta y_{1}}{2}+\frac{\Delta y_{2}}{2}}{\frac{w / 2}{2 \widetilde{k}_{1}}+\frac{\Delta y_{2}}{2 k_{m}}}
$$

If we re-organize equation (3), we will obtain the following form,

$$
\frac{\Delta y_{1}}{2 \widetilde{k}_{1_{y}}}=\frac{\Delta y_{1}+\Delta y_{2}}{2 k_{y_{\text {avg. }}}}-\frac{\Delta y_{2}}{2 k_{m}}
$$

re-organizing previous equation

$$
\tilde{k}_{1 y}=\frac{\Delta y_{1}}{2\left[\frac{\Delta y_{1}+\Delta y_{2}}{2 k_{y_{\text {avg }}}}-\frac{\Delta y_{2}}{2 k_{m}}\right]}
$$

re-organizing previous equation

$$
\tilde{k}_{1 y}=\frac{\Delta y_{1}}{\left[\frac{\Delta y_{1}+\Delta y_{2}}{k_{y_{a v g}}}-\frac{\Delta y_{2}}{k_{m}}\right]}
$$


Simplifying the equation by introducing the term $\mathrm{Z}$

$\tilde{k}_{1 y}=\frac{\Delta y_{1}}{\left[Z-\frac{\Delta y_{2}}{k_{m}}\right]}$

Expanding on $Z$, to account for equation of $k_{y}$ avg. from physical blocks in equation 1

$$
Z=\frac{\left(\Delta y_{1}+\Delta y_{2}\right)\left(\frac{w}{2 k_{f}}+\left[\frac{\Delta y_{1}+\Delta y_{2}-w}{2 k_{m}}\right]\right)}{\frac{\left(\Delta y_{1}+\Delta y_{2}\right)}{2}}
$$

Re-organizing the previous equation, we get

$Z=\frac{w}{k_{f}}+\frac{\Delta y_{1}+\Delta y_{2}-w}{k_{m}}$

Therefore, substituting equation (0) into equation (1), we obtain the final equation, which is

$\tilde{k}_{1 y}=\frac{\Delta y_{1}}{\left[\frac{w}{k_{f}}+\frac{\Delta y_{1}}{k_{m}}-\frac{w}{k_{m}}\right]}$ 


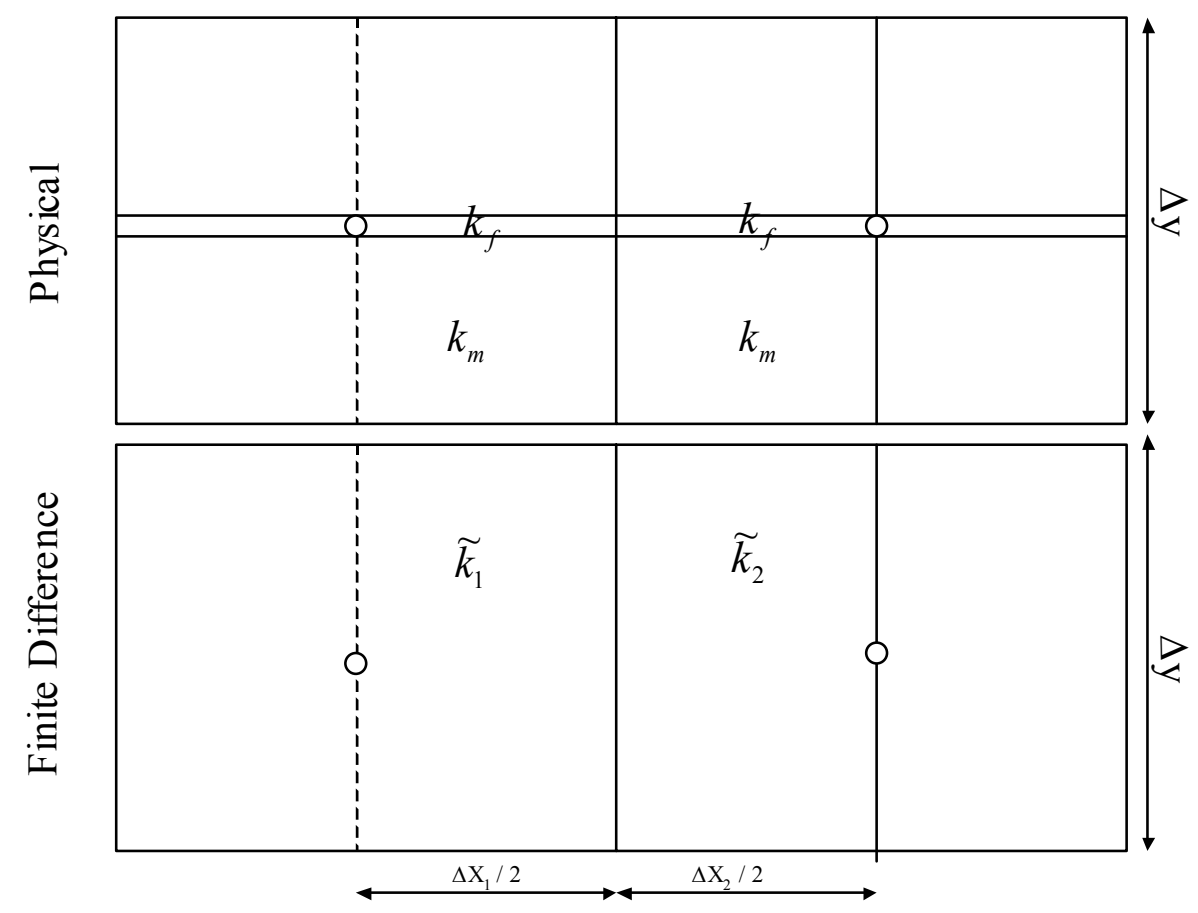

\section{Calculating pseudo permeability in x-direction:}

\section{For grid blocks $B_{1}$ and $B_{2}$ in the general diagram:}

We first are going to calculate the average permeability for parallel beds of fracture and matrix in grid block $B_{1}$ and we can do similarly for grid block $B_{2}$.

The equation of the arithmetic is used to account for the average in parallel beds:

$k_{\operatorname{avg}_{B 1}}=\frac{\sum k_{i} h_{i}}{\sum h_{i}}$

$k_{\operatorname{avg} B 1}=\frac{k_{m}\left(\frac{\Delta y}{2}-\frac{w}{2}\right)+k_{f} w+k_{m}\left(\frac{\Delta y}{2}-\frac{w}{2}\right)}{\Delta y}$ 
$k_{a v g B 1}=\frac{k_{m}(\Delta y-w)+k_{f} w}{\Delta y}$

Now we are going to calculate the flow is in series from Block B1 to B2, and thus we use harmonic average where:

$$
k_{x_{a v g}}=\frac{\sum L_{i}}{\sum\left(L_{i} / K_{i}\right)}
$$

From the drawing of physical blocks, we see that

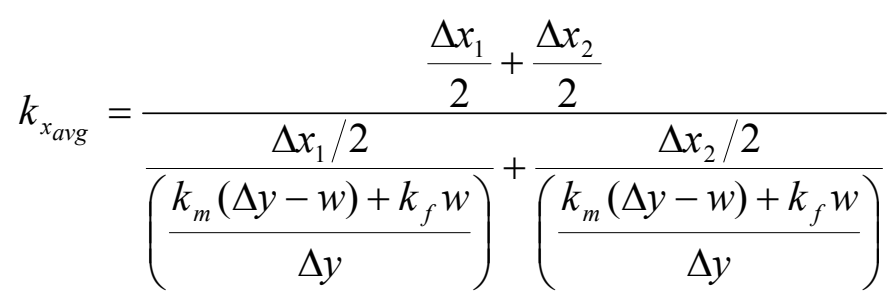

Re-arranging the previous equation, we will get

$$
\begin{aligned}
& k_{x_{\text {avg }}}=\frac{\frac{\Delta x_{1}}{2}+\frac{\Delta x_{2}}{2}}{\frac{\Delta x_{1} / 2+\Delta x_{2} / 2}{\left(\frac{k_{m}(\Delta y-w)+k_{f} w}{\Delta y}\right)}} \\
& k_{x_{\text {avg }}}=\frac{k_{m}(\Delta y-w)+k_{f} w}{\Delta y} \ldots
\end{aligned}
$$

If we now try to get the value of $\widetilde{k}_{1 x}$ assuming that $\widetilde{k}_{1_{x}}=\widetilde{k}_{2 x}$, we will use

$$
k_{x_{\text {avg }}}=\frac{\sum L_{i}}{\sum\left(L_{i} / K_{i}\right)}=\frac{\frac{\Delta x_{1}}{2}+\frac{\Delta x_{2}}{2}}{\frac{\Delta x_{1}}{2 \widetilde{k}_{1}}+\frac{\Delta x_{2}}{2 \widetilde{k}_{2}}}=\widetilde{k}_{1}
$$

Therefore, we deduce that

$\tilde{k}_{1}=\frac{k_{m}(\Delta y-w)+k_{f} w}{\Delta y}$ 


\section{APPENDIX D}

\section{DERIVATION OF A TRANSMISSIBILITY RELATION FOR MODELING COARSE GRIDS}

From the definition of Transmissibility, and applying it, to our work in this dissertation for the coarse grid in Chapter IV, it is seen that

The actual transmissibility is

$$
T_{E_{\text {data }}}=0.00633 \cdot \Delta y \frac{(k h)_{i}(k h)_{i+1}}{\left\{(k h)_{i+1} \frac{\Delta x_{i}}{2}+(k h)_{i} \frac{\Delta x_{i+1}}{2}\right\}}
$$

The desired transmissibility to have is

$$
T_{E_{\text {desired }}}=0.00633 \cdot \Delta y \frac{\left\{(\tilde{k} h)_{i}(k h)_{i+1}\right\}}{(k h)_{i+1}\left(\frac{\Delta x_{i}}{2}+a\right)+(\tilde{k} h)_{i}\left(\frac{\Delta x_{i+1}}{2}-a\right)}
$$

For the general case of variable thickness (Isopach Map), the transmissibility multiplier will be

TRANSI $=\frac{T_{E_{\text {desired }}}}{T_{E_{\text {data }}}}=\frac{\left[(k h)_{i+1} \frac{\Delta x_{i}}{2}+(k h)_{i} \frac{\Delta x_{i+1}}{2}\right]}{(k h)_{i+1}\left(\frac{\Delta x_{i}}{2}+a\right)+(\tilde{k} h)_{i}\left(\frac{\Delta x_{i+1}}{2}-a\right)}\left(\frac{\tilde{k} k h_{i} h_{i+1}}{k^{2} h_{i} h_{i+1}}\right)$

Assuming a case of a constant (uniform) thickness

$$
\text { TRANSI }=\frac{T_{E_{\text {desired }}}}{T_{E_{\text {data }}}}=\frac{k \frac{\Delta x_{i}}{2}+k \frac{\Delta x_{i+1}}{2}}{(k)_{i+1}\left(\frac{\Delta x_{i+1}}{2}+a\right)+(\widetilde{k})_{i}\left(\frac{\Delta x_{i}}{2}-a\right)}\left(\frac{\widetilde{k}}{k}\right)
$$

Assuming a case of a constant (uniform) $\Delta \mathrm{x}$ 


$$
\text { TRANSI }=\frac{T_{E_{\text {desired }}}}{T_{E_{\text {data }}}}=\frac{\tilde{k} \Delta x}{k\left[\frac{\Delta x}{2}+a\right]+\tilde{k}\left(\left[\frac{\Delta x}{2}-a\right]\right)}
$$




\section{VITA}

Name: $\quad$ Mohamed Hamed El-Ahmady

Permanent Address: c/o Department of Petroleum Engineering

Texas A\&M University

College Station, Texas 77843-3116

Education: $\quad$ B.S., Petroleum Engineering

Cairo University, Giza, Egypt, May 1998

M.S., Petroleum Engineering

Texas A\&M University

College Station, Texas, December 2000 